\title{
An analysis of student approaches to solving optimization problems in first semester calculus
}

Renee LaRue

Follow this and additional works at: https://researchrepository.wvu.edu/etd

\section{Recommended Citation}

LaRue, Renee, "An analysis of student approaches to solving optimization problems in first semester calculus" (2016). Graduate Theses, Dissertations, and Problem Reports. 6040.

https://researchrepository.wvu.edu/etd/6040

This Dissertation is protected by copyright and/or related rights. It has been brought to you by the The Research Repository @ WVU with permission from the rights-holder(s). You are free to use this Dissertation in any way that is permitted by the copyright and related rights legislation that applies to your use. For other uses you must obtain permission from the rights-holder(s) directly, unless additional rights are indicated by a Creative Commons license in the record and/ or on the work itself. This Dissertation has been accepted for inclusion in WVU Graduate Theses, Dissertations, and Problem Reports collection by an authorized administrator of The Research Repository @ WVU.

For more information, please contact researchrepository@mail.wvu.edu. 


\title{
AN ANALYSIS OF STUDENT APPROACHES TO SOLVING OPTIMIZATION PROBLEMS IN FIRST SEMESTER CALCULUS
}

Renee LaRue

\author{
Dissertation submitted \\ to the Eberly College of Arts and Sciences \\ at West Virginia University
}

in partial fulfillment of the requirements for the degree of

Doctor of Philosophy in
Mathematics

Nicole Engelke Infante, Ph.D., Chair

Johnna Bolyard, Ph.D.

Marjorie Darrah, Ph.D.

John Goldwasser, Ph.D.

Vicki Sealey, Ph.D.

Department of Mathematics

Morgantown, West Virginia

2016

Keywords: optimization, calculus, max/min, problem-solving Copyright 2016 Renee LaRue 


\section{ABSTRACT \\ An Analysis of Student Approaches to Solving Optimization Problems in First Semester Calculus}

\section{Renee LaRue}

The purpose of this dissertation is to investigate how students think about and understand optimization problems in first semester calculus. To solve an optimization problem, one must identify the quantity to be maximized or minimized and then construct an optimizing function modeling the scenario described in the problem, particularly paying attention to how the desired quantity varies under the given constraint. Once this optimizing function has been constructed, the problem solver uses calculus and algebra skills to analytically find the absolute maximum or minimum of the function in the realistic domain of the problem. These problems are notoriously difficult for students, but have been largely unexplored by the research community.

To examine how students think about and understand optimization problems, I interviewed seven first semester calculus students as they solved two optimization problems and answered questions related to the optimization problem-solving process. Analysis of this interview data revealed six mathematical concepts that play a key role in students' concept images of the optimizing function. In Paper 1, I describe how these mathematical concepts influence students' problem-solving activities and their construction of the optimizing function.

In this dissertation I also have created an Optimization Problem-Solving Framework that describes the desired conceptual and analytical thought processes students should engage in while solving an optimization problem. In Paper 2, I describe this framework and present the results of analyzing students' thought processes while solving a classic optimization problem. The students demonstrated evidence of engaging in pseudo-conceptual and pseudo-analytical thought processes as they solved the optimization problem, particularly in the orienting and planning phases.

Finally, in Paper 3, I describe students' responses while doing an activity designed to assess their ability to connect the optimizing function they constructed to the graphical representation of the optimizing function. This analysis is used to frame a discussion of suggested teaching interventions to help students develop a conceptual understanding of the optimization problem-solving process. 


\section{DEDICATION}

To my grandparents,

James Arthur \& Dina Mae LaRue 


\section{ACKNOWLEDGEMENTS}

First and foremost, thank you to my advisor Dr. Nicole Engelke Infante. This work would not exist without you. You were just the right blend of encouraging, motivating, pushing, and understanding. Thank you for working so hard to be such an amazing advisor - I couldn't have asked for more.

Mom, Dad, Michelle, and Grandma, it seems unfair to group you all together, because I could write paragraphs about what each of you have done for me over the years, but I am trying to be brief. Thank you for listening, proofreading, calming, cheering, lots and lots of mail, packing, moving, financial support, surprise gifts, and late night google chats. I would never have made it here without you. Seriously.

Jeremy, thank you for never letting me take myself too seriously, for coordinating our social life, for consistently challenging me to be a better person, for reminding me what life is really all about when I'm overwhelmed and stressed, and for keeping me exceptionally well fed during a time when I think I would otherwise have been living off of Panera and Jimmy John's. You are my perfect complement. I love you.

Amy, Cassie, Samantha, Emily and Jodie, thank you for keeping me from losing myself in my responsibilities and for letting me talk and talk and talk and talk about all sorts of things. You all help me keep my spirit alive, even on the worst days. Krista, thank you for endless hours of support and entertainment at Panera and beyond. If you ever get arrested for sneaking food into Panera, I'll bail you out.

Kristy, grad school has been a team effort for us, and I can't imagine having done it with anyone else. I don't know if I could have done it without you, honestly. I never imagined that grad school would leave me with a friend who is really more like family. That's worth more than 
the degree. And to all the other WVU people that have been part of my life along the way: Todd, Brittany, John, Janet, Martin, Priyanka, Kristin, Ben, Kyle, Shunika, and Victor. Thank you for the memories I have that will last a lifetime. To Jeannie, thank you for using your red pencil.

And last but certainly not least, Theo, thank you for consistently bringing light and joy to my life. Your giggles, snuggles, dance moves, and insistence that I stop working and "come play with me, Renee" have changed my life in the best possible way. I love you a whole lot. 


\section{TABLE OF CONTENTS}

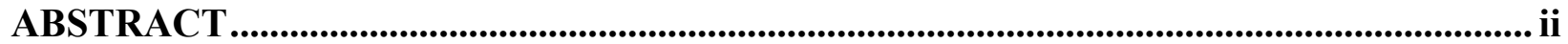

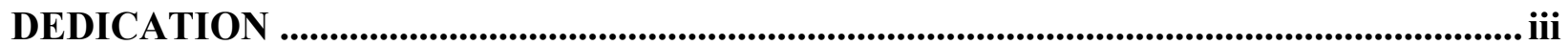

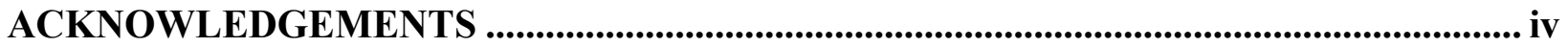

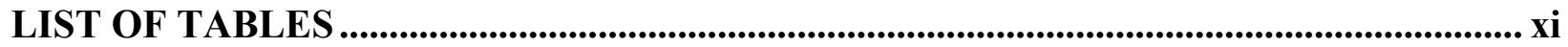

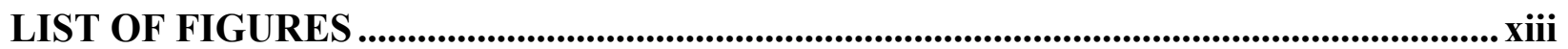

INTRODUCTION ....................................................................................................................................... 1

Discussion about "Optimization"................................................................................................................1

Existing Research About Optimization ..........................................................................................................

Research Questions .........................................................................................................................................4

Survey of the Literature ......................................................................................................................................5

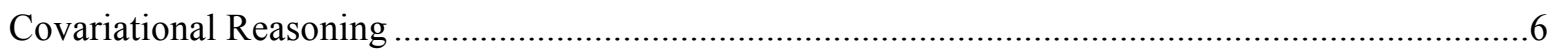

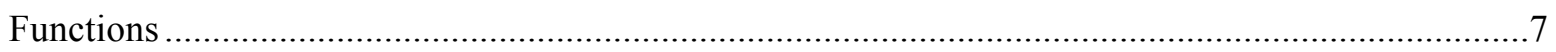

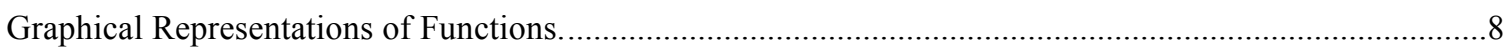

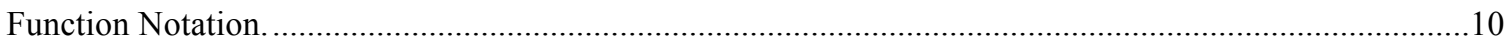

Derivative

Intuitive Ideas About Area/Perimeter and Volume/Surface Area......................................................12

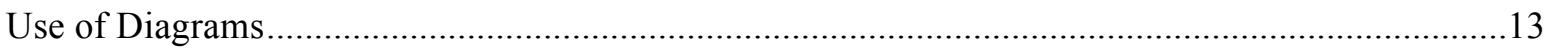

Conclusion ..................................................................................................................................................14

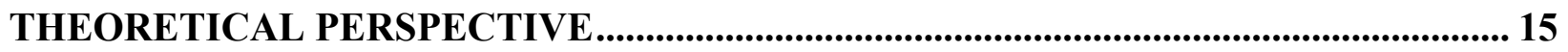

Carlson and Bloom's Multidimensional Problem-Solving Framework ..............................................16

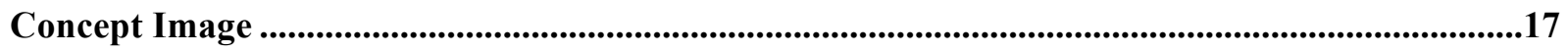

Conceptual/Analytical Thought Processes ...................................................................................................19

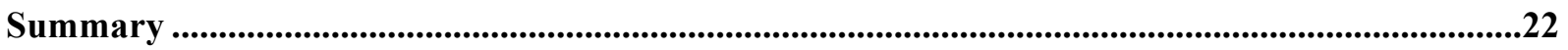




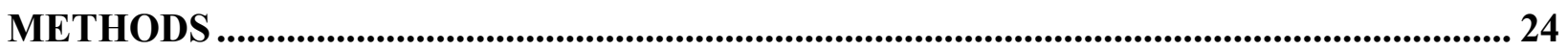

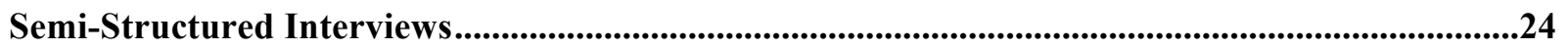

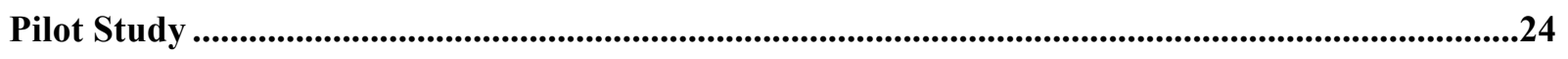

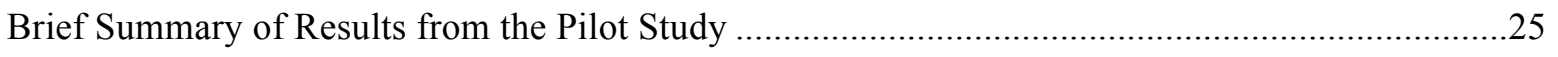

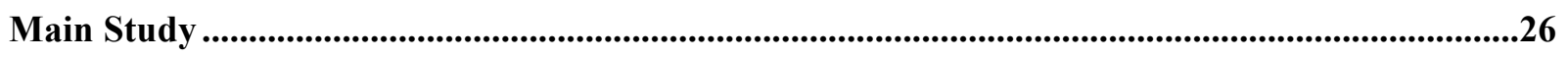

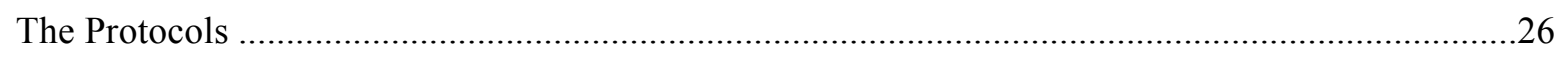

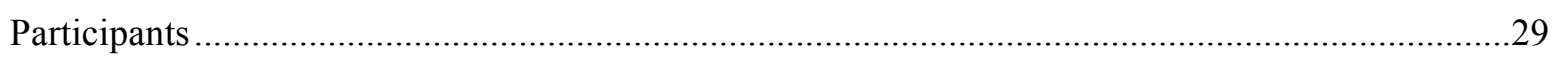

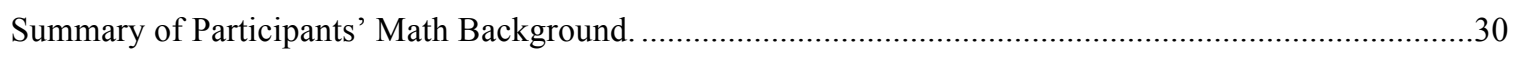

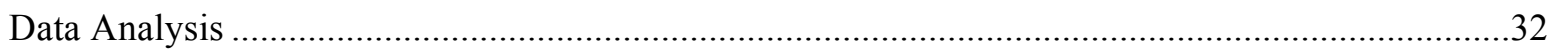

\section{PAPER 1: OPTIMIZATION IN FIRST SEMESTER CALCULUS: A LOOK AT A}

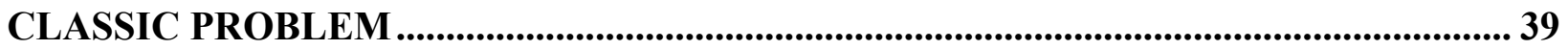

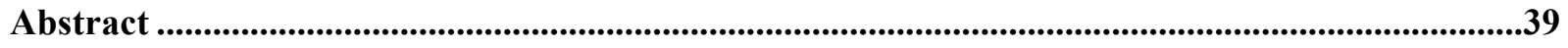

Introduction and Review of Literature ......................................................................................................39

Theoretical Perspective .................................................................................................................................41

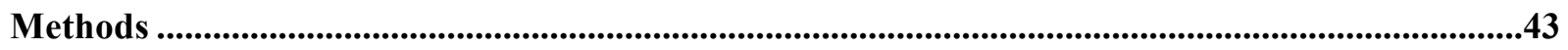

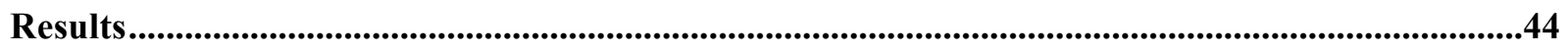

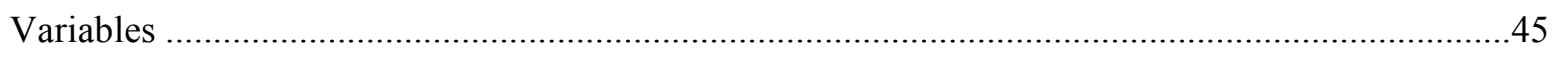

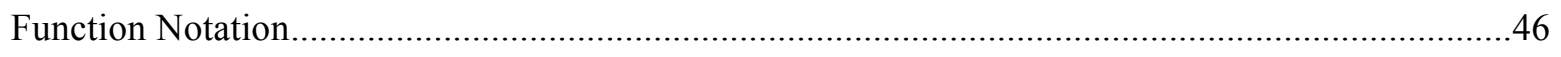

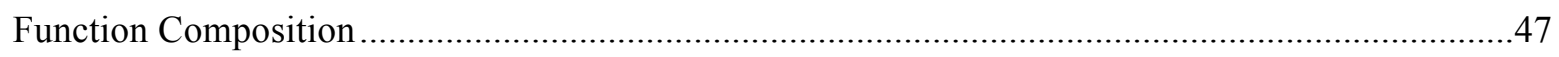

Properties of Rectangles and the Relationships Between Them ....................................................48

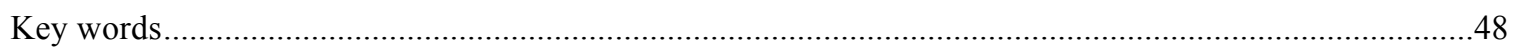

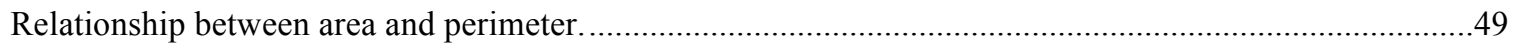

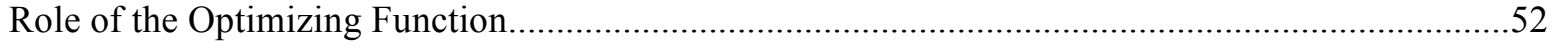

The Graphical Representation of the Optimizing Function ........................................................53

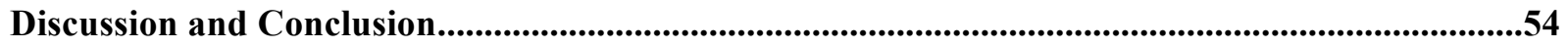




\section{PAPER 2: A PROBLEM-SOLVING FRAMEWORK FOR FIRST SEMESTER}

CALCULUS OPTIMIZATION PROBLEMS …..............................................................58
Abstract

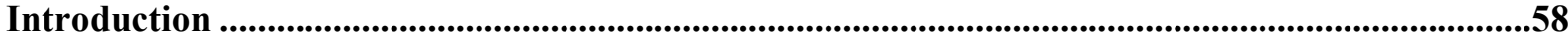
Literature Review .............................................................................................................................................59
Theoretical Framework ............................................................................................................................61

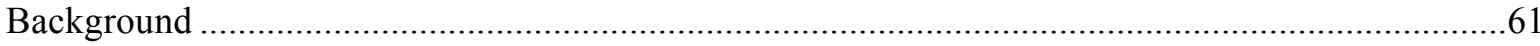

Mathematical Thought Processes..............................................................................................61

Multidimensional Problem-Solving Framework...………………………………………………..64

Related Rates Framework …………………………………………………………………..65

Introduction to the Optimization Problem-Solving Framework .......................................................65

An Optimization Problem-Solving Framework ……………………………………………….....66

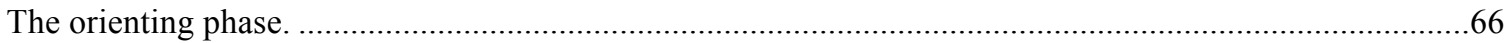

The planning phase

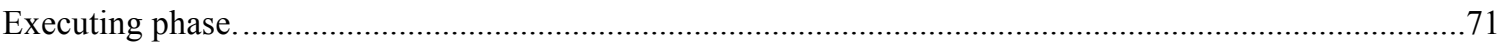

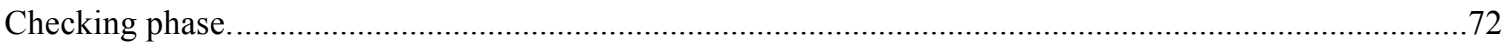

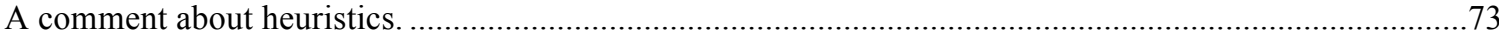

A note about the cyclical nature of the planning, executing, and checking phases. .....................................74

Final Comments About the Framework ...........................................................................................76

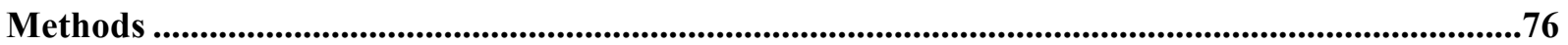

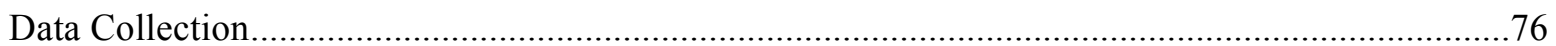

A Comment About the Results...............................................................................................................79

Case Study Results ..........................................................................................................................................79

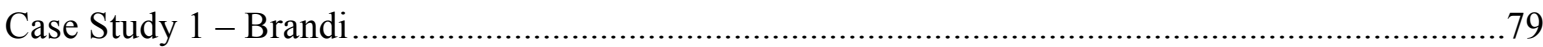

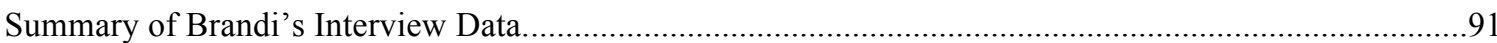

Case Study 2 - Ashod ……………………………………………………………………... 
Summary of Ashod's Interview Data.

Summary of the Results of Analyzing Transcripts from All Seven Students ...............................100

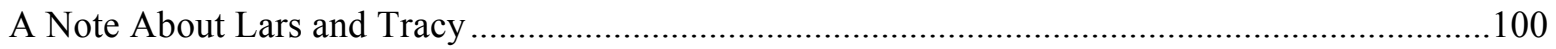

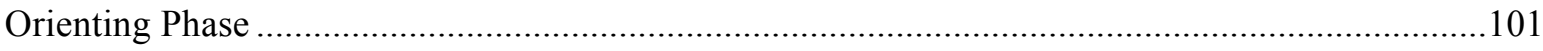

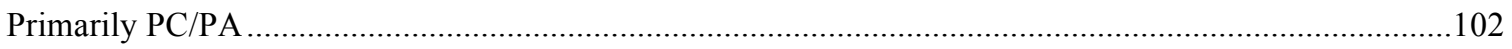

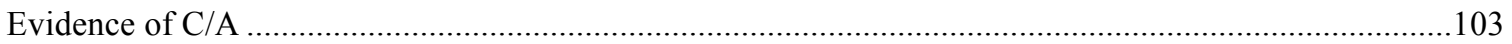

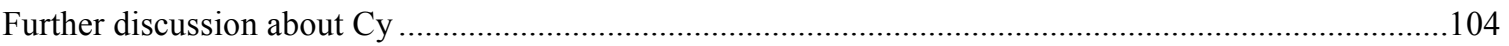

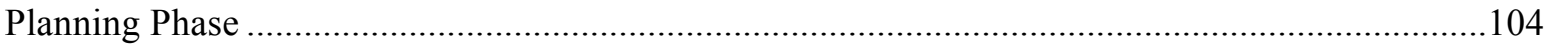

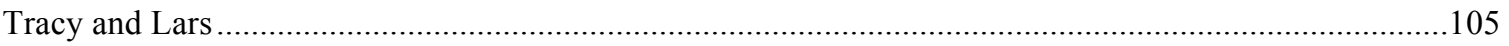

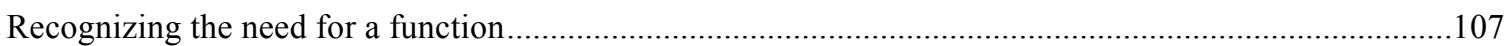

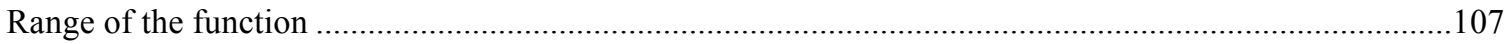

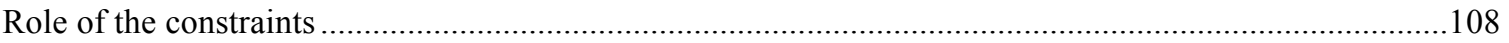

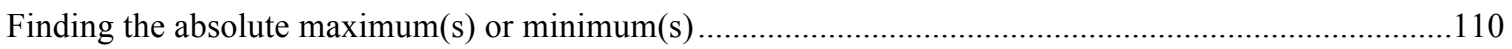

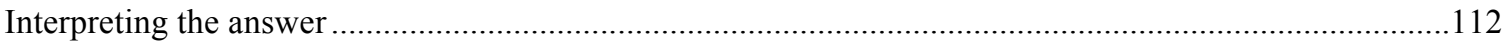

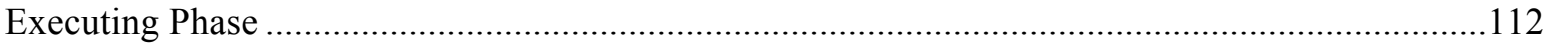

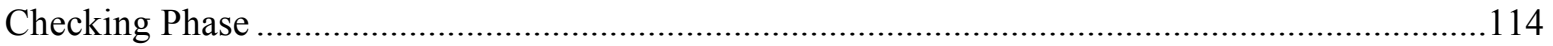

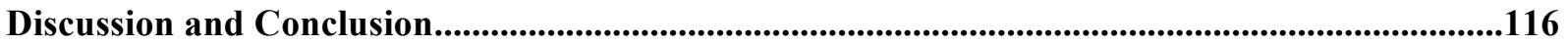

PAPER 3: THE GRAPHICAL REPRESENTATION OF THE OPTIMIZING

FUNCTION: THE MISSING LINK? .................................................................................... 120

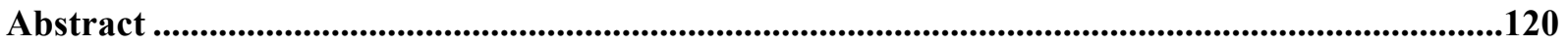

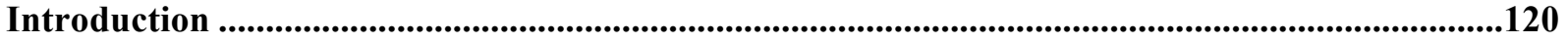

Literature Review …...................................................................................................................................121

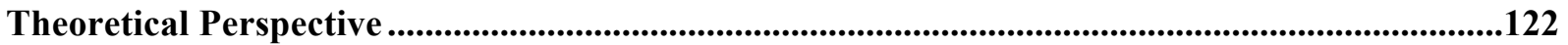

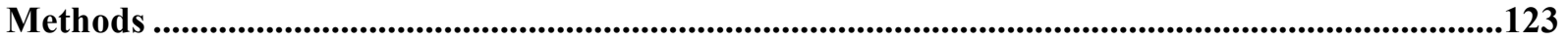

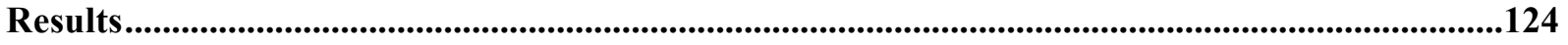

The Graphical Representation of the Optimizing Function .........................................................124 


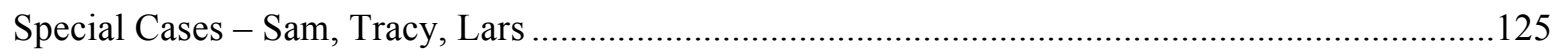

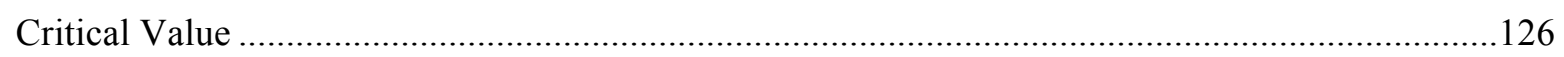

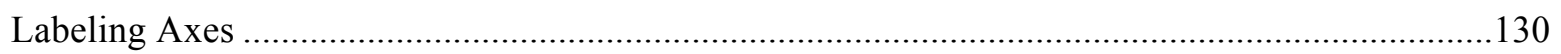

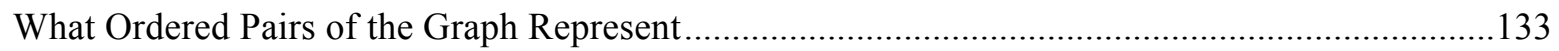

Discovering the Usefulness of Considering the Graph .................................................................135

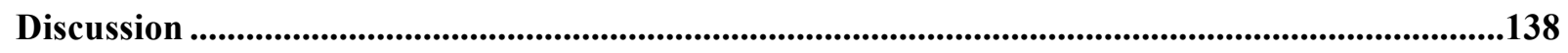

Implications for Teaching .........................................................................................................................139

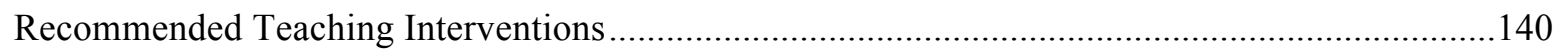

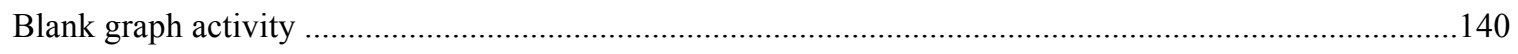

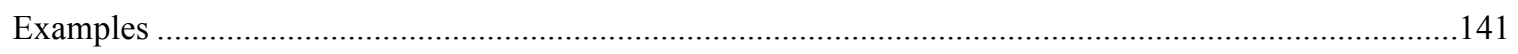

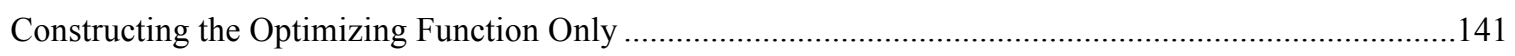

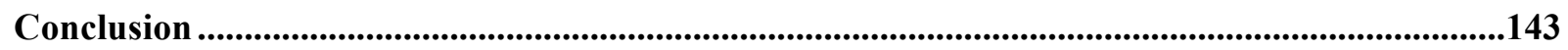

DISSERTATION CONCLUSION .................................................................................. 144

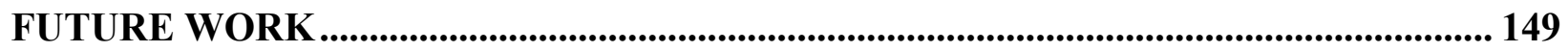

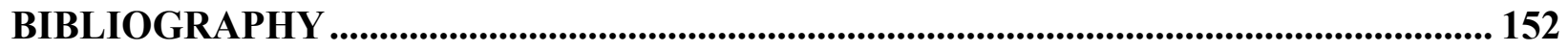

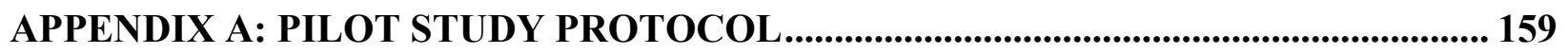

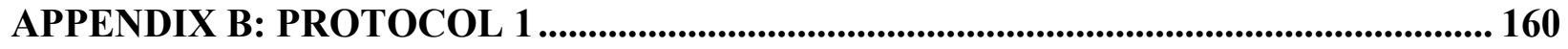

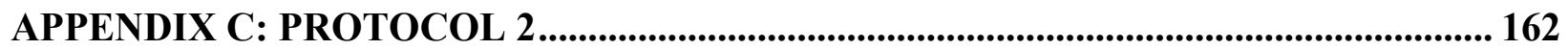

APPENDIX D: SUMMARY OF PARTICIPANTS' MATH BACKGROUND................. 164

APPENDIX E: SAMPLE OPTIMIZATION LESSON ................................................. 168 


\section{LIST OF TABLES}

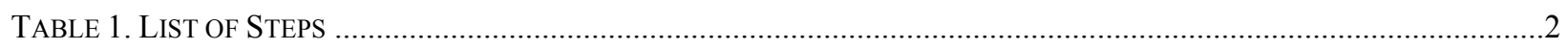

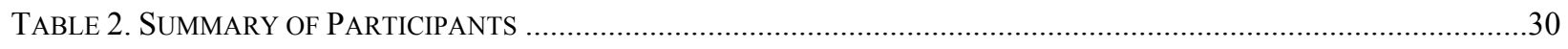

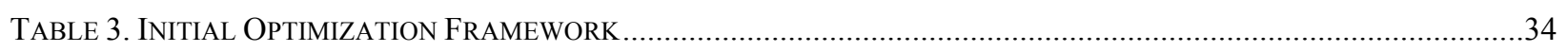

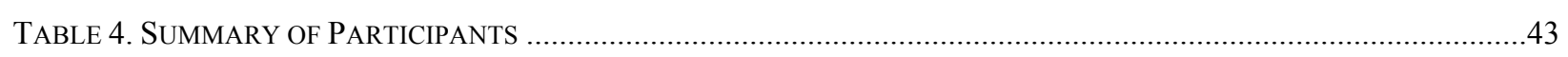

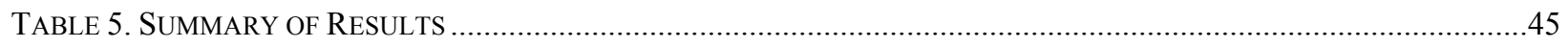

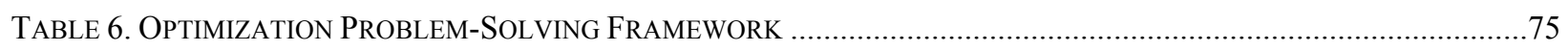

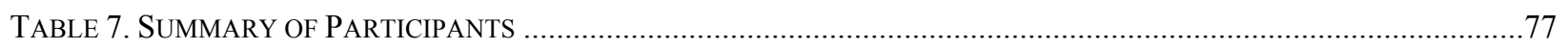

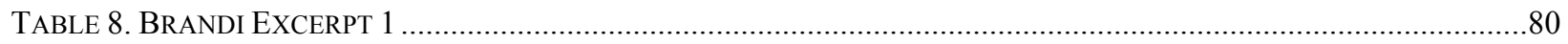

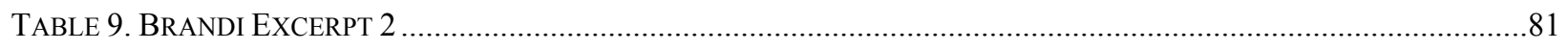

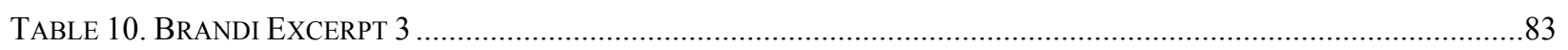

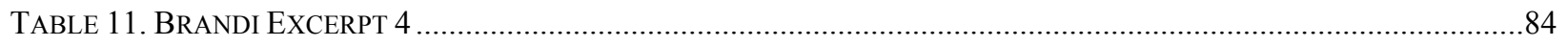

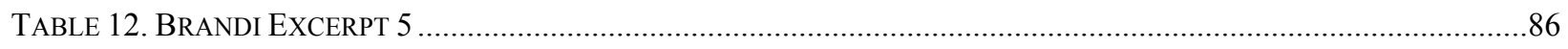

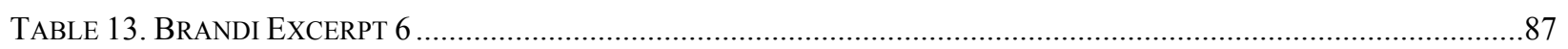

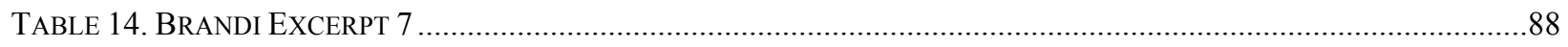

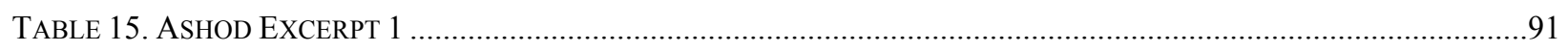

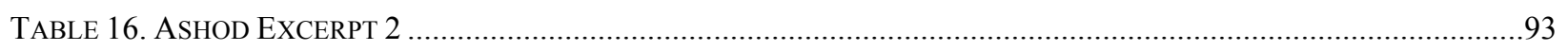

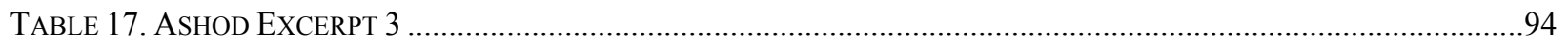

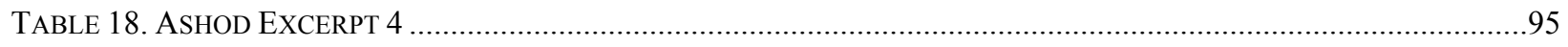

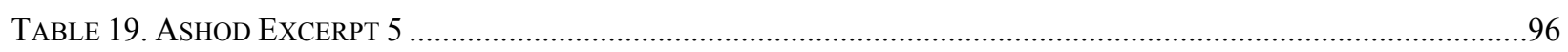

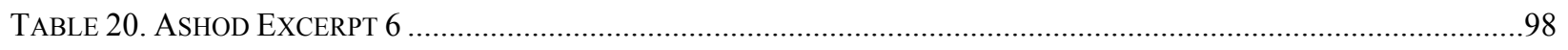

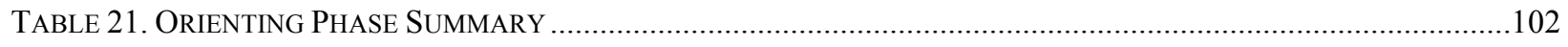

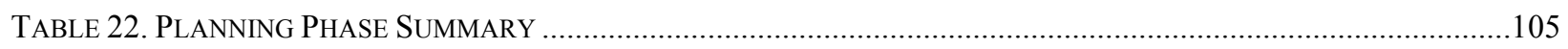

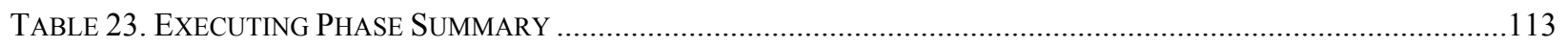

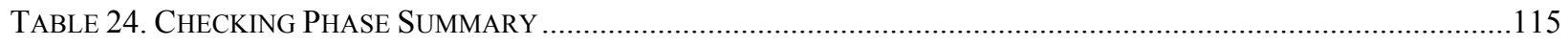

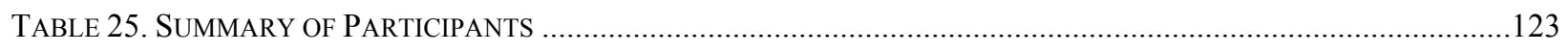

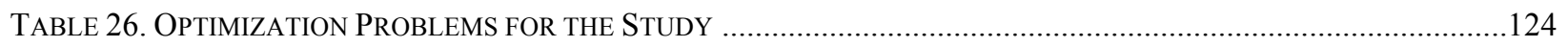




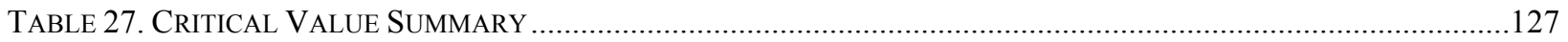

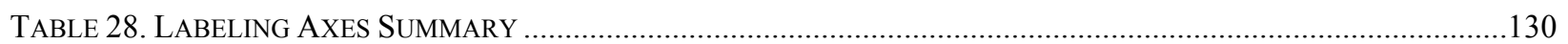

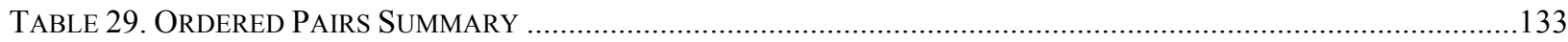

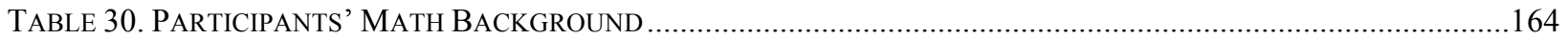




\section{LIST OF FIGURES}

FIGURE 1. FRANZ, BRANDI, AND ASHOD MARK THE LOCATION ON THE GRAPH WHERE THEY BELIEVE THE CRITICAL NUMBER BELONGS......

FIGURE 2. ASHOD, BRANDI, AND FRANZ (IN ORDER) MARK THE LOCATION ON THE GRAPH WHERE THEY BELIEVE THE CRITICAL VALUE BELONGS. NOTE THAT ALL THREE STUDENTS PLACED THE MARK SOMEWHERE OTHER THAN BELOW THE OBVIOUS MAXIMUM OR MINIMUM. 


\section{INTRODUCTION}

\section{Discussion about "Optimization"}

For the purpose of this dissertation, "optimization problems" refers to the standard word problems in first semester calculus that ask the student to determine how to maximize or minimize a quantity that is restricted by a constraint(s). Examples include: minimizing the amount of fencing needed to enclose a specified amount of area, maximizing the volume of a box with a fixed surface area, minimizing the cost of constructing a pipeline that must cross a river, etc.

Solving this kind of optimization problem involves constructing a single variable function that models the quantity to be maximized or minimized subject to the given constraint(s). I will refer to this as the optimizing function. Using previously learned calculus techniques, the student will find the value where the maximum or minimum of the optimizing function occurs. This information is then used to answer any other questions posed in the problem.

Optimization problems are interesting, because they provide an opportunity to study how previously learned mathematical concepts work together and how students react when presented with problems that do not explicitly suggest the use of these concepts, but rather require the student to discover a need for them. Optimization problems do not directly instruct students to construct functions, to use the derivative, or to find values where the derivative is equal to zero. The individual attempting to answer the question posed in the problem must recognize the utility of these mathematical concepts for solving the problem. 
Calculus textbooks (Rogawski, 2012; Salas, Hille, \& Etgen, 2003; Stewart, 2007) often

provide students with a list of steps to use to solve optimization problems. See Table 1 for the list of steps from both Stewart (2007) and Rogawski (2012).

Table 1. List of Steps

\begin{tabular}{|c|c|}
\hline Stewart (2007) & Rogawski (2012) \\
\hline 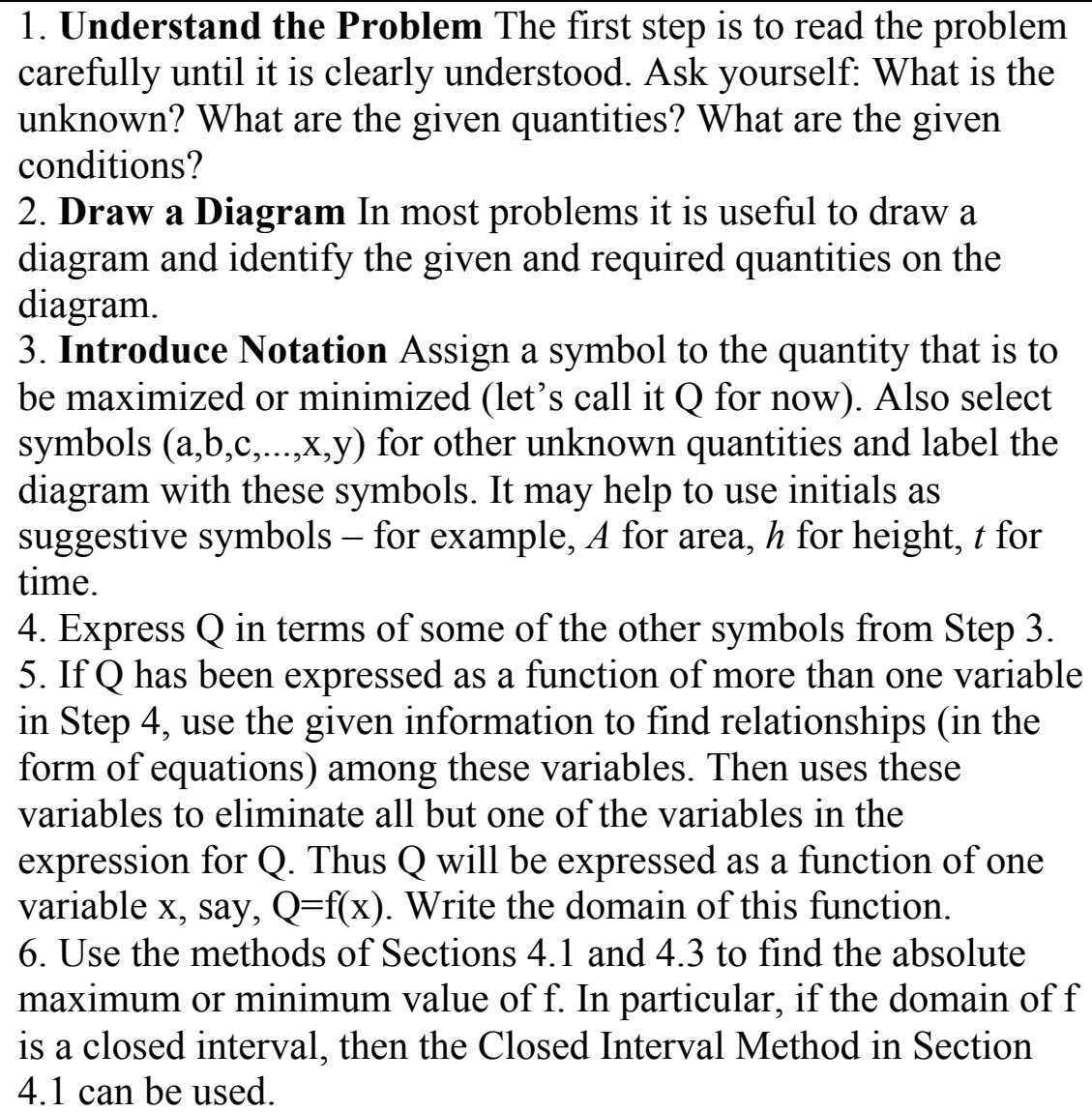 & $\begin{array}{l}\text { Step 1. Choose variables } \\
\text { Determine which } \\
\text { quantities are relevant, } \\
\text { often by drawing a } \\
\text { diagram, and assign } \\
\text { appropriate variables. } \\
\text { Step 2. Find the objective } \\
\text { function and the interval. } \\
\text { Restate as an } \\
\text { optimization problem } \\
\text { for a function f over an } \\
\text { interval. If f depends on } \\
\text { more than one variable, } \\
\text { use a constraint } \\
\text { equation to write f as a } \\
\text { function of just one } \\
\text { variable. } \\
\text { Step 3. Optimize the } \\
\text { objective function. }\end{array}$ \\
\hline
\end{tabular}

Stewart (2007) places these steps at the very beginning of the optimization section underneath two sentences stating, "In solving such practical problems the greatest challenge is often to convert the word problem into a mathematical optimization problem by setting up the function that is to be maximized or minimized. The following steps may be useful."

In my experience as a calculus teacher, however, I have found that these steps are only marginally helpful. If the student is faced with a standard optimization problem, he or she is 
often able to apply these steps to get to an answer, but does not always demonstrate an understanding of the process itself. This is particularly noticeable when students are asked to solve problems that require some additional thought beyond what is listed in the steps or when they are asked to solve an optimization problem after some time has passed and they have forgotten the precise list of steps.

\section{Existing Research About Optimization}

Very little research exists on how students learn and understand optimization problems. As part of a literature search to identify topics in calculus that remain largely unexamined by the mathematics education research community, Speer and Kung (2016) identified optimization problems as one of the topics needing more attention. Beers (1991) identified optimization problems as important applications that demonstrate the power of calculus in real-life scenarios. Whiteley and Mamolo (2012) describe their work on optimization problems with high school students who do not yet have the tools of calculus to help them solve the problems. They focused on helping students think about optimization problems by analyzing the rate of change of the desired quantity over time and helping students notice that as the rate of change approached zero, they approached the maximum or minimum value for the quantity. This is discussed in more detail later.

As part of a study examining high school AP calculus students' uses of diagrams in solving applied calculus problems, Bremigan (2005) found the construction of diagrams to be related to students' ability to solve optimization, but also found that appropriate use of diagrams was not enough to predict success. Most significantly, White and Mitchelmore (1996) conducted a study in which 40 university students took four tests over the course of a semester. Before conducting the study, they selected two optimization problems and created four versions of each 
problem. Each time the test was administered, a different version of each problem was presented on the test so that by the end of the semester, every student had solved each of the four versions of both problems. The students were divided into four groups of ten students, and the order in which the versions were presented was different for each group.

For all four versions, the students had to use calculus to find the maximum or minimum of the optimizing function for the problem. The most explicit version gave the algebraic representation of the function along with the instruction to find positive value(s) for $x$ where the derivative equaled zero. The least explicit version was written in paragraph form without algebraic expressions or direct instructions of how to solve the problem. Targeted interviews with some of the students after taking the tests confirmed that they did not realize they were solving the same problem four times.

Unsurprisingly, there were significantly more correct answers to the versions given explicitly than there were to the versions given in the form of a word problem. Targeted interviews and analysis of students' written work indicated that determining how to model the situation mathematically and then make a plan for solving the problem were the two biggest barriers to the students being able to solve the versions presented in the form of word problems.

White and Mitchelmore (1996) concluded that needing to define the variables, rather than using variables already provided made a significant difference in the students' ability to solve the problems. They state, "Defining variables in a modeling situation indicates that the solver is making choices with some plan in mind - a plan that has not been laid out in visible cues. Defining new variables therefore involves relationships at a higher level of generality than the concepts they connect" (White \& Mitchelmore, 1996, p. 91).

\section{Research Questions}


White and Mitchelmore's (1996) study provided broad categorizations of students' understanding of optimization problems, but left many unanswered questions. In this dissertation, I will provide additional insight into students' understanding of optimization by addressing the questions:

1. What mathematical concepts are involved in students' construction of the optimizing function? What aspects of students' concept images for these mathematical concepts and for the optimizing function play a role in their ability to construct an appropriate optimizing function?

2. How do students engage in conceptual and analytical thought processes while solving an optimization problem?

3. How can the above information inform teaching practices to support conceptual development of the optimization process?

By answering these questions, I will reduce the gap in the literature identified by Speer and Kung (2016).

\section{Survey of the Literature}

One of the most critical parts of solving an optimization problem is determining a plan for solving the problem and constructing an appropriate optimizing function (Stewart, 2007; White \& Mitchelmore, 1996). While not much literature exists specifically related to optimization problems, there is an abundance of literature about the many mathematical concepts that are involved in solving optimization problems. This is because many of these mathematical concepts are crucial to a strong understanding of calculus in general. My goal in focusing on optimization problems is to study, in part, how all of the moving pieces involved in optimization come together in the mind of the student and influence his or her ability to truly understand the 
optimization problem-solving process. Here I will synthesize the existing literature related to some of the mathematical concepts that play a role in students' work with optimization problems.

\section{Covariational Reasoning}

Optimization problems require students to consider relationships between variables representing different quantities. For example, a standard optimization problem requires students to consider how the perimeter of a fence changes in relationship to the length of one of its sides. In this example, both the perimeter and the side length are changing and the student must think about how these two quantities change simultaneously. This is referred to as covariational reasoning and is defined by Carlson, Jacobs, Coe, Larsen, and Hsu (2002) as "the cognitive activities involved in coordinating two varying quantities while attending to the ways in which they change in relation to each other" (p. 354). Research tells us that covariational reasoning skills are key to many mathematical concepts (Confrey \& Smith, 1995; Jacobson, 2014; Monk \& Nemirovsky, 1994; Moore, Paoletti, \& Musgrave, 2013; Oehrtman, Carlson, \& Thompson, 2008; Saldanha \& Thompson, 1998; Zeytun, Cetinkaya, \& Erbas, 2010), and it is clear that it plays a role in students' understanding of optimization problems as well.

Carlson et al. (2002) report that while many students are able to correctly determine the direction of the rate of change for some physical situations (such as the rate of change of the depth of water as it is poured in an oddly shaped bottle), they often have difficulty constructing images to reflect this rate of change, indicating that poor covariational reasoning skills can inhibit students' ability to understand graphical representations of functions. Covariational reasoning skills are so difficult that even in-service secondary school teachers have poor covariational reasoning skills and have difficulty thinking about functions and graphs in terms of 
covariation (Zeytun et al, 2010). Similarly, Saldanha and Thompson (1998) suggest that "understanding graphs as representing a continuum of states of covarying quantities is nontrivial and should not be taken for granted" (p. 7).

\section{Functions}

There is a large body of literature devoted to researching student understanding of functions (Breidenbach, Dubinsky, Hawks, \& Nichols, 1992; Carlson, 1998; Carlson, Oehrtman, \& Engelke, 2010; Dubinsky \& Harel, 1992; Dubinsky \& Wilson, 2013; Eisenberg, 1992; Hitt, 1998; Leinhardt, Zaslavsky, \& Stein, 1990; Monk, 1992; Vinner \& Dreyfus, 1989). Functions play a critical role in optimization problems, since the goal is to construct a function that models the given situation and then find the absolute maximum or minimum of that function. The function concept is complex and multifaceted.

Students often begin their study of functions by learning to determine the functional values for elements in the domain. Research by Engelke, Oehrtman, and Carlson (2005), Carlson (1998), and Carlson et al. (2010) found students are generally very comfortable with these kinds of basic algebraic manipulations - most students would have little trouble evaluating $f(2)$ given a function like $f(x)=x^{4}-1$ or composing two functions given algebraic expressions. Research results (Breidenbach et al., 1992; Carlson, 1998; Dubinsky \& Harel, 1992; Hitt, 1998; Vinner \& Dreyfus, 1989) indicate that the algebraic expression of a function is so central to some students' understanding of the function concept that they believe all functions must be able to be written as a single algebraic expression; Hitt (1998) found that some students erroneously believe conic sections are functions simply because they have algebraic expressions associated with them.

Breidenbach et al. (1992), Dubinsky and Harel (1992), Sfard (1992), and Monk (1992) found the action of performing step-by-step algebraic manipulations using functions to be a 
predominant part of students' understanding of functions, despite our desire for students to consider functions as acting on a collection of elements, rather than on one element at a time.

In fact, Carlson (1998) observed that of college algebra students who had just earned grades of " $\mathrm{A}$ " for the course, very few had a fully developed process view of function (were able to fully understand how functions act on a collection of elements). This indicates that it takes years for students to develop a strong process view of function and that it is unlikely that first semester calculus students are going to arrive or even leave with a process view of function. This is significant because, as noted by Carlson et al. (2010) and Engelke et al. (2005), students without a process view of functions tend to be more likely to answer conceptual questions involving functions incorrectly than those with a process view.

To discuss students' covariational reasoning skills, Carlson, Oehrtman, and Thompson (2005) give the example of a function that is commonly used in optimization - a function representing the area of a square in terms of one of its sides. With a process view of function, students are able to engage their covariational reasoning skills to discover that the area of the square increases more quickly as the side lengths increase. Thus, to correctly reason about the optimizing function that must be constructed for an optimization problem, a process view of function is needed, along with strong covariational reasoning abilities.

Graphical Representations of Functions. Graphical representations of functions can convey information about the function in a single image. To some extent, the graph of a function can help students to develop a process view of a function because it allows them to consider what the overall behavior of the function is, rather than focusing on individual elements. Students, however, are often reluctant to consider the graphical representation of a function, and when they do, they frequently have trouble interpreting the information correctly (Eisenberg, 
1992). Asiala, Cottrill, Dubinsky, and Schwingendorf (1997) mention that students may be able to think of functions as acting on a collection of elements when considering a function given by an expression, equation or set of ordered pairs, but may only be able to think of functions as acting on one element at a time when considering the graphical representation of the function. Sfard (1992) states, "Graphs provide another way of thinking about functions, but there is almost no connection between a graph and the underlying formula" (p. 75). Knuth (2000) reported, "three fourths of the students chose an algebraic approach as their primary solution method, even in situations in which a graphical approach seemed easier and more efficient than the algebraic approach" (p. 504). Carlson (1998), Clement (1985), and Monk (1992) observe that many students associate too much information with the shape of the graph, for example assuming that a speed vs. time graph mimics the movement of an object. Additionally, students sometimes oversimplify problems by assuming linear relationships between two quantities that are not linearly related (De Bock, Van Dooren, Janssens, \& Verschaffel, 2002; De Bock, Verschaffel, \& Janssens, 1998). Carlson et al. (2002) note that this is, in part, due to weak covariational reasoning skills.

Arcavi (2008) notes that analytic techniques are frequently "devoid of meaning" for students and suggests having students examine the graph of a function prior to using analytic techniques to determine information about the function (p. 9). He suggests using an electronic graphing tool (which he calls a dynamic graphing tool) to give even more information about a function than a static graph might give. This dynamic graphing tool allows the student to watch the function being drawn and displays the relevant information about the function at various points on the function. He argues, "a dynamical graphical model highlights aspects of the situation that were not as salient had we investigated it alone or even by modeling it 
symbolically" (p. 5) and gives the example of using dynamic graphs to examine the relationship between the perimeter of a rectangle and the length of one its sides and the relationship between the perimeter of a rectangle and the length of its diagonals. Such explorations may help students develop better covariational reasoning skills.

Function Notation. Optimization problems require the students to construct a new function, and usage of and understanding of appropriate function notation is key to this process. Carlson (1998) found that even at the end of the semester, the best college algebra students had very weak understanding of the notation associated with functions. She observed that these students,

"Do not understand the language of functions, in particular:

What it means for one quantity to be a function of another.

The role of the parentheses in the function representation.

That the "functional value" is referring to the y-value (assuming conventional labeling of the axes)." (Carlson, 1998, p. 141)

Carlson observed that these students had difficulty understanding the role the independent and dependent variables were playing when a function was given in terms of an algebraic expression. The student in the case study described by Sajka (2003) also exhibited some of these misconceptions, particularly evidenced by her confusion when considering the notation $f(x)$ and $f(y)$. She believed they were entirely separate functions, rather than different ways of expressing the same function. She said she believed that the $f$ in the expression $f(x)=$ [some algebraic expression] was a label indicating the beginning of something new or just an abbreviation for the word "function." This is troublesome, because while the students might be able to construct an appropriate function without using the correct notation, a complete 
understanding of the function construction process includes being able to use the correct notation.

\section{Derivative}

Two aspects of the derivative are particularly important for understanding optimization problems. The first is the derivative as it corresponds to the rate of change of the function, and the second is the derivative as it corresponds to the slopes of the lines tangent to points on the graph. Knowing that the derivative calculates the slope of the tangent line at a specific point on the function is very useful for helping students understand optimization problems. As observed in Vincent, LaRue, Sealey, and Engelke (2015), even students with weak concept images of tangent lines are able to draw and/or visualize horizontal tangent lines at maximums or minimums on a function graph and then recognize that the slope of such a tangent line is zero (since it is horizontal), so the derivative must be zero at this point. This suggests that, since this is something students seem to understand fairly well, using the graph and discussing horizontal tangent lines might be helpful for students.

According to Zandieh (2000) understanding the derivative as it corresponds to rate of change requires having an object view of the difference quotient so that it can be used in the limiting process. It also requires the student to consider the resulting limit as the output of the derivative function at the corresponding input value. Whiteley and Mamolo (2012) illustrate the usefulness of considering the derivative as the rate of change of the function when introducing the concept of optimization to students. They asked high school students to determine how to construct a popcorn box with maximum volume by cutting equal sized squares from all four corners of a piece of cardboard. These students were not expected to use calculus to solve the problem since they hadn't taken calculus yet, and instead were encouraged to consider the rate of 
change of the volume as the size of the squares varied. The students were able to observe (with the help of some graphing software) that the optimum value occurs when the rate of change is zero. Although the students were not able to calculate the exact answer, they were able to develop a strong intuitive understanding of the process without ever discussing derivatives explicitly. This suggests that once students have learned about the derivative, emphasizing the derivative as a rate of change could be useful in teaching students about optimization problems.

\section{Intuitive Ideas About Area/Perimeter and Volume/Surface Area}

An important part of understanding optimization problems in calculus is the notion that a system can be fixed in terms of one property but be allowed to vary in terms of another property. For example, in the classic optimization problem that asks the student to find the minimum amount of fencing needed to enclose a rectangular area with a specified area, the area is fixed, while the amount of fencing (perimeter) is free. Existing literature (Kospentaris, Spyrou, \& Lappas, 2011; Tirosh \& Stavy, 1999; Woodward \& Byrd, 1983) suggests that this concept is often challenging for students, many of whom believe area and perimeter directly influence one another.

Woodward and Byrd (1983) presented 129 eighth grade students with five rectangular gardens, all with perimeters of $60 \mathrm{ft}$ but with different areas. They asked the students which rectangle had the largest area and gave them the option of responding that all of the rectangles had the same area. Almost $60 \%$ (76 of 129) of students responded that all of the rectangles had the same area (Woodward \& Byrd, 1983). Perhaps more astonishingly, the authors gave the same test to students from an undergraduate math course for preservice teachers and had similar results. One student they interviewed explained, "rectangles with the same perimeter take up the same amount of space" (Woodward \& Byrd, 1983, p. 344). 
In a study conducted with students in grades 5-9, Tirosh and Stavy (1999) found that 85\% of the students believed that if two cylinders had the same surface area, they also had the same volume. They refer to this as an intuitive rule called "Same A - same B," which is connected to their intuitive rule of "More of A - more of B" (Tirosh \& Stavy, 1999, p. 52). In general, "More of A - more of B" means that students are presented with two objects both with property A such that $A_{1}$ is less than $A_{2}$. When the students are then asked to consider a different property, $B$, of the two objects, they frequently assume that $\mathrm{B}_{1}$ is less than $\mathrm{B}_{2}$ as well. As an example of this "rule," Kospentaris et al. (2011) found that many students believed that the longer the sides of a figure, the greater the area of the figure and that the larger the perimeter, the bigger the area. Tsamir (2003) points out that phrases like more A, more B are commonly used in the English language, citing as examples "the more you study the more you know" and "the more you eat the fatter you get” (p. 640). This incorrect intuition could cause significant problems for students attempting to understand optimization problems, because fixing the perimeter while allowing the area to vary would be very counterintuitive for them.

\section{Use of Diagrams}

Diagrams can be very helpful in mathematics because they are able to convey a lot of information in a relatively succinct format. We can convey information about a rectangular box much more quickly by displaying a labeled image of the box than by describing the box in words. Eisenberg (1992) states, "this added usefulness is not due to the fact that there is more information in the diagram but to the fact that this information is presented in such a way that it explicitly exhibits important pieces of information and important conceptual links between these pieces of information" (p. 170). 
In the case of optimization problems, Bremigan (2005) states that diagrams serve to organize information, define variables, and identify constraints (p. 250). She suggests that interpreting and constructing appropriate diagrams for applied calculus problems is one of the most important aspects of the problem solving process, and one that students struggle with more than we often acknowledge. Many students are used to being able to solve math problems without using diagrams or other pictorial representations, so the transition to more difficult problems where the diagrams are more important can be difficult for them.

Booth and Thomas (2000) highlight two skills students need to be able to use diagrams and other visual representations effectively: 1) the ability to construct a diagram that correctly displays the information given in a word problem and 2) the ability to extract appropriate information from a given diagram and understand how it is related to the word problem. Eisenberg (1992) adds that "it takes cognitive processing to make sense of diagrammatic representations" (p. 170). If the viewer isn't able to extract the appropriate information from the diagram, it will be essentially useless. It is for this reason that many students either do not create and use diagrams or are unable to make use of already available diagrams.

\section{Conclusion}

The aim of this dissertation is to fill the gaps in existing literature pertaining to optimization problems in first semester calculus. In the following chapters, I will outline the theoretical perspective I use to frame my discussion about optimization problems, describe the methods used for my study and then present three papers that are the result of my research. I conclude the dissertation with a discussion about all three papers and then suggest directions for future research. 


\section{THEORETICAL PERSPECTIVE}

The research questions for this study focus on students' understanding of the optimizing function and their overall understanding of the entire process of optimization. Recall the research questions are:

1. What mathematical concepts are involved in students' construction of the optimizing function? What aspects of students' concept images for these mathematical concepts and for the optimizing function play a role in their ability to construct an appropriate optimizing function?

2. How do students engage in conceptual and analytical thought processes while solving an optimization problem?

3. How can the above information inform teaching practices to support conceptual development of the optimization process?

Carlson and Bloom's (2005) Multi-Dimensional Problem-Solving Framework provides the backdrop of our study of students' work with optimization problems. Tall and Vinner's (1981) language of concept image is used to frame our discussion about students' construction of the optimizing function while answering the first research question. Vinner's (1997) language of conceptual and analytical thought processes is used to frame our discussion about students' overall approaches when solving optimization problems, as described in the second research question. The third research question is based on results from the previous two research questions and is thus informed by a blend of all three theoretical perspectives.

In the following sections, I describe each of the three perspectives is given. A discussion about how all three fit together to frame our discussion of students' understanding of optimization problems concludes this chapter. 


\section{Carlson and Bloom's Multidimensional Problem-Solving Framework}

Carlson and Bloom's (2005) Multidimensional Problem-Solving Framework was developed through interviews with 12 experts (eight research mathematicians and four $\mathrm{PhD}$ candidates) as they solved four problems involving basic mathematical concepts like geometry, algebra, and proportions. Because the framework was developed based on expert's problemsolving activities, the framework is not expected to predict the behavior of students who are engaged in problem-solving activities, but rather is expected to describe the problem-solving behaviors that instructors should be promoting in their students.

The framework is divided into four phases, and for each phase, Carlson and Bloom (2005) describe general behaviors associated with that phase along with a description of how resources, heuristics, affect, and monitoring played a role in the experts' problem-solving activities. The first phase is the orienting phase during which the problem solver studies and deciphers the problem, draws pictures, defines unknowns, and assembles other tools he or she thinks might be useful. For an optimization problem, this is when the student recognizes that the goal of the problem is to maximize or minimize a quantity and assembles any formulas that may be helpful. Once the problem solver is sufficiently situated in the problem, he or she moves into the second phase, the planning phase, during which he or she uses prerequisite knowledge to determine an appropriate course of action. For an optimization problem, this is when the problem solver constructs the optimizing function and makes a plan for using it. The third phase is the executing phase, during which the problem solver carries out the plan from the previous phase. In an optimization problem, this is when the problem solver uses calculus techniques to find the absolute maximum or absolute minimum of the optimizing function. Finally, the fourth phase is the checking phase. During this phase, the problem solver returns to the original problem to see 
if the answer makes sense. For an optimization problem this might involve using the first or second derivative test to verify that the answer occurs at a maximum or minimum as desired and to make sure that the answer makes sense in the real-world context of the problem.

A key aspect of this problem-solving framework is its cyclical nature. After the experts sufficiently oriented themselves in the problem, they frequently repeated the process of planning, executing, and checking until the checking phase no longer revealed a flaw in the approach. Additionally, during the planning phase, the experts were observed engaging in a "conjecture cycle" of conjecturing that an approach might work, imagining how it would take place, and verifying that this would be useful for solving the problem (Carlson \& Bloom, 2005).

\section{Concept Image}

Mathematical concepts belong to both the mathematical community at large and also to the individual learner. It is clear that individual learners often do not have a complete grasp of certain mathematical concepts and that it is possible for different individuals to have different understandings of the same concept. Tall and Vinner's (1981) language of concept image provides a lens for discussing this discrepancy.

Tall and Vinner (1981) define concept image as "all the cognitive structure in the individual's mind that is associated with the given concept" (p. 1). Mental pictures, which are defined as any images the learner associates with the concept, are key to a student's concept image. These might include graphs, diagrams, symbols, pictures, or physical models. Because we use the word concept image, it is important to emphasize that these mental pictures are only one part of the student's overall concept image. Also included are any properties and processes the individual relates to the concept. For example, a person's concept image of a function might 
include the property that "for every $x$ there is only one $y$ " or the process of function composition.

Because the concept image exists in the mind of an individual, and we know that individuals do not always have correct beliefs about mathematical concepts, this cognitive structure may not be complete, correct, or logically consistent. It may have very little to do with the formal mathematical definition. Thus, the aforementioned student's concept image of a function might consist of the (incorrect) property that "for every $y$ there is only one $x$." Furthermore, he or she may also believe a circle is a function, even though his or her concept image of a function includes the property "for every $x$ there is only one $y$."

Although there are many components to one's concept image, one rarely accesses every part of the concept image at the same time. When the need for the concept image arises, the parts of the concept image that are directly related to the need are called upon, but the rest of the concept image remains dormant, ready to be accessed if needed, but not until then. Tall and Vinner (1981) refer to the part of the concept image that is presently activated as the evoked concept image.

The distinction between the evoked concept image and the concept image is important, because it explains how an individual can have conflicting information in his or her concept image. Unless the two logically inconsistent parts are activated simultaneously, the individual may never realize that there is a conflict. However, when the two conflicting parts of the concept image are both accessed at the same time, the individual experiences confusion known as cognitive conflict. Tall and Vinner (1981) state, "in certain circumstances cognitive conflict factors may be evoked subconsciously with the conflict only manifesting itself by a vague sense 
of unease" (p. 154). Other times, this cognitive conflict is so strong that the student is forced to react and make an adjustment to the concept image.

Vinner (1983) argues that although collegiate instructors seem to expect students to develop their concept images based on the formal concept definitions presented in class, this is not how most students develop and use their concept images. Vinner (1983) states, "in thinking, almost always the concept image will be evoked" (p. 293). If a student is presented with a formal concept definition in class that is not in line with his or her concept image, Vinner (1983) identifies three main responses. The first option is to readjust the concept image to align with the definition. The second option is to keep the concept image as is, temporarily add the new concept definition to the concept image, but then allow the new concept definition to fade away and disappear over time. The third option is to maintain both the concept image and concept definition, using whichever one is called for in a given situation. The last two instances are generally what tend to lead to cognitive conflict and a change in the concept image.

In our study, we have chosen to use this language of concept image to discuss how students think about the optimizing function while solving an optimization problem. Students often develop their own intuitions about the behavior of the optimizing function, what it represents, and how it should be used, and these do not always line up with the definition of an optimizing function. Using the language of concept images allows us to discuss what the students appear to believe to be true about the optimizing function and how this differs from instructors' expectations.

\section{Conceptual/Analytical Thought Processes}

There are certain thought processes that teachers and experts hope students will use while solving mathematics problems. Vinner (1997) divides these desired thought processes into two 
categories: conceptual thought processes and analytical thought processes. Conceptual thought processes involve the student thinking about "concepts, their meaning, and their interrelations" (p. 99). Analytical thought processes are related to solving a specific problem and thinking about why certain procedures are appropriate for solving the problem. This is different from conceptual thought, because the students are more focused on the procedures they are using than they are on the more general underlying concepts.

As an alternative to developing the desired conceptual thought processes, students sometimes develop “simpler, easier, and shorter" processes, called pseudo-conceptual thought processes, to stand in place of conceptual thought processes (Vinner, 1997, p. 101). Likewise, students sometimes develop pseudo-analytical thought processes in place of analytical thought processes (Vinner, 1997).

Vinner (1997) provides room for overlap in his description of conceptual and analytical thought processes. Due to the complexity of mathematics, there are some instances when certain thought processes can be appropriately described as conceptual or analytical, depending on the lens of the analyst. For our purposes, we anticipate student's thought processes while working an optimization problem to move fluidly back and forth between conceptual and analytical (or pseudo-conceptual and pseudo-analytical).

Generally, we refer to the thought processes while the students are working through the procedures of solving the problem as analytical thought processes. For example, when a student differentiates the optimizing function and sets it equal to zero, he or she may have one of the following thought processes in his or her head: 1) I need to find points in the domain where the derivative is equal to zero because minimums and maximums can only occur when the derivative is equal to zero or does not exist and 2) I need to differentiate because when we do these 
problems, we always take the derivative after we have created this function. In the first case, we would say the student's thought process is analytical. In the second case, the student's thought process is pseudo-analytical, because he or she is recalling a familiar procedure, but not thinking about why those procedures work.

We refer to thought processes that are involved with the general concept of optimization, and are not focused on a specific step, as conceptual thought processes. For example, when constructing the optimizing function, the student may consider why this function is being created. Analytical thought processes will aid him or her in determining which equations are useful and how to get the equation to represent the quantity to be maximized or minimized, while conceptual thought processes will aid the student in determining why he or she needs to construct such a function and in thinking about why the function needs to represent the quantity to be maximized or minimized instead of something else. A student who decides to construct a function representing the area of a rectangle might do so because he or she recognizes that the goal is to maximize area. In this case, the student is using conceptual thought processes. However, in the same problem, a student might construct a function representing the area of a rectangle because perimeter is given in the problem and so it seems to make sense to construct a function for the other property.

In both cases, pseudo-analytical and pseudo-conceptual, the key is that the student is not thinking deeply about the underlying mathematics, but is rather relying on heuristics to expedite his or her thought processes. Relying on heuristics and engaging in pseudo-analytical and pseudo-conceptual thought processes is not necessarily undesirable. Sometimes it is important to solve the problem quickly without taking the time to think deeply about the mathematics involved. However, when approaching a new problem or even a similar problem with an added 
level of difficulty or complexity, it often becomes necessary to return to conceptual and analytical thought processes to be able to solve the problem. For this reason, we would like to see evidence of the students being able to engage in these types of thought processes when asked, and we encourage our students to take steps to encourage these kinds of thought processes. This was our reason for pressing further when interviewing our students. Just because a student didn't indicate that he or she was using conceptual and analytical thought processes while initially solving the problem, we asked more questions to see if they were able to engage in these kinds of thought processes when prompted. We found that some students could, but others were stuck at the pseudo-conceptual and pseudo-analytical level.

\section{Summary}

First semester calculus optimization problems require students to engage in complex, multi-faceted problem-solving activities. We use a blend of the above three theoretical perspectives to enable us to discuss the complexities involved in solving optimization problems. Tall and Vinner's (1981) language of concept image allows us to discuss students' apparent beliefs about the optimizing function, as this emerged as a very important component of students' overall understanding of the optimization process.

To focus on the overall optimization process, we analyzed students' thought processes, both conceptual and analytical, as they moved through the four phases of Carlson and Bloom's (2005) Multidimensional Problem-Solving Framework and used this to develop the Optimization Problem-Solving Framework that is described in detail in Paper 2. Adapting Carlson and Bloom's framework by using Tall and Vinner's language of conceptual and analytical thought processes allows us to focus on the discrepancies between the students' written, algebraic work and their underlying thought processes and helps us identify the parts of the problem-solving 
process that are most difficult for students. This blend of theoretical perspectives allows us to be attentive to the complex nature of optimization problems and to gain insight into how students make sense of the many big ideas that are involved. 


\section{METHODS}

\section{Semi-Structured Interviews}

To collect data for this study, I conducted semi-structured clinical interviews. Semistructured interviews allow the interviewer to insert additional questions as the interview takes place, in response to the interviewee's answers. These questions are for the purpose of clarifying something the interviewee said or probing deeper into the interviewee's thoughts. This approach was most useful for me, because I wanted to have the flexibility to temporarily follow the student down an unexpected path or to ask follow-up questions in order to capture as much of the student's thought processes related to solving optimization problems as possible. Throughout the interviews, I used open ended questions as described by Cohen, Manion, and Morrison (2011), such as "What made you decide to use this approach?" or "Why did you take the derivative here?" I video recorded the interviews and then transcribed them so that during data analysis I could "make inferences about the mathematical thinking, learning, and/or problem solving of the subjects" (Goldin, 2000, p. 519). The purpose of my research was generative, which is defined by Clement (2000) as generating "new observation categories and new elements of a theoretical model in the form of descriptions of mental structures or a process that can explain the data" ( $p$. $557)$.

\section{Pilot Study}

In the spring of 2014, I conducted and video recorded semi-structured interviews with three second semester calculus students as they solved optimization problems. I chose to conduct my pilot study with second semester calculus students because it enabled me to gain insight into which parts of the optimization problem-solving process remain prominent for students after they have likely forgotten any list of steps they might have memorized for solving the problem. 
Similarly, I was able to observe which aspects of the problem-solving process presented challenges for the students. Without a memorized list of steps, the students were forced to rely on their mathematical reasoning abilities and existing cognitive structures. The students were asked to solve three optimization problems, thinking out loud and describing their thought processes while solving. When they were unclear or did not provide detailed explanations, I asked followup questions to further probe their thought processes. The full protocol for the pilot study can be found in Appendix A.

I analyzed the pilot study data focusing on the evidence of students' thought processes pertaining to optimization, and then I used this analysis to develop a protocol for the main study. Certain aspects of the problem-solving process were problematic for the second semester calculus students in the pilot study, so I knew to ask targeted questions about these aspects to draw out as much information as possible about the students' related thought processes while still in first semester calculus. To conduct the analysis, I watched the videos several times, took detailed notes, reflected on what I observed, and transcribed and coded portions of the interviews based on these reflections and notes. Emergent themes from this analysis led to the development of the protocols for the main study and also suggested initial codes to use for analysis of the main study.

\section{Brief Summary of Results from the Pilot Study}

All three students knew they needed to differentiate something while solving an optimization problem, but were not sure what to differentiate. Two of the three students began by trying to differentiate an expression pertaining to the quantity that was given in the problem, instead of the quantity to be minimized. All three students eventually realized they needed a single variable function, but none of them were able to explain why, other than saying that they 
did not know how to differentiate something with more than one variable. In other words, there was no attention to the role of the constraint in the problem. Two of the students did not remember how to solve the problem. After several leading questions and interventions pertaining to the graphical representation of the optimizing function, they finally realized they needed to set the derivative equal to zero to find critical values. The one student who remembered to set the derivative equal to zero without intervention was not able to explain why it worked at first, but eventually used the graphical representation of the optimizing function to explain. All three students had trouble describing what the optimizing function represented. These results suggested the need to focus on the role of the optimizing function, in particular the construction of the optimizing function.

\section{Main Study}

For the main study, I conducted interviews with first semester calculus students instead of second semester calculus students, because I was interested in how students understand optimization problems during first semester calculus when they first learn how to solve them. The data obtained from the pilot study illuminated areas of interest and helped me develop a robust protocol for the interviews with the first semester calculus students. I limited the number of optimization problems to two, in the interest of conducting interviews of reasonable length for the students.

\section{The Protocols}

The protocols changed slightly between the first set of interviews in the summer and the second set of interviews in the fall, which I describe further below. The entire protocols can be found in Appendix B and Appendix C, but I will briefly summarize them here. Both followed this general format: 
I. Background information, ice breaker questions

II. The Garden Problem: A rectangular garden of area $200 \mathrm{ft}^{2}$ is to be fenced off against rabbits. Find the dimensions that will require the least amount of fencing if a barn already protects one side of the garden.

III. Questions about pre-requisite material

IV. A second optimization problem

In Part I of both protocols the students were asked to report on their mathematics backgrounds and any strengths or weaknesses they felt they had with mathematics. In the first protocol, the students were then asked to find the derivative of two functions, which served as a warm-up. This warm-up caused trouble for some students because they had forgotten the quotient rule, and thus did not serve its purpose as an easy warm-up. For this reason, I created a different warm-up for the second protocol, tailoring it be more related to optimization problems. For the warm-up for the second protocol, the students were asked to calculate the area and perimeter of a rectangle, and calculate $f(2)$ for the function $f(x)=-3 x^{2}+1$. In the second protocol, I also asked the student to relate their answer for $f(2)$ to the graph of the function and then define "function."

In Part II of both protocols, the students were asked to solve the Garden Problem which is a standard introductory problem in most calculus textbooks. This problem was chosen as it is representative of one of the first types of optimization problems presented in both the classroom and the textbook. The algebra is not overly complex, which allows the student to focus on the bigger ideas involved in optimization.

Based on responses from my pilot study, I became interested in what students understand about the optimizing function. In particular, I was interested in examining how students make 
sense of the graphical representation of the optimizing function. To do this, I presented the students with the Blank Graph Activity. For this activity, I gave the students a sketch of the optimizing function on a pair of unlabeled coordinate axes. I asked the students to label the axes and any other important information they knew about the graph. The goal here was to see if they understood what the optimizing function represented. In the first protocol, I asked this question after the students had completed the second optimization problem, so the graph corresponded to the optimizing function for that problem. I found that because the students were mentally exhausted by that point in the interview and they could tell the interview was almost over, they were not as willing to give as detailed explanations as they had been earlier in the interview. I also found that some of the students figured out some things about the graphical representation as they were answering questions in Part III and so I hypothesized that perhaps their answers were somewhat influenced by their earlier responses. Therefore, in the second protocol, I presented the students with the Blank Graph Activity after the first optimization problem. The responses were not as different as I had anticipated, so I feel comfortable discussing the results from both versions of the protocol.

The questions in Part III were the direct result of my literature review. There is a significant body of research suggesting that students incorrectly believe that area and perimeter are directly related (Kospentaris, Spyrou, \& Lappas, 2011; Tirosh \& Stavy, 1999; Tsamir, 2003; Woodward \& Byrd, 1983) and that students have a lot of difficulty with the concept of function (Breidenbach, Dubinsky, Hawks, \& Nichols, 1992; Carlson, 1998; Carlson, Oehrtman, \& Engelke, 2010; Dubinsky \& Harel, 1992; Dubinsky \& Wilson, 2013; Eisenberg, 1992; Hitt, 1998; Leinhardt, Zaslavsky, \& Stein, 1990; Monk, 1992; Vinner \& Dreyfus, 1989). I wanted to 
gain some insight into the students' understanding of these two concepts and compare that with their responses to the optimization problems.

In this portion of the interview, I asked the students if changing the area of a rectangle changes the perimeter and if changing the perimeter of a rectangle changes the area. I also asked the students how many rectangles they could draw with a specific area or perimeter. In the first protocol, I also used this as an opportunity to ask the students to give me a definition for the term "function." I asked this question in the second protocol too, but in the second protocol, I asked them to define the term "function" before they started solving optimization problems. I changed the order thinking it went nicely with the warm-up questions I chose for that protocol and I did not think their answers would be significantly different no matter where the question was placed in the protocol.

In both cases, I selected a more complicated problem for Part IV, specifically choosing a problem with a three dimensional aspect. I designed this part so that the student would not have to do many algebraic manipulations, but could instead focus on the key parts of the optimization process, thinking that I would obtain more information about their underlying thought processes.

\section{Participants}

For the main study, I conducted semi-structured interviews with seven students who were enrolled in a first semester calculus course. I conducted interviews with four students during the Summer 2014 semester and with three students during the Fall 2014 semester. At the time of the interviews, all seven of the students had recently completed the section on optimization, had taken an exam that included optimization problems, and were preparing for their final exam for the course. 
Students volunteered for the Summer 2014 interviews using a sign-up sheet that was passed around the only calculus class taking place at the time (I was not the instructor). I selected four students from the nine volunteers based on scheduling convenience. For the Fall 2014 interviews, a sign-up sheet was passed around several calculus classes (I was not teaching any of these classes), and I selected four students from the eight volunteers based on scheduling convenience. Unfortunately, the video cameras were also being used for another project at the time and the video data for one of these interviews was inadvertently not downloaded from the camera before it was used again. The data was deleted and replaced with other video data, leaving with me three interviews for the Fall 2014 iteration. The interviews took place at the end of the semester, so there was no time to solicit another volunteer to replace the one that was lost. A summary of the students is given in the table below.

Table 2. Summary of Participants

\begin{tabular}{|l|l|l|}
\hline Semester & Names & Majors Represented \\
\hline Summer 2014 & Franz, Sam, Tracy, Lars & Engineering (3), Psychology (1) \\
\hline Fall 2014 & Ashod, Brandi, Cy & Engineering (2), Biology (1) \\
\hline
\end{tabular}

The students were not asked to report on their grades in the class or grades in previous math classes. However, each student was asked to describe his or her "math background" and strengths or weaknesses in mathematics. I will briefly summarize their responses here. The students' full responses can be found in Appendix D.

Summary of Participants' Math Background. Before college, Franz took a survey math class that included some calculus. In college, he took a semester of trigonometry and then enrolled in calculus. When asked how he felt about math, he replied, "If I practice, I can do well. Math is like, if you practice, it's better." He concluded by saying that math is his favorite subject. 
Sam took an honors calculus class in high school, but didn't receive college credit for it. He enrolled in Calculus I upon entering college, dropped the class, enrolled again the next semester, dropped the class again, and was currently enrolled in the class for the third time. He explained, "I got to college and I kind of goofed around my first time, so I may have taken this class once or twice, but this is as far as I've made it so far." When asked how he felt about math he said, "Yeah. I understand things well. I feel like I can grasp concepts, and then from that it's a lot of plug and chug, and you just understand why and how it works kinda."

Tracy took a two semester pre-calculus/calculus class in high school that did not count for college credit. She took a trigonometry class her first semester in college and took Calculus I the next semester, earning a D. She was currently enrolled in the class for the second time and reported having a $95 \%$ in the class. When asked about her strengths or weaknesses in mathematics, she said, 'I'm really bad with anything that involves like, the problems where you have to like look at the problem and know what you're supposed to do and draw a picture and come up with a formula on your own. I'm really bad with those."

Lars had not had calculus in high school and took a trigonometry class his first semester of college. The next semester he enrolled in Calculus I and did not pass. At the time of the interview, he was retaking the course and reported, "It's been a lot more solid this semester." When asked about his strengths and weaknesses in mathematics, he said, "Kind of extrapolating from the information it gives you the equations that you need to use to actually get related to each other. Cause that part's, I'm okay at that, but figuring out the information that I have to work with has been the difficult part."

Ashod also did not take calculus in high school. Upon entering college, he took college algebra the first semester, trigonometry the next semester and then calculus the third semester 
(the semester during which the interview took place). When asked how it was going, he said it was going well, and he anticipated getting a B in the course. When asked about his strengths or weaknesses, he said, "I don't really like optimization that much," and "I just never liked word problems in general, and, um, what I'm good at is like differentiation, derivatives, stuff like that. Concavity. Stuff like that."

Brandi took AP calculus in high school and passed the AP exam. She reported that her scores did not reach the university in time, so she was retaking calculus at the time of the interview. She said the class was going well and that it was fun. She concluded by saying, "I love math."

Cy took AP Calculus AB in high school, and was taking Calculus I at the time of the interview. When asked how it was going, he said, "It's pretty easy. It's like not even a problem really." When asked if he has any strengths or weaknesses, he said, "you know the standard, oh, sometimes I make stupid mistakes sort of thing, but I wouldn't say anything stands out, like, nothing comes to mind really."

\section{Data Analysis}

Initial passes through the data revealed that the students' responses to Part IV of the interview protocol corresponded to their responses to Parts I, II, and III in one of two ways: 1) During Part IV, the students answered questions by repeating their responses from the earlier parts or the students otherwise indicated that they were thinking about this problem the same way they thought about the first problem, or 2) During Part IV, the students indicated a difference in thinking about the problem based on what they learned by solving the problem in Part I and then answering questions during Parts II and III. 
No new data was obtained in Part IV from students falling into the first case and the data obtained in Part IV from students in the second case fell more in line with the results of a teaching experiment, which was not the goal of my study. In both cases, the data obtained from Part IV was not necessary or useful for answering my research questions. It could be useful for future studies related to students' affect and monitoring while solving algebraically complex optimization problems, or for analyzing students' construction of equations for volume and surface area of three dimensional objects, but was not relevant for the purposes of this dissertation. Thus, the focus of my dissertation is on data obtained from Parts I, II, and III, with the exception that I analyzed all students' responses to the Blank Graph Activity, which took place during Part IV in the second protocol.

After transcribing the interviews, I used open and axial coding as defined by Strauss and Corbin (1998) to analyze the data. To do the open coding, I followed the instructions of Strauss and Corbin (1998) and divided the data into smaller chunks, studied each piece, drew conclusions, and used these conclusions to develop categories for the data.

Strauss and Corbin (1998) suggest beginning with an in-depth analysis based on notes and observations for each of the large chunks of data and developing appropriate names and labels based on this analysis. Using my pilot study data, the results of my literature search, and my own experiences teaching and solving optimization problems, I created a loose framework for optimization problems based on Infante's (2007) Hypothesized Optimization Framework, which was informed by her related rates framework. Infante's Hypothesized Optimization Framework has six phases - draw a diagram, construct a functional relationship, differentiate the functional relationship, determine the extreme values of the function, answer the question, and check the answer for reasonability. Each phase also includes the associated solution artifact(s), 
mental model(s), and content knowledge and related heuristics. My modification of Infante's framework is shown below. For this dissertation, I am not examining or describing students' mental models, so I left this out of my framework. The solution artifacts correspond to the following optimization problem: A box is to be constructed using SAin ${ }^{2}$ of cardboard. The box will have four sides, a top, and a bottom. Find dimensions that will maximize the volume of the box.

Table 3. Initial Optimization Framework

\begin{tabular}{|c|c|c|}
\hline Phase & $\begin{array}{l}\text { Solution Artifact(s) } \\
\text { example from a selected } \\
\text { optimization problem }\end{array}$ & $\begin{array}{l}\text { Content Knowledge and } \\
\text { Related Heuristics }\end{array}$ \\
\hline Draw a diagram & Labeled diagram & Geometry \\
\hline \multirow{2}{*}{$\begin{array}{l}\text { Orient oneself in the problem } \\
\text { (gather necessary } \\
\text { equations/relationships) }\end{array}$} & $V=x^{2} y$ & \multirow{2}{*}{ Geometry } \\
\hline & $S A=2 x^{2}+4 x y$ & \\
\hline \multirow{2}{*}{$\begin{array}{l}\text { Construct an optimizing } \\
\text { function }\end{array}$} & $V(x)=\frac{x^{2}\left(S A-2 x^{2}\right)}{4 x}$ & \multirow{2}{*}{$\begin{array}{l}\text { Function, Composition, } \\
\text { Equality, Variable }\end{array}$} \\
\hline & $V(x)=\frac{S A}{4}-\frac{x^{3}}{2}$ & \\
\hline $\begin{array}{l}\text { Differentiate the functional } \\
\text { relationship }\end{array}$ & $V^{\prime}(x)=\frac{S A \cdot x}{4}-\frac{3 x^{2}}{2}$ & Derivative rules \\
\hline \multirow{2}{*}{$\begin{array}{l}\text { Determine the extreme values } \\
\text { of the function }\end{array}$} & Set $V^{\prime}(x)=0$ & \multirow[b]{2}{*}{ Critical numbers } \\
\hline & Critical numbers: $x= \pm \sqrt{\frac{S A}{6}}$ & \\
\hline \multirow{3}{*}{ Verify solution } & $\begin{array}{l}\text { Indicate that } x=-\sqrt{\frac{S A}{6}} \text { is not } \\
\text { a practical solution. }\end{array}$ & \multirow{3}{*}{$\begin{array}{l}\text { First or second derivative test, } \\
\text { Function }\end{array}$} \\
\hline & $\begin{array}{l}\text { Use first or second derivative } \\
\text { test or check endpoints to } \\
\text { determine where the } \\
\text { minimum occurs. }\end{array}$ & \\
\hline & $\begin{array}{l}\text { Identify that the minimum } \\
\text { occurs at } x=\sqrt{\frac{S A}{6}}\end{array}$ & \\
\hline $\begin{array}{l}\text { Answer the question posed in } \\
\text { the problem }\end{array}$ & $\begin{array}{l}\text { Use } x=\sqrt{\frac{S A}{6}} \text { and original } \\
\text { equations to calculate the } \\
\text { height of the box. }\end{array}$ & Function \\
\hline
\end{tabular}


I developed this framework to help with the initial coding of the data. This framework gave me two areas of focus, and two ways to divide the data into large chunks. The first approach was to identify mathematical concepts relevant to the optimization problem-solving process and to code the data according to these concepts: looking for trends, ways in which these concepts influenced the students' problem-solving activities, and looking for other mathematical concepts that were not already accounted for by these initial codes. The initial codes I used were: Geometry, Function, Variable, Equality, Derivative.

The second approach was to divide the data into chunks based on the initial phases of the framework, and analyze each of these chunks individually. The initial codes I used for this approach were: Diagram, Orient, Construct, Differentiate, Max/Min, Verify, and Answer. After passing through the data using both sets of codes, I observed that the initial codes for the phases of the framework were not reflecting what I was observing in the data. I attempted to correct this by refining and changing the initial codes. After doing this several times, I noticed that my new codes aligned closely with Carlson and Bloom's (2005) Multidimensional Problem-Solving Framework, and so I re-coded the data using the phases of this framework: Orienting, Planning, Executing, and Checking.

Paper 1 was designed to answer the first research question, and so I focused on the mathematical concepts that influenced students' problem-solving activities as they worked through Carlson and Bloom's problem-solving framework. Analyzing the data through the lens of the mathematical concepts at play revealed that the initial codes did not capture what was occurring in the data. For example, I found that "equality," which was to be used when the student said or did something that identified two quantities as equal (for example, plugging $y=$ 
$\frac{200}{x}$ into the expression $P=2 x+y$ ), was too broad, and the excerpts that were being coded with "equality" were not as similar as they should have been. Instead, I found that splitting this code into categories, based on the instances that appeared after the initial coding, worked much better. The new codes corresponded to the underlying mathematical concepts that were related to the students' action of setting two quantities equal. These new codes were: variables, key words, function notation, and function composition. The last two codes, function notation and function composition, also captured what had previously been identified using the initial code of "function," so I was able to eliminate that code. After several iterations of passing through the data, refining the codes, and passing through the data with new codes, I ended with the following codes for the first paper: Variables, Key Words, Function Notation, Function Composition, Rectangles, and Role of the Optimizing Function.

Additionally, I created a document for the Rectangle Problem and isolated students' responses from that problem. For each student, I labeled their responses by indicating whether the students believed increasing the area meant increasing the perimeter, increasing the perimeter meant increasing the area, and highlighting any explanations by the students that were specifically about those two ideas.

I used a priori coding for the second paper based on an Optimization Problem-Solving Framework I developed based on Carlson and Bloom's (2005) Multidimensional ProblemSolving Framework. The Optimization Problem-Solving Framework had the same four phases as Carlson and Bloom's framework did (orienting, planning, executing, checking) and then included categories for conceptual and analytical thought processes for each of these four phases. I began by isolating the portions of the transcript pertaining to each phase of the framework and 
then coded the data in accordance with the thought processes that I identified for each phase of the framework. This data analysis is described in detail in Paper 2.

Analysis for the third and final paper was conducted in a manner similar to that of Paper 1, focusing on students' responses when asked to compare the graphical representation of the optimizing function to their algebraic work. Some of this analysis had already been completed on a broad scale, but I was able to refine my categories and dig deeper into the data this time since I was focusing only on this small portion of the interviews. More categories emerged when passing through the data again, and I was able to conduct a more targeted analysis, focusing individually on students' responses when placing the critical value on the graph, when labeling the axes, when discussing what ordered pairs on the function represented, and when describing how the graphical representation of the optimizing function related to the overall optimization problem-solving process. Each of these had a specific code, and I was able to further code the students' responses according to their responses in each of these categories. For example, for placing the critical value on the graph I coded the students' responses in terms of whether they placed the critical value in the correct location, incorrect location, or were unsure. For those who placed the critical value in the incorrect location, I then created labels corresponding to the reasons they gave for the incorrect placement of the critical value. In doing this, I was able to see that all three students who placed their critical value incorrectly on the axis were using similar reasoning.

In each case, I terminated my data analysis when I observed that further passes through the data were not revealing new codes and that the codes I was using to analyze the data from the first set of interviews were still useful and sufficient for analyzing the data from the second set of interviews. The emergent themes from the first and second interviews corresponded to the 
emergent themes from the pilot study data, further confirming that I was not going to obtain significant new insights by collecting more data from the same university. In the future study section, I will mention ways the research could be extended on a larger scale. 


\title{
PAPER 1: OPTIMIZATION IN FIRST SEMESTER CALCULUS: A LOOK AT A CLASSIC PROBLEM
}

This paper was published in 2015 in the International Journal of Mathematical Education in Science and Technology, Volume 46, Issue 7. See references for the full citation.

\begin{abstract}
Optimization problems in first semester calculus have historically been a challenge for students. Focusing on the classic optimization problem of finding the minimum amount of fencing required to enclose a fixed area, we examine students' activity through the lens of Tall and Vinner's (Tall \& Vinner, 1981) concept image and Carlson and Bloom's (Carlson \& Bloom, 2005) Multidimensional Problem Solving Framework. We are particularly interested in students' evoked concept images for the mathematical concepts that play a role in the construction of the function whose minimum is needed. Data analysis revealed several gaps in student understanding of the optimization process. We highlight the mathematical concepts that play a role in these gaps, focusing on variables, function notation, function composition, properties of rectangles and the relationships between them, the role of the optimizing function, and the graphical representation of the function.
\end{abstract}

Keywords: calculus, optimization, concept image

Subject classification codes: 97

\section{Introduction and Review of Literature}

In this paper, we examine student responses while solving the classic optimization problem of determining the minimum amount of fencing needed to enclose a garden with a fixed area. We particularly focus on student activity as they are in the process of constructing the function whose minimum is to be found, referring to this function as the optimizing function. We 
concentrate on the following two questions: 1) What facets of learners' concept images influence their construction of the optimizing function when solving calculus optimization problems? and 2) How can this shed light on teaching interventions that could support conceptual development of optimization?

There is little existing research focused on students' understanding of optimization problems in first semester calculus, but as part of a larger study, White and Mitchelmore (1996) presented students with one of four versions of a standard optimization problem. Most students correctly answered the version that provided them with the optimizing function, while there were significantly fewer correct answers to the version that gave students a short paragraph describing the situation, leaving it up to them to construct the necessary function. They attribute this to students' weak concept images of variables, arguing, “defining and using new variables involves forming relationships at a higher level of abstraction than relating those already given" (White \& Mitchelmore, 1996, p. 91). The idea that a weak concept image of variable often plays a role in students' difficulties with calculus is supported by other research as well (Clement, Lochhead, \& Monk, 1981; Gray, Loud, \& Sokolowski, 2007; Kaput, 1987; Malisani \& Spagnolo, 2009).

There is a large body of literature devoted to student understanding of functions (Breidenbach, Dubinsky, Hawks, \& Nichols, 1992; Dubinsky \& Harel, 1992; Sfard, 1992; Vinner \& Dreyfus, 1989). Two aspects of the function concept are particularly useful when solving optimization problems: composition and graphical representations. Engelke, Oehrtman, and Carlson (2005) reported that most students were able to correctly answer questions about function composition that involved algebraic formulas, but less than half were able to answer questions about function composition involving graphical representations. Eisenberg (1992) and 
Even (1998) found students are often reluctant to consider the graphical representation of a function, and when they do, they frequently have trouble interpreting the information correctly.

An important part of understanding optimization problems in calculus is the notion that a system can be fixed in terms of one property but vary in terms of another property. Kospentaris, Spyrou, and Lappas (2011) found many students believe the longer the sides of a figure, the greater the area or the larger the perimeter, the bigger the area (2011, p. 123). Tirosh and Stavy (1999) describe this with their intuitive rule, "More of A - more of B," meaning that when students are presented with two objects with property $A$ such that $A_{1}$ is less than $A_{2}$, they frequently assume that for any other property $B, B_{1}$ is less than $B_{2}$ as well (p. 52).

Research has thus examined students' understanding of variable, function, derivative, and other related mathematical concepts, but we now add to the discussion by looking at how the students' related concept images interact with one another and influence the students' ability to develop their concept images for the optimizing function, thus contributing to their overall understanding of optimization.

\section{Theoretical Perspective}

We are studying the facets of learners' concept images that influence their problem solving approaches when solving optimization problems using Carlson and Bloom's (2005) Multidimensional Problem Solving Framework and Tall and Vinner's (1981) concept image.

Carlson and Bloom's (2005) problem solving framework allows us to describe students' activity as they solve optimization problems. The framework is divided into four main phases: orienting, planning, executing, and checking. In the orienting phase, the student deciphers the problem and assembles the tools he or she thinks may be required. In the planning phase, the student uses conceptual knowledge to determine an appropriate course of action, which is then 
implemented during the executing phase. Finally, during the checking phase, the problem solver goes back to the original problem to see if the answer makes sense. Tall and Vinner define a learner's concept image as "all the cognitive structure in the individual's mind that is associated with the given concept" (1981, p. 1). Because it exists in the mind of an individual, and we know that individuals do not always have correct understandings of mathematical concepts, this cognitive structure may be incomplete, incorrect, or logically inconsistent. When a need arises, the parts of the concept image that are directly related to the need are called upon, but the rest of the concept image remains dormant, ready to be accessed if needed, but not until then. This allows students to maintain conflicting information in their concept images without realizing it. Unless the two logically inconsistent parts of the concept image are evoked simultaneously, the individual may never realize something is wrong. However, when the two conflicting parts of the concept image are evoked at the same time, the individual experiences confusion known as cognitive conflict, which sometimes stimulates the student to resolve the conflict, often developing a better understanding, and other times leaves the student feeling uneasy and frustrated but ultimately unable to address the conflict.

In this paper, we focus on the concept images that are evoked while the students are constructing their optimizing function and how these concept images influence the students' understanding of the optimization process. Students often have conflicting concept images for functions, variables, and geometric properties. Some students are able to reason their way through an optimization problem without these conflicting concept images being evoked simultaneously, but when pressed, we can see that these conflicting concept images often prevent students from fully understanding what they are doing when they solve an optimization problem. 


\section{Methods}

Data was collected through a series of semi-structured interviews with first and second semester calculus students at a large state university in the United States. Interviews were conducted during the spring, summer, and fall semesters of 2014. The students volunteered to participate in the study, and self-reported average to strong mathematical backgrounds. During the Spring 2014 semester, we conducted a small pilot study with three second semester calculus students. These students' activity while trying to figure out how to solve the optimization problems gave us insight into key ideas that help students make sense of the optimization process and key ideas that are sometimes missing from their reasoning. This informed the structure of the two subsequent studies, which are the focus of this paper. A brief summary of the seven first semester calculus students from these two subsequent studies is given in Table 4.

Table 4. Summary of Participants

\begin{tabular}{|c|c|c|}
\hline Semester & Names & Majors Represented \\
\hline Summer 2014 & Franz, Sam, Tracy, Lars & Engineering (3), Psychology (1) \\
\hline Fall 2014 & Ashod, Brandi, Cy & Engineering (2), Biology (1) \\
\hline
\end{tabular}

In both of these subsequent studies, we asked students to solve two optimization problems (one problem was the same for both studies and the other was different) and to answer questions related to prerequisite material we observed playing a role in students' responses during the pilot study. In particular, each student was asked to solve what we refer to as the garden problem: A rectangular garden of area $200 \mathrm{ft}^{2}$ is to be fenced off against rabbits. Find the dimensions that will require the least amount of fencing if a barn already protects one side of the garden. This problem was chosen as it is representative of one of the first types of optimization problems presented in both the classroom and the textbook. The algebra is not 
overly complex, which allows the student to focus on the bigger ideas involved in optimization. The reasoning demonstrated by the students on this problem was representative of their reasoning about the other optimization problem.

If it did not arise naturally in the students' responses, we asked whether the area of a rectangle is related to its perimeter. Specifically, we probed their understanding by asking if changing the area of a rectangle would change the perimeter and if changing the perimeter of a rectangle would change the area. We refer to this line of inquiry as the rectangle problem.

We asked the students to think aloud as much as possible as they solved the problems and asked follow-up questions to elicit more information about their thought processes. The interviews were video recorded and then transcribed for analysis. Based on emergent themes observed in the pilot study, we conducted a targeted coding to further examine these specific themes.

\section{Results}

Here we present the results of students' interview responses to: 1) the garden problem; 2) the rectangle problem; and 3) the graphical representation of the optimizing function. Our data aligns with the results of White and Mitchelmore (1996). Our students had little trouble solving the problem once they had constructed an optimizing function, but had difficulty constructing the function and/or explaining the role of the function they had constructed. Data analysis revealed several mathematical concepts that played a role in how students understand and construct the optimizing function. Below we identify these concepts and describe how they influenced the students' concept images of the optimizing function. Table 5 summarizes these results. 
Table 5. Summary of Results

\begin{tabular}{|l|c|c|c|c|c|c|c|}
\hline Common Misconceptions & Franz & Sam & Tracy & Lars & Ashod & Brandi & Cy \\
\hline Variables & $\mathrm{X}$ & & $\mathrm{X}$ & & $\mathrm{X}$ & & \\
\hline Function Notation & $\mathrm{X}$ & $\mathrm{X}$ & & $\mathrm{X}$ & & & \\
\hline Function Composition & & $\mathrm{X}$ & & & & & \\
\hline Key Words & $\mathrm{X}$ & $\mathrm{X}$ & $\mathrm{X}$ & $\mathrm{X}$ & $\mathrm{X}$ & $\mathrm{X}$ & $\mathrm{X}$ \\
\hline $\begin{array}{l}\text { Relationship Between Area \& } \\
\text { Perimeter }\end{array}$ & $\mathrm{X}$ & & $\mathrm{X}$ & & $\mathrm{X}$ & & $\mathrm{X}$ \\
\hline $\begin{array}{l}\text { Role of the Optimizing } \\
\text { Function }\end{array}$ & $\mathrm{X}$ & & & & $\mathrm{X}$ & $\mathrm{X}$ & \\
\hline $\begin{array}{l}\text { Graphical Representation of the } \\
\text { Function }\end{array}$ & & & & $\mathrm{X}$ & $\mathrm{X}$ & \\
\hline
\end{tabular}

\section{Variables}

In order to construct an optimizing function, the student must first define variables to represent the quantities involved in the problem and then set up an equation relating the quantity we would like to maximize or minimize to the other variables. This equation may need to be altered to make it into a single variable function, requiring the student to do some substitution. All of this requires the student to be comfortable working with functions and variables.

Franz, Ashod, and Tracy expressed some concern about the variables they were defining as they were in the orienting phase of the problem solving framework. Because the garden problem states a barn is to border one side of the garden, these three students were unsure whether the amount of fencing should be represented by $2 x+y$ or $2 y+x$ (or something similar with other variables), not recognizing that $x$ and $y$ have been chosen arbitrarily. Franz said, "it says barn already protects one side of the garden, but we don't know which side though, $x$ or $y$. Now I'm confused about that." When asked if it would make a difference if the barn was opposite $x$ instead of $y$, and his response was, "I have no idea." Here we see Franz is unclear about the use of the variables $x$ and $y$. He does not show signs of understanding that $x$ and $y$ are arbitrary 
variables, and it does not matter whether the barn is opposite the side labeled $x$ or the side labeled $y$. The arbitrary nature of variables appears to be a problem for him.

Ashod wrote $P=2 l+2 w$ and then realized he had used $x$ and $y$ when drawing his picture. He struggled for a few seconds before deciding to write $P=2 y+2 x$ because he believed the length had to be $y$ and the width had to be $x$, based on his picture. He failed to recognize the choice of $x$ and $y$ is insignificant. Tracy also demonstrated the same confusion. Talking about the barn protecting one side of the garden, she said, "So is it going to be a length or a width side?" These three students demonstrated a weak concept image of variables, but this did not prevent them from solving the problem. They all chose to ignore the cognitive dissonance and move on. Tracy demonstrated another difficulty with variables. She wrote "minimize materials $=2 y+x$ " but did not know what to do with this expression because it did not look like an equation to her. She was unable to continue working at this point, so the researcher intervened. When the researcher suggested she use " $M$ " in place of "minimize materials," she said, "Even then, I don't think that'd help me. That's just adding another variable." Her weak concept image of variables was enough of a barrier to keep her from continuing.

\section{Function Notation}

Carlson (1998) indicated students often have issues with the $f(x)$ notation, and our data indicates this is an important part of constructing the optimizing function. During the planning phase, Lars, Franz, and Sam wrote expressions for the amount of fencing, wrote an equal sign after the expression, and then did not know what to write on the other side. Lars wrote " $2 x+y=$ " and then wrote " $2 x+200 / x$ " on the line below. At this point, he hesitated and said it "wasn't a function like that" and was unable to move on to the executing phase. After a lot of discussion, the researcher suggested using the letter $P$ for function notation, meaning Lars should write $P$ 
$=2 x+200 / x$ or $P(x)=2 x+200 / x$. Lars responded by writing " $f(P)=2 x+200 / x$." Similarly, Franz

wrote " $2 x+y=$ " and said, "I don't know what's it equal to now." When he was asked about using $f(x)$, he said that would not work because, "We know that $f(x)$ is $y$, that's a very common thing, you know?"

Sam had the expression " $P=2 l+400 / l$," but when he attempted to write the same thing using more standard function notation, he wrote $P(f t)$ and then explained that it was like $P(x)$, except he would use $f t$ instead of $x$. Lars, Franz, and Sam all used incorrect function notation, but only Lars needed intervention at this point. Franz and Sam ignored their difficulties and proceeded without deciding what to write on the other side of the equal sign.

\section{Function Composition}

Constructing the optimizing function often requires the student to use function composition to get a single variable function. In the garden problem, the students began with a two variable function, $P(x, y)=2 x+y$, and a single variable function, $x(y)=200 / y$. The students needed to compute $P(x(y), y)=2(200 / y)+y$ to get a single variable function. This step converts the first expression from a multivariable function to a single variable function specific to the problem. Engelke et al. (2005) reported students are good at these kinds of computations when they have algebraic formulas; our data is consistent with this finding.

Six students of the seven students did not express any confusion about this step. They did not mention anything about function composition, nor would we necessarily expect them to do so, but they said things like, "since they are both pertaining to the same rectangle, I could solve for one here and plug that variable into this equation.” However, one student, Sam, spent several minutes talking about this step. Referring to the transition from $P=2 l+2 w$ to $P=2 l+2 *(200 / l)$, he said, "I know how to manipulate it, but I don't know why or what gives me the right to do that 
and have them know that it'll equal." He argued repeatedly that both statements are valid, but when he eventually (after a lot of prompting) wrote $P(l)=2 l+2 *(200 / l)$, he was convinced that this no longer represented the perimeter of the garden, but instead was some function he could use to calculate a value for $l$. Thinking the function did not represent the amount of fencing caused him to be confused about how "taking the derivative and finding a minimal number for the function... how that means that it's going to be a minimal value of how much fence you need." Additionally, he continually said plugging in 2 for $l$ would give the length of one of the sides of the garden, even though he was sure the original expression represented the perimeter of the garden.

Although Sam was the only student to express this confusion, we mention it because we hypothesize other students may have similar confusions about the connection between the original equation and the newly created optimizing function, even though none of the other students brought it up. We suggest further research examine this.

\section{Properties of Rectangles and the Relationships Between Them}

Key words. The garden problem states a garden is to be constructed alongside a barn, meaning the garden only needs fencing on three sides. All of the students except Sam drew a picture of a garden and labeled the sides, most of them using $x$ and $y$ as their variables, and eventually set up an expression to represent the amount of fencing needed for the garden. Ashod, Brandi, and Sam neglected to factor the barn into their function construction.

Ashod: And um, the area is 200 equals $x$ times $y$, but they want to know the dimensions that require the least amount of fencing if it protects one side of the garden, so we have to use the perimeter formula as well. Two $l$ plus two $w$ and... 
Here, Ashod reads the phrase, "least amount of fencing if a barn already protects one side of the garden" and the only information he extracted from this phrase is that he needs the perimeter formula.

Brandi: All right, you know you have a rectangular garden. So you already have a rectangle. And this is at an area equal to 200 feet squared. So since it's a rectangle, this is gonna be $x$ and that's going to be the same as $x$. So I'm just going to leave that. But this is $y$ and this is also the same as $y$, lengthwise.

She focused on the word "rectangle" and used that to determine how to label her picture. While in the orienting phase, she relied on the picture to construct her perimeter equation, causing her to not factor the barn into her equation representing the amount of fencing. Similarly, Sam saw the words "amount of fence" and immediately assumed he needed to use the standard perimeter formula.

Key words played a very important role in these students' function construction. During the orienting phase of the problem solving framework, they read the problem quickly and immediately drew and labeled a picture. They had such strong evoked concept images associated with key words in the problem that they neglected to think about the rest of the problem. While not necessarily a negative trait, they clearly played too dominant of a role.

Relationship between area and perimeter. In the garden problem, the goal is to minimize the amount of fencing needed to enclose an area of $200 \mathrm{ft}^{2}$. In this scenario, the area is fixed, but the amount of fencing remains undetermined. Thus, the optimizing function represents the amount of fencing needed for a garden with area $200 \mathrm{ft}^{2}$, given the length of one of the sides. For each side length, there is a corresponding amount of fencing. This function's existence is a 
direct result of having a fixed area, because without some sort of constraint, we would not be able to construct a single variable function.

Pilot study data and existing literature suggested students often believe area and perimeter of rectangles are directly related in such a way that changing one forces the other to change as well (Kospentaris et al., 2011; Tirosh \& Stavy, 1999). Our data showed this to be true. Immediately after finishing the garden problem, the students were asked how area and perimeter are related and what would happen if one changed. They all believed if the area is changed, the perimeter must change too. Only three students, Franz, Ashod, and Brandi, said if the perimeter is changed, the area must change too. Tracy declined to give a definitive answer, and Sam, Cy, and Lars all said the perimeter could change without changing the area.

Sam was the only student who expressed any doubt about the perimeter changing when the area is changed. Interestingly, he was confused about what happens when the area changes, but was completely convinced the perimeter could be changed without changing the area. The structure of the area and perimeter equations are different, and he explained it is easier to think of two different pairs of numbers that multiply to equal the same area than it is to think of two different pairs of numbers that can be doubled and summed to get the same perimeter.

Cy and Lars also believed the perimeter could change without changing the area. We do not know what caused them to believe the relationship only happens in one direction, but we suggest it may be related to Sam's comment about the two formulas, or maybe the students have concept images associated with area and perimeter that lead them to focus on different aspects of the two properties. This is a topic for future research.

All of the students' concept images for rectangles included incorrect ideas about the relationship between area and perimeter. This portion of the interview occurred immediately 
after the students finished the garden problem, signifying a discrepancy between the students' evoked concept images for rectangles while solving the optimization problem and the students' entire concept images for rectangles. Most of the students had incorrect beliefs about the connection between area and perimeter, yet this did not come up at all while they were solving the garden problem. We suggest this discrepancy is indicative of a larger problem: the students are consistently in the habit of constructing optimizing functions without pausing to figure out what the function actually represents. If they had thought about and understood what the optimizing function represented, they would have had to think about the idea of having one property fixed while the other varied. Their responses show this had not happened.

Without being prompted, two students, Cy and Lars, finished their explanations about the perimeter changing while the area remained fixed by concluding that there was a connection to the optimization problem they had just completed.

$C y$ : Since there's oh here we go, here we go, there's two terms in the perimeter, and since you can adjust both and make them balance each other out and offset the change in each other, you can keep the area constant and that's why the garden thing happened the way it happened. I guess. Also. That's cool.

Sam, Ashod, and Brandi also made this connection, but only after they were prompted to think about it. Each of these five students concluded the interview with much better explanations about what the optimizing function represented than they did earlier in the interviews. For this reason, we suggest it is especially important to engage the students in activities allowing them to explore the interaction between the properties involved in an optimization problem. In our case, we asked students to sketch several rectangles with the same area and then asked them to calculate the perimeters. Then, we asked them to sketch several rectangles with the same perimeter and 
calculate the areas. This was very helpful for our students, and we believe it would be helpful for other students as well.

\section{Role of the Optimizing Function}

Differentiating the optimizing function is an important step, and is what distinguishes these types of optimization problems from the ones occurring in algebra courses. There are several key ideas related to differentiation that we would like students to have in their concept images for the optimizing function. Namely that we are differentiating the function representing the quantity we want to optimize, because the derivative represents the instantaneous rate of change of the function, and points in the domain where the derivative is zero (i.e. critical numbers) represent places where the function may switch from increasing to decreasing or vice versa, indicating a local maximum or local minimum may occur.

All seven students knew they needed to take the derivative of something, and all but Franz immediately knew to set the derivative equal to zero and solve the resulting equation. Four students had evoked concept images for the optimizing function that were very weak regarding differentiation. Franz and Tracy did not know why they were differentiating at all, and Ashod and $\mathrm{Cy}$ were unclear about why the function they were differentiating needed to represent the amount of fencing (the quantity we are trying to optimize).

Franz and Tracy did not know why they were differentiating. Franz said, "It's just a standard thing that we do," and Tracy said, "I honestly don't remember why that works, I just know that it does." She began by trying to find a way to differentiate the area equation, even though that was not the quantity to be maximized or minimized.

Ashod and Cy were very focused on the key word, "dimensions," in the problem and discussed using the function for amount of fencing only as a means for finding dimensions. For 
these two students, the goal of the problem was to find dimensions, and they believed the function for amount of fencing could help. Ashod said, "Basically what we would do is we solve for either variable to plug it in to find the perimeter of this. That's, to find the perimeter which would give us the dimensions of it," and Cy said, "now perimeter is something we also care about very much in this one because we're, I mean, you know ... you're finding your dimensions which comes from perimeter." He made similar statements at other times during the interview, so the researcher asked, "So that's the only reason you're using perimeter, really? Because the goal is to find dimensions?" His response was, "Yeah that and also I wouldn't know what other formula to use really, in that situation, because area and perimeter seem to be old reliable when it comes to rectangular stuff."

The formulas for area and perimeter of a rectangle were part of Ashod's and Cy's evoked concept image for optimization problems involving rectangles, but they were not attending to the fact that their optimizing function should be representing the quantity they wanted to optimize. Cy even said he might have used another function if he could have thought of one.

\section{The Graphical Representation of the Optimizing Function}

Only Lars mentioned the graph without being prompted, supporting Even's (Even, 1998) observation that students resist transitioning to different representations of functions. Regarding optimization problems, Cy said, "It's weird to, like, make the jump from numbers into a graph sometimes. In some situations, the numbers are really just a stand-in for the work I'm doing in my head with graphs, but in this situation, it's more, the numbers are all I really ever thought about this.”

It is possible to solve optimization problems without considering the graph, so we do not fault the students for avoiding the graphical representation. However, we would like the students 
to be able to correctly interpret and identify key information on the graph of the optimizing function, even if they would not have used it on their own. Figure 1 shows three students marking where they believed the critical number belonged on the graph. The graphs are different because, for the first study, the students were asked this question for a different optimizing function. The idea, however, remained the same.
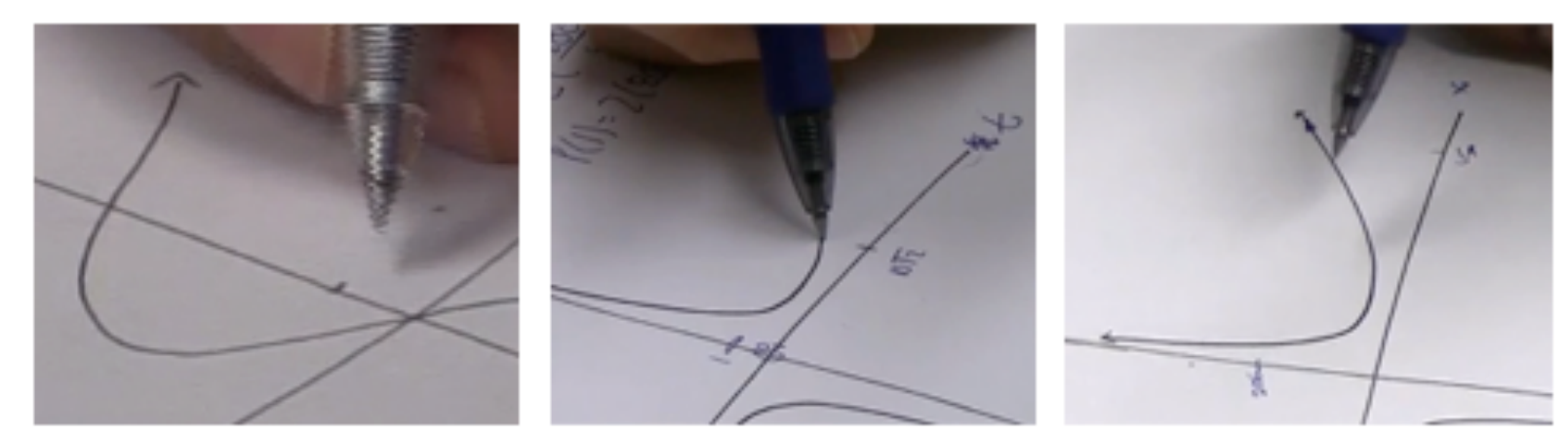

Figure 1. Franz, Brandi, and Ashod mark the location on the graph where they believe the critical number belongs.

When they marked the point in the domain corresponding to the critical point, these three students did not place it below what was clearly the absolute maximum or minimum of the graph. Even though they were able to find an answer, being unable to correctly place it on the graph suggests they either did not know what the answer signified or the significance of the answer did not play a dominant role in their minds as they solved the problem. Thus, when these students were in the planning phase of the problem solving process, they were not planning ahead based on the goal of finding the absolute minimum of the optimizing function; rather, they were just looking for a function to differentiate without thinking about why.

\section{Discussion and Conclusion}

Examining the students' evoked concept images as they constructed the optimizing function illuminated several gaps in student understanding. Even though five students (Franz, 
Sam, Ashod, Brandi, and Cy) were able to solve the optimization problem with minimal errors and without intervention, their verbal explanations made clear they did not have a strong conceptual understanding of the optimization process.

Ideally, we would like first semester calculus students' concept images of the optimizing function to include the following two properties:

(1) The optimizing function is a single variable function representing the quantity we would like to maximize or minimize.

(2) Our goal is to find the maximum or minimum value of this function.

In actuality, the students had fragments of each of these two properties in their concept images for the optimizing function, but weak concept images for other, related mathematical concepts prevented these properties from being fully developed. Above, we highlighted mathematical concepts that play an important role in the development of Properties 1 and 2 in the students' concept images. These mathematical concepts were: variables, function notation, function composition, the properties of rectangles and the relationships between them, the role of the optimizing function, and the graphical representation of the function.

Variables, function notation, and the role of the optimizing function are vital ingredients in the construction of an optimizing function. Several students were not working towards the goal of constructing an optimizing function with Property 1, evidenced by their unwillingness or inability to use function notation appropriately. For many students, the evoked concept images of the role of the derivative when constructing an optimizing function appeared to be limited to the knowledge that the derivative was useful, and that setting the derivative equal to zero would somehow lead to the correct answer, demonstrating that Property 2 was not part of their evoked concept image for the optimizing function. 
The students' evoked concept images for rectangles had a strong influence on their function construction. In some cases, the evoked concept images associated with rectangles led students to neglect other information in the problem because they were too focused on using the standard equations associated with rectangles. The students' concept images for rectangles included the idea that area and perimeter are directly related, contradicting the driving force behind the construction of the optimizing function. The fact that this part of their concept image was not evoked suggests the students were not thinking about the quantity they were trying to maximize or minimize, part of Property 1. Similarly, the responses from students when asked to relate their optimizing function to the graph suggest Property 2 was not evoked as they were solving the problem.

We believe during the checking phase of the problem solving process, when the students are proving that their answer gives the desired maximum or minimum value, their thought processes may bring to light further incorrect evoked concept images. The checking phase has not been the focus of our research thus far and may present an opportunity for future research. Our studies examined the relationship between students' tendency to incorrectly assume Tirosh and Stavy's (1999) "More of A - more of B" rule and their thought processes related to an optimization problem involving the area and perimeter of a rectangle. We hypothesize that since many optimization problems involve allowing one property to change while the other remains fixed, this issue may arise with other optimization problems as well, and we suggest further research examine such relationships.

Most of the students in our study were able to follow correct procedures to solve the optimization problem, but were unable to explain why these procedures worked. Thus, for the purposes of instruction, we recommend exploring ways to elicit the appropriate evoked concept 
images for the optimizing function, particularly focusing on Property 1 and Property 2. Simply asking students to solve an optimization problem may not elicit the thought processes we hope. Additionally, when assessing student understanding, instructors should be intentional about developing questions intended to probe student understanding of the optimization process beyond getting the correct answer.

A good starting place is creating opportunities for students to explore the optimizing function in detail, such as asking them to provide examples of several scenarios that, while not optimal, would meet the requirements of the problem. For example, the students could be asked to sketch several gardens with area $200 \mathrm{ft}^{2}$ and then discuss how these gardens are connected to the optimizing function (each garden corresponds to an ordered pair of the optimizing function). We recommend encouraging students to examine the graph of the optimizing function each time they solve an optimization problem and to consider key aspects of the graph, such as how their defined variables are related to the axes of the graph or how a point on the function corresponds to a scenario of the optimization problem. We believe such questions will help them develop a better understanding of the ways in which the function and its graph is related to their answer. Much work remains to be done with regard to optimization problems. This study focuses on a specific optimization problem. We hypothesize that many of these themes are relevant to other kinds of optimization problems, but further research is needed. 


\title{
PAPER 2: A PROBLEM-SOLVING FRAMEWORK FOR FIRST SEMESTER CALCULUS OPTIMIZATION PROBLEMS
}

\begin{abstract}
In recent years, there has been a push to provide students with opportunities to use mathematics in "real world" situations. Optimization problems in first semester calculus provide students an opportunity to apply the skills they have been learning in calculus to solve interesting, relevant problems. Unfortunately, these problems tend to be very challenging for students, and have thus far been unexplored by the research community. Focusing on the classic optimization problem of minimizing the amount of fencing needed to enclose a garden with a fixed area, we shed light on the thought processes students use while solving these problems. In this paper we present an Optimization Problem-Solving Framework and then use the framework to structure a discussion about seven students' conceptual and analytical thought processes while solving the Garden Problem.
\end{abstract}

Keywords: optimization, calculus, problem-solving

\section{Introduction}

Optimization problems are one of the most practical applications that students encounter in first semester calculus. These problems typically involve a quantity that is to be maximized or minimized while under constraint(s). Solving such a problem involves constructing a function to model the situation (we call this the optimizing function) and using calculus techniques to find the absolute maximum or absolute minimum of the function. These types of problems tend to be very difficult for students, yet they have remained largely unexamined by the research community, as noted by Speer and Kung (2016). 
Solving optimization problems involves two kinds of thought processes: conceptual thought processes and analytical thought processes (Vinner, 1997). Conceptual thought processes occur as students are thinking about the general concepts involved in solving the entire optimization problem, without focusing on a specific step, while analytical thought processes occur as students are working through the specific steps of a problem, thinking carefully about how to carry out each step. With the goal of answering the research questions stated below, we present our Optimization Problem-Solving Framework which focuses on students' conceptual and analytical thought processes as they solve optimization problems, and then use the framework to analyze seven students' problem-solving activities and thought processes while solving the classic Garden Problem: A rectangular garden of area $200 \mathrm{ft}^{2}$ is to be fenced off against rabbits. Find the dimensions that will require the least amount of fencing if a barn already protects one side of the garden.

Our research questions are: 1) While solving the Garden Problem, how do students engage in conceptual and analytical thought processes during each phase of the Optimization Problem-Solving Framework? and 2) During what phases of the Optimization Problem-Solving Framework do we see students engaging in pseudo-conceptual and pseudo-analytical thought processes? What components of the phases present challenges for students? How do we see that influencing their work?

We begin with a literature review and a discussion about the theoretical perspective guiding our study, and then we present the methods used to collect and analyze data.

\section{Literature Review}

Optimization problems involve many complicated mathematical concepts. Without a deep understanding of the mathematical concepts involved in the process, students are more 
likely to struggle to understand the more general concept of optimization. Likewise, without a deep understanding of the general concept of optimization, students often struggle with knowing when and how to use their knowledge of mathematical concepts to solve a new problem.

In LaRue and Infante (2015), which is also Paper 1, we identified six key mathematical concepts that play a role in students' concept image of the optimizing function. These were: variables, function notation, function composition, properties of rectangles and the relationships between them, the role of the optimizing function, and the graphical representation of the function.

White and Mitchelmore (1996) conducted a study in which they examined students' answers while solving max/min problems with varying degrees of complexity. They found that students were much more capable of solving the problem when they were presented with an algebraic representation of a function and asked to the find its absolute maximum(s) or absolute minimum(s) than they were when they were presented with a word problem where a function needed to be constructed first. White and Mitchelmore concluded that this was partially due to students' weak concept images of variables, because the students had to define variables that were not already provided for them.

Because the students must construct a function with these variables, their understanding of functions is crucial to developing robust conceptual and analytical thought processes for solving optimization problems. There is a large body of literature devoted to student understanding of functions (Breidenbach, Dubinsky, Hawks, \& Nichols, 1992; Dubinsky \& Harel, 1992; Sfard, 1992; Vinner \& Dreyfus, 1989). Of particular relevance to optimization problems is the graphical representation of the optimizing function. Eisenberg (1992) and Even (1998) found students are often reluctant to consider the graphical representation of a function, 
and when they do, they frequently have trouble interpreting the information correctly. Function composition is also an important aspect of the function concept, as students are composing functions when they are constructing the optimizing function. Engelke, Oehrtman, and Carlson (2005) reported that most students were able to correctly answer questions about function composition that involved algebraic formulas, but less than half were able to answer questions about function composition involving graphical representations.

\section{Theoretical Framework}

\section{Background}

For our theoretical framework we have applied Carlson and Bloom's (2005) Multidimensional Problem-Solving Framework to optimization problems, taking the view of the student as the problem solver. Our adaptation of Carlson and Bloom's framework was informed by Infante's (2007) related rates framework and Vinner's (1997) language of conceptual and analytical thought processes.

\section{Mathematical Thought Processes}

There are certain thought processes that teachers and experts hope students will use while solving mathematics problems. Vinner (1997) divides these desired thought processes into two categories: conceptual thought processes and analytical thought processes. Conceptual thought processes involve the student thinking about "concepts, their meaning, and their interrelations" (Vinner, 1997, p. 99). Analytical thought processes are related to solving a specific problem and thinking about why certain procedures are appropriate for solving the problem. This is different from conceptual thought because the students are more focused on the procedures they are using than they are on the more general underlying concepts. 
As an alternative to developing the desired conceptual thought processes, students sometimes develop "simpler, easier, and shorter" processes, called pseudo-conceptual thought processes, to stand in place of the desired conceptual thought processes (Vinner, 1997, p. 101). Likewise, students sometimes develop pseudo-analytical thought processes in place of the desired analytical thought processes (Vinner, 1997).

For our purposes, we refer to thought processes that are involved with the general concept of optimization, and are not focused on a specific step, as conceptual thought processes. For example, when constructing the optimizing function, the student may consider why this function is being created. A student who decides to construct a function representing the perimeter of a rectangle for the Garden Problem might do so because he or she recognizes that the goal is to minimize perimeter. In this case, the student is using conceptual thought processes. However, for the same problem, a different student might construct a function representing the perimeter of a rectangle because the area is given in the problem and the other familiar quantity related to rectangles is area. This student is using a pseudo-conceptual thought process.

Likewise, we refer to the thought processes while the students are working through the procedures of solving the problem as analytical thought processes. For example, when a student differentiates the optimizing function and sets it equal to zero, he or she may have one of the following thought processes in his or her head: 1) I need to find points in the domain where the derivative is equal to zero because minimums and maximums can only occur when the derivative is equal to zero or does not exist. 2) I need to differentiate because when we do these problems, we always take the derivative after we have created this function. In the first case, we would say the student's thought process is analytical. In the second case, the student's thought process is 
pseudo-analytical, because he or she is recalling a familiar procedure, but not thinking about why those procedures work.

Vinner (1997) provides room for overlap in his description of conceptual and analytical thought processes. Due to the complexity of mathematics, there are some instances when certain thought processes can be appropriately described as conceptual or analytical, depending on the lens of the analyst. For our purposes, we anticipate students' thought processes while working an optimization problem to move fluidly back and forth between conceptual and analytical (or pseudo-conceptual and pseudo-analytical). Generally, analytical thought processes will aid the student in activities like determining which equations are useful and how to construct a function to represent the quantity to be maximized or minimized, while conceptual thought processes will aid the student in determining why he or she needs to construct such a function and in thinking about why the function needs to represent the quantity to be maximized or minimized instead of something else.

The indication that a student is engaged in pseudo-analytical and pseudo-conceptual thought processes is that the student is not thinking deeply about the underlying mathematics, but rather is relying on heuristics to expedite his or her thought processes. This is not always a problem - sometimes it is important to solve a problem quickly without taking the time to think deeply about the mathematics involved. However, when approaching a new problem or even a similar problem with an added level of difficulty or complexity, it often becomes necessary to return to conceptual and analytical thought processes to solve the problem. For this reason, we would like to see evidence of the students being able to engage in these types of thought processes when prompted. This is our justification for pressing further when interviewing our students. If a student did not indicate that he or she was using conceptual and analytical thought 
processes while initially solving the problem, we asked more questions to see if they were able to engage in these kinds of thought processes when prompted.

\section{Multidimensional Problem-Solving Framework}

Carlson and Bloom's (2005) Multidimensional Problem-Solving Framework is divided into four phases: orienting, planning, executing, and checking. During the orienting phase, the problem-solver reads and deciphers the problem, defines variables, draws pictures, and categorizes the problem. Once sufficiently situated in the problem, he or she moves on to the planning phase to determine an appropriate course of action.

Carlson and Bloom (2005) include a mini cycle of conjecture-imagine-evaluate in the planning phase. While creating a "plan of attack," expert problem solvers typically go through many cycles of conjecturing that an approach may work, imagining how that approach would play out, and then evaluating whether this approach will be effective or not. The problem solver may repeat this cycle many times before settling on a specific course of action and moving on to the executing phase of the framework. Students at the calculus level tend not to engage in this cycle.

The executing phase is when the problem solver uses everything that he or she has assembled during the orienting and planning phases to implement the plan and solve the problem. Finally, during the checking stage, the problem solver goes back to the original problem to see if the answer makes sense. If the answer does not make sense, the problem solver would then return to the planning stage and begin the cycle again.

For each of the four phases of their framework, Carlson and Bloom (2005) examine four attributes of problem-solving: resources, heuristics, affect, and monitoring, describing how each one manifests in the phases of the problem-solving process. Affect and monitoring are important 
aspects of a student's approach to problem-solving, but are beyond the scope of this study. Instead, we have chosen to focus solely on resources and heuristics.

\section{Related Rates Framework}

Infante's (2007) related rates framework was also informed by Carlson and Bloom's (2005) framework. The related rates framework is divided into phases and focuses on the relationships between the resources and heuristics for each phase. To create a framework specifically for related rates problems, Infante defines five phases based on tasks specifically related to solving a related rates problem and identifies the solution artifacts, content knowledge (adapted from Carlson and Bloom's (2005) "resources"), mental model, and heuristics for each phase. For each phase, the mental model (the problem solver's mental representation of the problem situation), content knowledge, and heuristics work together to produce solution artifacts. The phases of the related rates framework are: Draw a Diagram, Construct a Meaningful Functional Relationship, Relate the Rates, Solve for the Unknown Rate, and Check the Answer for Reasonability.

Infante's (2007) use of Carlson and Bloom's framework to assist in the construction a framework specifically for related rates problems laid the groundwork for a similar framework for optimization problems. While Infante's (2007) framework was an emergent framework, our optimization problem-solving framework was developed based on a mathematical decomposition of the optimization problem-solving process and the results of Infante's work.

\section{Introduction to the Optimization Problem-Solving Framework}

We developed the Optimization Problem-Solving Framework informed by Carlson and Bloom's (2005) Multi-Dimensional Problem-Solving Framework. Carlson and Bloom's (2005) framework was developed to analyze problem-solving behavior in general. Our focus is on 
problem-solving activities strictly related to optimization problems, so we have adapted Carlson and Bloom's (2005) framework to meet our needs.

We present this framework as the lens through which we analyzed our data. We maintain Carlson and Bloom's (2005) four problem-solving phases (orienting, planning, executing, and checking), identify resources, and give examples of heuristics related to each phase, specifically focusing on those directly related to the optimization problem-solving tasks for each phase.

Carlson and Bloom (2005) define resources as "the conceptual understandings, knowledge, facts, and procedures used during problem-solving" (p. 50). For our study, we have chosen to broaden the definition of resources by dividing resources into three categories: conceptual thought processes, analytical thought processes, and content knowledge. Using Vinner's (1997) language of conceptual thought processes allows us to discuss how the students' conceptual understandings influence their problem-solving and the language of analytical thought processes helps us discuss how the students access knowledge, facts, and procedures and relate them to the problem. We refer to knowledge, facts, and procedures as content knowledge, and then define resources for the Optimization Problem-Solving Framework as all of the conceptual thought processes, analytical thought processes, and content knowledge needed for the phase.

\section{An Optimization Problem-Solving Framework}

The orienting phase. During the orienting phase of an optimization problem, the student will read the problem and ideally begin a conceptual thought process about the information presented. The conceptual thought process associated with the orienting phase involves making sense of the problem, identifying the goal, and extracting useful information from the text. Reading and making sense of the problem should lead the student to the conclusion that the goal 
of the problem is to determine how to maximize or minimize some quantity, $Q$, that is restricted by constraint(s). Identifying the goal is important because it guides the student in determining what information to extract from the text. If the student has correctly identified the goal of the problem, then thinking conceptually about the goal leads to identifying the quantity $Q$ that is to be maximized or minimized as a key part of the problem. Additionally, the student will determine that the constraint(s) on this quantity must be considered as well.

In addition to engaging in this conceptual thought process, the student must also engage in the analytical thought process of determining how to translate the important information in the problem into mathematical language. Heuristics such as sketches representing the scenario and appropriate labeling often accompany this thought process. The student will need to define variables for the quantities given in the problem and then determine how to relate these quantities to the goal of the problem. Because the goal has been identified as maximizing or minimizing some quantity, an expression relating variables to this quantity will be needed. Likewise, the constraints are key to the problem, so they will also have to be expressed mathematically. Depending on what the quantities represent, this part of the analytical thought process may be extremely simple or extremely complex. For example, students have a much easier time determining an equation to represent the area of a rectangle than they do determining an equation to represent the cost of constructing a three dimensional box.

In the Garden Problem, the student is asked to find dimensions that will require the least amount of fencing while enclosing an area of $200 f t^{2}$. Implicit in the conceptual thought process leading the student to determine that the goal of the problem is to minimize the amount of fencing is the recognition that there are many ways to construct a fence that produces an area of $200 \mathrm{ft}^{2}$. The goal, then, is to figure out which scenario will lead to the optimal construction. The 
student may define variables for the side lengths of the garden and think analytically about the equations that relate these variables to the area and the amount of fencing. In the Garden Problem, finding these equations is relatively straightforward since most students are very comfortable with the area and perimeter of a rectangle. The Garden Problem has the additional caveat of having a rectangular garden only requiring fencing on three sides due to a barn bordering one side. This means the student must think analytically about the equation for the amount of fencing, determining that $Q=2 x+y$. Once these equations are assembled, the student is prepared to move into the planning phase.

The planning phase. In the orienting phase, the student should have thought conceptually and analytically to identify the goal of the problem (to maximize or minimize some quantity), to define variables for relevant quantities, and to find equations relating the variables to the scenario in the problem. The planning phase is when the student thinks conceptually and analytically about how to how to use everything assembled in the orienting phase to accomplish the goal of the problem.

Carlson and Bloom (2005) include a conjecture-imagine-evaluate sub-cycle in the planning phase of their problem-solving framework, meaning that problem-solvers often conjecture that a particular approach may work, imagine how the approach would work, and then evaluate the approach to see if it will be successful. If the approach does not work, the problemsolver returns to the conjecture phase to try something different. We expect to see evidence of the conjecture-imagine-evaluate sub-cycle in this phase of the Optimization Problem-Solving Framework, but consider it to be a part of the students' analytical thought process for this phase. Thus, although we do expect it to be present, we do not specifically identify it as a separate part of our framework. 
During the planning phase of the framework, the student will construct a function modeling the situation described in the problem (we call this the optimizing function) and make a plan for how to use the optimizing function to solve the problem. The first component of the conceptual thought process involved in the planning phase is recognizing that a function can be used to model the situation described in the problem. The second component is recognizing that in order for the function to model the situation, it must represent the desired quantity and must take the constraint(s) into consideration. Often, the word problems that first semester calculus students encounter in prerequisite courses require them to begin by setting up and solving an equation, so it is common for students to begin a word problem by searching for an equation to solve. In an optimization problem, the student begins with a function and eventually transitions to an equation (setting the derivative equal to zero), so recognizing that a function is useful and determining what the function should represent can involve significant conceptual thought for students.

Recognizing that the maximum or minimum of the function being constructed will correspond to the maximum or minimum of the desired quantity is another piece of the conceptual thought process the student needs to use when determining a plan of action. This part of the thought process occurs as the student transitions from thinking about what the function represents to how it can be used.

Once the student has determined that a function is needed, he or she will also need to think analytically about how to construct a function that accurately reflects the situation. If the student is engaged in an analytical thought process, he or she will observe that because we wish to maximize or minimize some quantity $Q$, the function we are constructing must have $Q$ as the functional value. In the orienting phase, it is likely that the student wrote down an equation for 
$Q$, but if not, he or she may write this equation and study it to see if this function appropriately models the scenario described in the problem, particularly making sure the constraint(s) are considered. If not, the student may consider the equations that correspond to the constraint(s) in the scenario and think about how to incorporate them into the equation for $Q$. Precisely how to do this varies from problem to problem, thus requiring the student to think analytically.

Finally, in addition to thinking analytically about how to construct the optimizing function, the student must also think analytically about how to use the optimizing function. The student will think about properties of functions and the derivative to determine that a maximum or minimum can only occur at endpoints or values for which the instantaneous rate of change of the function is zero or does not exist. This will lead the student to determine that the next step is to find critical values for the function by taking the derivative of the optimizing function and solving for values where the derivative is equal to zero. A common heuristic for this thought process is, "To solve an optimization problem, I take the derivative and set it equal to zero."

In the Garden Problem, the equation $Q=2 x+y$ and the constraint $200=x y$ must be considered. Recognizing that the constraint $200=x y$ means $y=\frac{200}{x}$. Substituting this in for $y$ in the equation $Q=2 x+y$ gives $Q=2 x+\frac{200}{x}$. The new equation is now also a function for $Q$ in terms of $x$; where $x$ is the length of one of the sides not opposite the barn and $Q$ is the amount of fencing needed to enclose an area of $200 \mathrm{ft}^{2}$ that borders a barn. Thus the goal of constructing a function modeling the situation has been achieved. The plan for using the function is to differentiate $Q(x)=2 x+\frac{200}{x}$, set the derivative equal to zero, and solve for the critical values where $Q^{\prime}(x)=0$. The original problem asked for the dimensions needed to minimize the amount of fencing. Once the value for $x$ has been determined, the area equation $200=x y$ can be used to solve for $y$. 
Thus, as part of the planning phase, the student should think conceptually and analytically about constructing an optimizing function and creating a plan to use a previously learned technique to find its absolute maximum or minimum. The key conceptual thought process involved in this phase is that one must construct a function to model the situation, the absolute maximum or minimum value of this function will correspond to the absolute maximum or minimum value of the quantity $Q$.

Executing phase. The executing phase of an optimization problem is almost exclusively comprised of an analytical thought process for constructing the optimizing function and finding its absolute maximum or minimum. This thought process is focused on determining how to differentiate (using derivative rules), what to do after differentiating (set the derivative equal to zero), how to solve an equation (algebra techniques), and how to find other values asked for in the problem. Several heuristics are associated with this analytical thought process, such as tricks used to remember derivative rules, remembering that many equations involving the derivative are of the form $f^{\prime}(x)=0$, and the fact that the answer should be of the form $x=$ An analytical thought process will help the student determine if the derivative does not exist at any critical values, how best to format the function before differentiating, how to simplify the result after differentiating, what algebraic techniques will help isolate the independent variable when solving, what (if any) critical values should be eliminated for practical reasons, and what to do if more than one critical value remains.

After finding a value for $x$, the student must return to the original problem and determine if any other work remains to be done. The student may need to use this answer to find values for other variables. If this is the case, the student will think analytically about the relationships that exist between the missing variable and the value he or she has found for $x$. Further work may be 
needed and some conceptual thought related to the context of the problem may be required, but this will vary from problem to problem.

For the Garden Problem, the executing phase is simple. The optimizing function is of the form $Q(x)=2 x+\frac{200}{x}$, or $Q(y)=2\left(\frac{200}{y}\right)+y$. Both cases result in simple algebra, so we will use the first version. The derivative $Q^{\prime}(x)=2-\frac{200}{x^{2}}$. Setting the derivative equal to zero results in $2-\frac{200}{x^{2}}=0$, and solving this equation gives $x= \pm 10$. Since $x$ represents the length of a side of a fence, it cannot be negative, so the student must throw out the result $x=-10$, leaving only $x=10$. The problem asked the student to find the dimensions that will minimize the garden, so the student will then use the equation $200=x y$ to solve $200=10 y$, and find $y=20$. The final dimensions then are $10 \mathrm{ft} \times 20 \mathrm{ft}$.

Checking phase. In the executing phase, the student finds a value for $x$. During the checking phase, the student thinks analytically to determine whether this answer makes sense in the context of the problem and to verify that the work indeed produced the correct response. Several methods of verifying the answer exist. If the answer found in the executing phase was the only critical value, the student may reason about the function and determine that if only one critical value exists, it must be the maximum or the minimum. Alternatively, the student may choose to use the first or second derivative test to verify that the answer is a maximum or a minimum. If more than one critical value was found, the student should have calculated functional values for all of the critical values during the executing phase and eliminated all but the greatest or least. In this case, all that remains for the student to do is verify that the answer makes sense in the context of the problem. To use most of the methods of verification, the student must be able to think conceptually about the graphical representation of the optimizing function - being able to determine how the axes of the graph of the function should be labeled, 
what the shape of the graph conveys, and how to connect the value for $x$ to the graphical representation of the optimizing function.

Conceptually, the student must be able to think about how the value for $x$ corresponds to the goal of the problem. In doing this, the student recognizes that there are many ways to satisfy the constraints of the problem, and the goal is to determine how to do this in an optimal way. He or she must conclude that the answer fixes some variable that was previously allowed to vary. Now that this quantity has been fixed, the other variables in the problem become fixed as well. Some students may choose to look at the graphical representation of the function using a graphing utility to verify that an answer makes sense for the problem. Heuristics in this phase depend on the method of verification employed by the student. The first and second derivative tests often have visual aids and/or memory tricks associated with them.

In the Garden Problem, the student may verify the answer $x=10$ using several techniques. The first derivative test indicates that $x=10$ occurs at a minimum. The second derivative test indicates that the function $Q$ is concave up at $x=10$ and so $x=10$ occurs at a minimum. The student might look at the graph of $Q$ and observe that since a minimum exists along the positive side of horizontal axis and $x=10$ is the only positive critical value, it must correspond to the minimum. Other rationales not listed here might work as well. Additionally, as a method of checking for algebraic errors, the student might confirm that letting $x=10$ and $y=$ 20 does indeed result in the area of the garden being $200 f t^{2}$.

A comment about heuristics. Many students recognize that superlatives such as largest, smallest, cheapest, and fastest often indicate that the problem is an optimization problem. Classifying the problem as an optimization problem typically leads the problem-solver to call upon other heuristics he or she has developed to recall the standard procedure for solving 
optimization problems. Sometimes these heuristics lead the students to follow correct solutions paths, and other times they do not. The conceptual and analytical thought processes we describe are the tools we want students to be able to use when solving optimization problems. We do not mean to suggest that the students must engage in these occasionally time-consuming thought processes every time they solve an optimization problem, but students ought to be able to access these thought processes if needed and these thought processes should be available to them when developing and using heuristics for solving optimization problems. In our theoretical framework, we listed some examples of heuristics we have observed students using in each phase.

\section{A note about the cyclical nature of the planning, executing, and checking phases. In} an optimization problem, there are two main activities that fall into the executing phase constructing the optimizing function and finding the absolute maximum(s) or minimum(s) of this function. Although we have presented the planning, executing, and checking phases in a linear fashion, some fluidity between these phases is necessary in order to capture the essence of an optimization problem. For example, a student might recognize the need for an optimizing function, think about how to construct the function and then go ahead and do so before thinking about exactly how the function will be used. On the other hand, a student might think about the problem, recognize the need for an optimizing function, think about how it would be constructed, and plan how to use it before doing any construction or solving. Thus, although we are able to categorize certain thought processes and behaviors as falling into a specific phase, we allow for the possibility of the student moving back and forth between the phases as needed. 
Table 6. Optimization Problem-Solving Framework

\begin{tabular}{|c|c|c|c|c|}
\hline \multirow{2}{*}{ Phase } & \multicolumn{3}{|c|}{ Resources } & \multirow{2}{*}{ Examples of Heuristics } \\
\hline & Conceptual Thought Processes & Analytical Thought Processes & Content Knowledge & \\
\hline $\begin{array}{l}\text { Orienting } \\
\text { Phase }\end{array}$ & $\begin{array}{l}\mathrm{C} 1 \text {. The goal of the problem is to determine } \\
\text { how to maximize or minimize some quantity } \\
\text { C2. We have a quantity that is allowed to } \\
\text { vary } \\
\text { C3. We are interested in the quantity to be } \\
\text { maximized or minimized } \\
\text { C4. The constraints given in the problem } \\
\text { must be considered }\end{array}$ & $\begin{array}{l}\text { A1. We need equations to relate the variables } \\
\text { to the goal of the problem } \\
\text { A2. We need an expression for the quantity to } \\
\text { be maximized/minimized } \\
\text { A3. We need an expression for the } \\
\text { constraint(s) }\end{array}$ & $\begin{array}{l}\text { K1. Background information about the } \\
\text { topic of the problem (i.e. geometry, } \\
\text { economics, population growth) } \\
\text { K2. Defining and using variables } \\
\text { K3. Setting up equations }\end{array}$ & $\begin{array}{l}\text { H1. When I see superlative words such } \\
\text { as largest, smallest, cheapest, fastest, } \\
\text { etc., I will be solving an optimization } \\
\text { problem. } \\
\text { H2. For optimization problems, I need } \\
\text { two equations } \\
\text { H3. Sketches representing the scenario } \\
\text { H4. Appropriate labeling }\end{array}$ \\
\hline $\begin{array}{l}\text { Planning } \\
\text { Phase }\end{array}$ & $\begin{array}{l}\text { C1. A function can be used to model the } \\
\text { situation described in the problem } \\
\text { C2. The function must represent the desired } \\
\text { quantity } \\
\text { C3. The function must address the } \\
\text { constraint(s) } \\
\text { C4. The maximum or minimum of this } \\
\text { function will be the maximum or minimum } \\
\text { for the desired quantity }\end{array}$ & $\begin{array}{l}\text { A1. The functional value of the optimizing } \\
\text { function must be the quantity we are trying to } \\
\text { maximize or minimize } \\
\text { A2. Determine how to construct the optimizing } \\
\text { function so it accurately models the scenario } \\
\text { described in the problem - particularly making } \\
\text { sure the constraint(s) are considered } \\
\text { A3. Determine how to find the absolute max or } \\
\text { absolute min of a function (take the derivative, } \\
\text { set equal to zero, solve for critical value) }\end{array}$ & $\begin{array}{l}\text { K1. Function construction } \\
\text { K2. Substitution of variables } \\
\text { K3. Technique for finding the absolute } \\
\text { maximum or absolute minimum of a } \\
\text { function }\end{array}$ & $\begin{array}{l}\text { H1. To solve an optimization problem, } \\
\text { I take the derivative and set it equal to } \\
\text { zero. }\end{array}$ \\
\hline $\begin{array}{l}\text { Executing } \\
\text { Phase }\end{array}$ & & $\begin{array}{l}\text { A1. Use algebra to solve for the critical value } \\
\text { A2. Solve for other unknown values as } \\
\text { specified by the problem }\end{array}$ & $\begin{array}{l}\text { K1. Derivative rules } \\
\text { K2. Algebra rules for solving } \\
\text { equations } \\
\text { K3. Background information about the } \\
\text { topic of the problem (i.e. geometry, } \\
\text { economics, population growth) }\end{array}$ & $\begin{array}{l}\text { H1. Tricks for derivative rules } \\
\text { H2. Many equations we solve that } \\
\text { involve the derivative are of the form } \\
f^{\prime}(x)=0 \\
\text { H3. The answer should be of the form } \\
x=\text {. }\end{array}$ \\
\hline $\begin{array}{c}\text { Checking } \\
\text { Phase }\end{array}$ & $\begin{array}{l}\text { C1. Recognize that there are many scenarios } \\
\text { that correspond to the problem, but the goal } \\
\text { is to find the optimal solution } \\
\text { C2. Understand the connection to the } \\
\text { graphical representation }\end{array}$ & $\begin{array}{l}\text { A1. Verify that the answer makes sense } \\
\text { A2. Use the first or second derivative test (or } \\
\text { some other technique) to verify that the answer } \\
\text { occurs at a max or min }\end{array}$ & $\begin{array}{l}\text { K1. Background information about the } \\
\text { topic of the problem (i.e. geometry, } \\
\text { economics, population growth) } \\
\text { K2. Techniques for verifying } \max / \min \end{array}$ & $\begin{array}{l}\text { H1. Cues indicating that something } \\
\text { might be off } \\
\text { H2. Mental pictures of what a } \\
\text { maximum or minimum looks like on a } \\
\text { graph }\end{array}$ \\
\hline
\end{tabular}




\section{Final Comments About the Framework}

The Optimization Problem-Solving Framework is summarized in Table 6. Just as Carlson and Bloom's (2005) framework represents an ideal framework used by an expert problem solver, our framework is an ideal framework and is not expected to predict what a student will actually think or do while solving an optimization problem. Rather, it models the conceptual and analytical thought processes we would like our students to use and allows us to identify where students use each type of thought process. Associated heuristics often free up the students' mind and allow them to avoid deep conceptual or analytical thoughts. Shortcuts like this can be key to quick problem-solving for experienced mathematicians. However, when pressed to think more deeply, we would like the students to be able to engage in the desired conceptual and analytical thought processes. When we asked students to discuss their underlying thought processes, we observed most students using a blend of conceptual, pseudo-conceptual, analytical, and pseudoanalytical thought processes, as we see in the discussion below.

\section{Methods}

\section{Data Collection}

The data for this study was collected through a series of semi-structured interviews with students enrolled in first semester calculus at a large state university in the United States. Interviews were conducted during the summer and fall semesters of 2014. Four students were interviewed during the first iteration in the summer and three students were interviewed during the second iteration in the fall. All of the students self-reported average to strong mathematical backgrounds. During both iterations, the students reported being taught optimization and taking an exam including optimization problems within the past month. Optimization was taught near the end of the semester, so the students were in the process of preparing for their final exam for 
the course. The protocols for the interviews were informed by previously conducted pilot studies and were designed to capture how students make sense of optimization problems. A brief summary of these students is presented in Table 7.

Table 7. Summary of Participants

\begin{tabular}{|c|c|c|}
\hline Semester & Names & Majors Represented \\
\hline Summer 2014 & Franz, Sam, Tracy, Lars & Engineering (3), Psychology (1) \\
\hline Fall 2014 & Ashod, Brandi, Cy & Engineering (2), Biology (1) \\
\hline
\end{tabular}

In both iterations, we asked students to solve two optimization problems along with questions related to prerequisite material we observed playing a role in students' work during the pilot studies. The first optimization problem was the same for both iterations, while the second problem was different. The first problem each student was asked to solve was the previously mentioned Garden Problem, which we restate here for convenience: A rectangular garden of area $200 \mathrm{ft}^{2}$ is to be fenced off against rabbits. Find the dimensions that will require the least amount of fencing if a barn already protects one side of the garden. This problem was chosen as it is representative of one of the first types of optimization problems presented in both the classroom and the textbook. The algebra is not overly complex, which allows the student to focus on the bigger ideas involved in optimization. In both iterations, the reasoning demonstrated by the students while solving this problem was representative of their reasoning while solving the second optimization problem, so we have elected to focus solely on the students' responses to the Garden Problem, which was common across all seven interviews.

During the problem-solving process, we asked the students to think aloud as much as possible and asked follow-up questions to elicit more information about their thought processes. The interviews were video recorded and then transcribed for analysis. 


\section{Data Analysis}

We developed the framework using a mathematical decomposition of the optimization problem-solving process and then used this framework to code the data using a priori coding. We began by coding the data to mark which phase of the problem-solving framework was occurring (O for orienting, $\mathrm{P}$ for planning, $\mathrm{E}$ for executing, and $\mathrm{C}$ for checking). On the second pass through the data, we coded the data to identify the instances where students showed evidence of engaging in the components of the conceptual or analytical thought processes we defined for each phase. At this point, we were not concerned about whether the thought processes were conceptual or pseudo-conceptual, analytical or pseudo-analytical, we simply identified any instances related to the components. Finally, we identified whether these instances demonstrated evidence of conceptual, pseudo-conceptual, analytical, or pseudo-analytical thought processes. This was the final piece of coding.

To achieve our goal, we focus on whether the students demonstrated evidence of engaging in the desired conceptual and analytical thought processes. In order for the student to be identified as engaging in a conceptual or analytical thought process, the student had to display evidence of performing the task that would be the result of the thought process, and of having a correct, well-reasoned mathematical explanation as to why he or she performed the task, specifically referring to the indicated component of the thought process. For example, if a student wrote down the equation for the amount of fencing around the garden, $P=2 x+y$ and could not explain why he or she did this, even when asked to do so, we would not indicate that the student engaged in the conceptual component of the orienting phase that states, "we are interested in the quantity that is to be maximized or minimized." Instead, we would label the student with the letters PC, to indicate that he or she was using a pseudo-conceptual thought 
process. The student still performed the necessary task for solving the problem, but did not think about it conceptually. To be marked as engaging in this component of the conceptual thought process (labeled with a $\mathbf{C}$ ), the student would have needed to say something like, "I want the least amount of fencing, so I needed an expression for that quantity."

In summary, a transcript excerpt where a student demonstrated evidence of a pseudoconceptual thought process pertaining to component $\mathrm{C} 1$ in the orienting phase received a code of O-C1-PC (O for orienting, $\mathrm{C} 1$ for component $\mathrm{C}$ 1, and PC for pseudo-conceptual). After all of the coding, the results of this analysis were organized into tables, which are presented below.

\section{A Comment About the Results}

Our results are divided into two sections. First, we present detailed results from two case studies - students Brandi and Ashod. Almost all of the thought processes we observed the other five students demonstrating were also reflected in one of these cases, so we are able to provide a significant amount of insight into our data through these two students. We present excerpts from the interview transcripts along with the associated codes. In the second section, we present a summary of the results of analyzing all seven students using the Optimization Problem-Solving Framework. We focus on the four phases of the framework and include tables summarizing the student data for each phase.

\section{Case Study Results}

Here we present the reader with detailed case study results from two students in the study - Brandi and Ashod. We discuss each student individually and include transcript excerpts that include line numbers and the codes that were assigned during analysis.

Case Study 1 - Brandi 
Brandi began by reading the problem and setting it up. In the following excerpt, we see her draw and label a picture of a garden, identify the goal of the problem, and assemble useful equations. Brandi forgot the portion of the problem stating that a barn was to border one side of the garden, so she forgot to exclude fencing for that side. Thus, the equation she used for the amount of fencing was for all four sides of the rectangular garden, instead of just three. We will see later that she notices her mistake, and quickly explains how to fix it.

Table 8. Brandi Excerpt 1

\begin{tabular}{|c|c|c|c|}
\hline$\#$ & Speaker & Transcript & Codes \\
\hline 1. & Brandi & $\begin{array}{l}\text { [Reads problem silently] Alright, you know you have a } \\
\text { rectangular garden. So you already have a rectangle. And } \\
\text { this is at an area equal to } 200 \text { feet squared. So since it's a } \\
\text { rectangle, this is gonna be } x \text { and that's going to be the same } \\
\text { as } x \text { [labels one side with } x \text { and points at opposite side to } \\
\text { indicate that it would also be length } x \text {. So I'm just going } \\
\text { to leave that. But this is } y \text { and this is also the same as } y \text {, } \\
\text { lengthwise [labels perpendicular side with y and again } \\
\text { points at opposite side to indicate it is the same length]. }\end{array}$ & $\begin{array}{l}\mathrm{O}-\mathrm{A} 1-\mathrm{A} \\
\mathrm{O}-\mathrm{C} 3-\mathrm{PC}\end{array}$ \\
\hline 2. & Brandi & $\begin{array}{l}\text { Your area is } 200 \text {, so you know } A \text { equals } x y \text {, so } x y \text { equals } \\
200 \text { feet. Your perimeter, you don't know. }\end{array}$ & $\begin{array}{l}\text { O-C3-PC } \\
\text { O-A3-A } \\
\text { O-C2-C }\end{array}$ \\
\hline 3. & Brandi & $\begin{array}{l}\text { You want the dimensions of this that require the least } \\
\text { amount of fencing. }\end{array}$ & $\mathrm{O}-\mathrm{C} 1-\mathrm{PC}$ \\
\hline
\end{tabular}


Two important phrases here are "your perimeter, you don't know" and "you want the dimensions that require the least amount of fencing." She identified the fact that the perimeter is unknown, leading her to be labeled as engaging in a conceptual thought process about the need to consider the quantity to be maximized. She also mentioned that the constraint (area) must be considered and an expression is needed (components O-C3 and O-A3). She quoted the problem directly, saying, "you want the dimensions that require the least amount of fencing," which led to her being labeled as using a pseudo-conceptual thought process here.

Table 9. Brandi Excerpt 2

\begin{tabular}{|c|c|c|c|}
\hline \# & Speaker & Transcript & Codes \\
\hline 4. & Brandi & $\begin{array}{l}\text { So you want the minimum amount for each side. So you } \\
\text { want to find an equation for the perimeter and find the min } \\
\text { of it. }\end{array}$ & $\begin{array}{l}\text { O-A1-A } \\
\text { O-A2-A } \\
\text { O-C1-PC } \\
\text { O-C2-C } \\
\text { P-C1-C } \\
\text { P-C4-C }\end{array}$ \\
\hline 5. & Brandi & So your perimeter would be, say, $P$ equals $2 x$ plus $2 y$. & $\mathrm{O}-\mathrm{A} 2-\mathrm{A}$ \\
\hline 6. & Brandi & $\begin{array}{l}\text { You have two separate equations so you could solve for } \\
\text { one of these and plug it into there [points at the } x \text { and } y \text { in } \\
\text { the area equation and then at the } x \text { and } y \text { in the perimeter } \\
\text { equation]. So we'll go with } x \text { equals } 200 \text { over } y \text {. So we } \\
\text { have that. }\end{array}$ & P-A2-PA \\
\hline 7. & Brandi & $\begin{array}{l}\text { So we can plug it into this other equation [points at } \\
\text { perimeter equation] and say the perimeter equals } 2 \text {, times }\end{array}$ & P-A2-PA \\
\hline
\end{tabular}




\begin{tabular}{|r|l|l|l|}
\hline & & $\begin{array}{l}\text { we solved for } x \text {, so that's } 200 \text { over } y \text {, plus } 2 y \text { and now that } \\
\text { we have one variable, we can... I'm going to distribute this } \\
\text { out. }\end{array}$ & \\
\hline $\mathbf{8 .}$ & Interviewer & Ok. & \\
\hline
\end{tabular}

In line 4, Brandi stated, "So you want the minimum amount for each side." This is not correct, and the codes to the side indicate that she was labeled as engaging in a pseudoconceptual thought process here. However, later in the interview, with more time to think, she explained the goal more clearly, stating in line 359, "The purpose of this is to find the minimum of the amount of fencing." Because of this later statement, she was classified as being able to engage in a conceptual thought process for component $\mathrm{C} 1$ of the orienting phase, which states, "The goal of the problem is to determine how to maximize or minimize some quantity," even though she was not demonstrating that in line 4 .

In the above excerpt we also see indications of Brandi's thought process about constructing the optimizing function by solving for a variable in the area equation and plugging it into the perimeter equation. She began by saying, "You have two separate equations, so you could solve for one of these and plug it into there," and continued to say, "So we can plug it into this other equation," and "now that we have one variable, we can..." These explanations suggest Brandi had developed a heuristic of needing to construct an equation using only one variable, enabling her to use only pseudo-conceptual and pseudo-analytical thought processes to construct a function representing the scenario described in the problem, rather than thinking conceptually and analytically about the role of the constraints. 
Next, we see Brandi describe her plan for using her newly constructed optimizing function to solve the problem. Notice that she never used the word function, but she did utilize the expression as though it is a function by taking the derivative of the expression and briefly referred to the graph of the "amount of feet that could be used."

Table 10. Brandi Excerpt 3

\begin{tabular}{|c|c|c|c|}
\hline \# & Speaker & Transcript & Codes \\
\hline 9. & Brandi & $\begin{array}{l}\text { And so it's } 400 \text { over } y \text { plus } 2 y \text { and since we want a } \\
\text { minimum, we want to take the derivative of this [points at } \\
\text { newly constructed optimizing function] and find our critical } \\
\text { numbers so we can see if there's a minimum in the slope }\end{array}$ & P-A3-A \\
\hline 10. & Interviewer & What do you mean a minimum in the slope? & \\
\hline 11. & Brandi & $\begin{array}{l}\text { Well, slope. Minimum in derivative. Like a minimum } \\
\text { amount. Cause the. Ok. How do I want to word this? Sorry. }\end{array}$ & P-A3-PA \\
\hline 12. & Interviewer & No that's okay. & \\
\hline 13. & Brandi & $\begin{array}{l}\text { Cause like the amount of feet that could be used, if you } \\
\text { think of it on the graph. Like if this certain amount can be } \\
\text { used, there's higher numbers that could be lower. You } \\
\text { just... }\end{array}$ & $\begin{array}{l}\text { P-C4-PC } \\
\text { C-C } 1-C\end{array}$ \\
\hline 14. & Brandi & $\begin{array}{l}\text { Ok. I'll just say this, you take the derivative because you } \\
\text { want a minimum amount for your perimeter and if you take } \\
\text { the derivative of this, you can find, um, a certain value for } \\
y \text {, well, you get your critical numbers. }\end{array}$ & $\mathrm{P}-\mathrm{C} 2-\mathrm{C}$ \\
\hline 15. & Interviewer & Ok & \\
\hline
\end{tabular}




\begin{tabular}{|c|c|c|c|}
\hline 16. & Brandi & $\begin{array}{l}\text { And you need to set those values back into the derivative to } \\
\text { see if uh the slope is positive on one side or negative. }\end{array}$ & C-A2-A \\
\hline 17. & Interviewer & Ok. & \\
\hline 18. & Brandi & $\begin{array}{l}\text { See if you have a minimum value somewhere in this line } \\
\text { right here. }\end{array}$ & $\mathrm{C}-\mathrm{C} 2-\mathrm{C}$ \\
\hline 19. & Interviewer & Ok. Ok. That's good. & \\
\hline
\end{tabular}

After explaining her plan, Brandi spent a little over two minutes taking the derivative, setting it equal to zero, solving for $y$, and simplifying her answer to get $y=10 \sqrt{2}$. She spent the next seven minutes using the first derivative test to verify that this critical value occurred at a minimum on the function. It took her a long time to do this for two reasons. First, she inaccurately assumed she had a closed interval domain and needed to consider endpoints (she called these boundaries). Then, once she found what she believed were the endpoints ( 0 and 200), she chose 1 and 12 for her test points for the first derivative test because she approximated that $10 \sqrt{2}$ to be 10.3 . Since $10 \sqrt{2}$ is actually greater than 14 , both of her choices produced a negative value in the derivative, leading her to believe that $10 \sqrt{2}$ did not occur at a minimum. This led to a lot of confusion for her, but she began to express doubt that 12 was greater than $10 \sqrt{2}$. Near the end of the seven minutes, she was given a calculator and discovered that $10 \sqrt{2}$ was greater than 12 . She then picked a new number, 15 , as her second test point, confirmed that $10 \sqrt{2}$ occurred at a minimum, and moved on to finding the second dimension for the garden. Table 11. Brandi Excerpt 4

\begin{tabular}{|c|c|c|c|}
\hline$\#$ & Speaker & Transcript & Codes \\
\hline
\end{tabular}




\begin{tabular}{|c|c|c|c|}
\hline 116. & Brandi & $\begin{array}{l}\text { So then we do have a min at } 10 \sqrt{2} \text {, and since we have a } \\
\text { minimum here, we can go back and say, "Ok, well, } y \\
\text { equals } 10 \sqrt{2} \text {, ok, we want the dimensions." }\end{array}$ & E-A2-A \\
\hline 117. & Interviewer & Mhm & \\
\hline 118. & Brandi & $\begin{array}{l}\text { So we'll say, } y \text { equals } 10 \sqrt{2} \text { for the perimeter, so when we } \\
\text { plug } y \text { into that, we get our perimeter equals } 2 x \text { plus } 2 \\
\text { times } 10 \sqrt{2} \text { and we'll set that equal to zero. }\end{array}$ & E-A2-NE \\
\hline 119. & Interviewer & Ok, why? & \\
\hline 120. & Brandi & $\begin{array}{l}\text { Uh because we're starting out with zero amount of fencing } \\
\text { and we want to find the minimum, so if set that equal to } \\
\text { zero and solve for this, then we can find our } x \text { value. }\end{array}$ & E-A2-NE \\
\hline 121. & Interviewer & $\begin{array}{l}\text { Ok. What. How does that work? How does setting it equal } \\
\text { to zero, you're saying setting it equal... Setting the } \\
\text { perimeter equal to zero is going to give you... }\end{array}$ & \\
\hline 122. & Brandi & $\begin{array}{l}\text { Well, no, I was going to take } y \text { and plug it into this } \\
\text { equation for our perimeter. No we plug it into here [points } \\
\text { at the equation } x=\frac{200}{y} \text { ] because we already have it. Duh! } \\
\text { Right? Yeah! So } x \text { times } 200 \ldots \text { [writes } x(10 \sqrt{2})=200 \text { ] } \\
\text { So } x \text { equals } 200 \text { over } \sqrt{2} \text { [initially forgets the } 10 \text {, but } \\
\text { corrects this later]. }\end{array}$ & E-A2-A \\
\hline
\end{tabular}


We see here that Brandi attempted to solve for the other dimension of the garden, the $x$ value, but initially did so incorrectly, plugging $10 \sqrt{2}$ into the perimeter equation and setting the perimeter equal to zero. However, when asked to explain, she realized that she should have been using the area equation, and she did so correctly.

Her final answer was $x=10 \sqrt{2}$, and in the excerpt below, we see Brandi thinking logically about the implications of this answer, demonstrating that she was checking to be sure her answer made sense in the context of the problem.

Table 12. Brandi Excerpt 5

\begin{tabular}{|c|c|c|c|}
\hline \# & Speaker & Transcript & Codes \\
\hline 128. & Brandi & $\begin{array}{l}\text { So, ok. That's } x \text { equals } 20 \text { over } \sqrt{2} \text {, so then we'll multiply } \\
\text { by } \sqrt{2} \text { over } \sqrt{2} \text { because that's essentially } 1 \text {. Which give us } \\
20 \sqrt{2} \text {, all over } 2 \text {, which is } 10 \sqrt{2} \text {. Hey, look at that! }\end{array}$ & $\begin{array}{l}\text { E-A2-A } \\
\text { C-A1-A }\end{array}$ \\
\hline 129. & Interviewer & Why do you say that? & \\
\hline 130. & Brandi & Because they're both the same. & C-A1-A \\
\hline 131. & Interviewer & Huh, interesting. & \\
\hline 132. & Brandi & $\begin{array}{l}\text { So it's a square, not a rectangle. So then we have } y \text { equals } \\
10 \sqrt{2} \text { and } x \text { equals } 10 \sqrt{2} \text {, and that's the dimensions that } \\
\text { will give you your least amount of fencing. }\end{array}$ & $\begin{array}{l}\mathrm{C}-\mathrm{C} 1-\mathrm{C} \\
\mathrm{C}-\mathrm{A} 1-\mathrm{A}\end{array}$ \\
\hline
\end{tabular}

After a short discussion about the boundary points again, Brandi worked on a part of the interview protocol from the larger study that is not a focus of this paper. At the end of this activity, Brandi was asked to go back and explain some of the steps she had taken to solve the optimization problem. See below. 
Table 13. Brandi Excerpt 6

\begin{tabular}{|c|c|c|c|}
\hline \# & Speaker & Transcript & Codes \\
\hline 321. & Interviewer & $\begin{array}{l}\text { So, first of all, why did you draw a picture? Do you have } \\
\text { any reason? }\end{array}$ & \\
\hline 322. & Brandi & $\begin{array}{l}\text { Uh, it helps me see it, really. I could do it without drawing } \\
\text { a picture, this just puts things in place for me. It's better to } \\
\text { draw one and see what you're finding out. }\end{array}$ & $\mathrm{O}-\mathrm{C} 1-\mathrm{C}$ \\
\hline 323. & Interviewer & $\begin{array}{l}\text { Ok, um, and then how did you know you were going to } \\
\text { need those equations that you came up with? }\end{array}$ & \\
\hline 324. & Brandi & Well it already tells you that the area is 200 feet squared. & $\mathrm{O}-\mathrm{C} 3-\mathrm{C}$ \\
\hline 325. & Interviewer & Mhm. & \\
\hline 326. & Brandi & $\begin{array}{l}\text { And so I drew the picture and I labeled the two sides. Since } \\
\text { it's a rectangle, these two are going to be the same and } \\
\text { those two are going to be the same, so I knew already this } \\
\text { equation was true. Because your area is } 200 \text { feet and your } \\
\text { area variable wise is equal to } x \text { times } y \text {, so you knew that } x \\
\text { times } y \text { was going to be } 200 \text { feet, but then if you go on it } \\
\text { says you want the dimensions that require the least amount } \\
\text { of fencing. Ohhhhh... }\end{array}$ & $\begin{array}{l}\text { O-A1-A } \\
\text { O-A2-A } \\
\text { O-A3-A }\end{array}$ \\
\hline 327. & Interviewer & It's okay. What are you ohhhhhing about? & \\
\hline 328. & Brandi & I did it wrong. I'm sorry. & \\
\hline
\end{tabular}


At this point, Brandi noticed that the problem said one side of the garden bordered a barn and did not need fencing, which she had not taken into consideration when solving the problem. She said, "I forgot a barn was on one side." She explained that to correct it, she would change the perimeter equation to include two $x$ and only one $y$. She offered to redo the problem, but the interviewer chose not to pursue this, because she had already explained how to correct the mistake. After this momentary detour, the questioning continued.

Table 14. Brandi Excerpt 7

\begin{tabular}{|c|c|c|c|}
\hline \# & Speaker & Transcript & Codes \\
\hline 337. & Interviewer & $\begin{array}{l}\text { You had the one set of equations, you had the } A=200, x \\
\text { times } y \text { equals } 200 \text {. }\end{array}$ & \\
\hline 338. & Brandi & $\begin{array}{l}\text { Yeah you had the dimensions of it, so the dimensions, you } \\
\text { want to find the perimeter of it, cause that would } \\
\text { automatically give you, well it wouldn't give you, but like } \\
\text { if you had the dimensions, it would give you the perimeter. }\end{array}$ & $\begin{array}{l}\text { P-C1-C } \\
\text { P-C2-C } \\
\text { P-A1-A }\end{array}$ \\
\hline 339. & Brandi & $\begin{array}{l}\text { And I knew that if I found the perimeter, like an equation } \\
\text { for it, I could solve for a variable of my area, which I } \\
\text { already had an equation for. }\end{array}$ & $\begin{array}{l}\text { P-C3-PC } \\
\text { P-A2-PA }\end{array}$ \\
\hline 340. & Interviewer & Ok & \\
\hline 341. & Brandi & And plug it into here and find the critical number and... & P-A3-A \\
\hline 342. & Interviewer & $\begin{array}{l}\text { Ok. So is there any reason you started with writing the area } \\
\text { down first instead of writing down the perimeter? }\end{array}$ & \\
\hline 343. & Brandi & Because it was a given. & $\mathrm{O}-\mathrm{C} 3-\mathrm{C}$ \\
\hline 344. & Interviewer & Ok, so that was the first thing you saw, so you just... So if & \\
\hline
\end{tabular}




\begin{tabular}{|c|c|c|c|}
\hline & & $\begin{array}{l}\text { there had been other information in the problem that you } \\
\text { didn't even need, would you still have written that down if } \\
\text { you saw it? }\end{array}$ & \\
\hline 345. & Brandi & $\begin{array}{l}\text { Um. Probably just so I'd have it. Cause at the beginning of } \\
\text { the problem, my thought process is okay, this is what I } \\
\text { have. }\end{array}$ & O-A1-A \\
\hline 346. & Interviewer & $\mathrm{Ok}$ & \\
\hline 347. & Brandi & $\begin{array}{l}\text { And then I look at what I need and then I'd probably go } \\
\text { through and cross out what I need and don't need }\end{array}$ & O-A1-A \\
\hline 348. & \begin{tabular}{|l|} 
Interviewer \\
\end{tabular} & $\begin{array}{l}\text { Ok, ok that sounds good. So why did you have to solve for } \\
x \text { equals } 200 \text { over } y \text { ? Why did you have to do that? }\end{array}$ & \\
\hline 349. & Brandi & $\begin{array}{l}\text { Well you could do, you could solve for } x \text { or } y \text {. Cause you } \\
\text { have an } x y \text { right here and you have an } x y \text { right here. So I } \\
\text { could solve for } y \text { and said } y \text { is equal to } 200 x \text {, then I would } \\
\text { have } x \text { is equal to this whole ordeal. }\end{array}$ & $\begin{array}{l}\text { P-C3-PC } \\
\text { P-A2-PA }\end{array}$ \\
\hline 350. & Interviewer & $\begin{array}{l}\text { What would } x \text { be equal to? Do you know what it would } \\
\text { have come out to be? }\end{array}$ & \\
\hline 351. & Brandi & $\begin{array}{l}\text { Well, wouldn't it just be the same because this is a set place } \\
\text { and like there's no, like, it would still be that because it's a } \\
\text { square essentially. }\end{array}$ & C-A1-A \\
\hline 352. & Interviewer & $\begin{array}{l}\text { Ok. But in general, why did you have to do either one of } \\
\text { those two things? }\end{array}$ & \\
\hline 353. & Brandi & Either, like this? & \\
\hline
\end{tabular}




\begin{tabular}{|c|c|c|c|}
\hline 354. & Interviewer & Like why did you have to solve for one variable at all? & \\
\hline 355. & Brandi & $\begin{array}{l}\text { Because you have the two equations and it's sort of like the } \\
\text { systems of equations }\end{array}$ & $\begin{array}{l}\text { P-C2-PC } \\
\text { P-A2-PA }\end{array}$ \\
\hline 356. & Interviewer & $\mathrm{Ok}$ & \\
\hline 357. & Brandi & $\begin{array}{l}\text { And like I could solve for one here and since they are both } \\
\text { pertaining to the same rectangle I could solve for one here } \\
\text { and plug that variable into this equation, cause this is } \\
\text { gonna turn out, the, I'm talking about the perimeter of the } \\
\text { square and the area of the square. }\end{array}$ & $\begin{array}{l}\text { P-C2-PC } \\
\text { P-A2-PA }\end{array}$ \\
\hline 358. & Interviewer & $\begin{array}{l}\text { Ok. So why couldn't you just use the } P=2 x+2 y \text { by } \\
\text { itself? I guess that's my question. Like why did you have to } \\
\text { do anything else? }\end{array}$ & \\
\hline 359. & Brandi & $\begin{array}{l}\text { Because you have two variables. In order. Well, I mean. } \\
\text { The purpose of this is to find the minimum of the amount } \\
\text { of fencing. And in order to do that, I would only need one } \\
\text { variable. Cause if I took the derivative of this, I would. Ok. }\end{array}$ & $\begin{array}{l}\mathrm{O}-\mathrm{C} 1-\mathrm{C} \\
\mathrm{P}-\mathrm{C} 2-\mathrm{PC} \\
\mathrm{P}-\mathrm{A} 2-\mathrm{PA}\end{array}$ \\
\hline 360. & Brandi & $\begin{array}{l}\text { So. I, you, okay, well, I'll say this. You have a perimeter } \\
\text { equation which has two different variables in it. And if I } \\
\text { want to find the minimum amount of it, I need at least one } \\
\text { of those variables to plug into it to see at this certain value } \\
\text { there is or isn't a minimum. }\end{array}$ & $\begin{array}{l}\text { P-C2-PC } \\
\text { P-A2-PA }\end{array}$ \\
\hline
\end{tabular}


Again, we see Brandi explained her need to solve for one variable in the area equation and plug it into the other equations by saying, "The purpose of this is to find the minimum of the amount of fencing. And in order to do that, I would only need one variable." Her focus was on creating a function with only one variable so she could take the derivative, not on making sure her function accurately reflects the constraints stated in the problem, indicating her use of a pseudoconceptual thought process while thinking about the need to use the constraint and a pseudoanalytical thought process while using the constraint to construct her function.

Summary of Brandi’s Interview Data. Brandi demonstrated evidence of engaging in conceptual and analytical thought processes for almost the entire process. She was clear about the goal of the problem, how her algebraic work pertained to the goal of the problem, and why her optimizing function needed to represent the quantity to be maximized or minimized. She received codes of pseudo-conceptual and pseudo-analytical for only two components: P.C3, which states "The function must address the constraint(s)," and P.A2, which states, "Determine how to construct the optimizing function so it accurately models the scenario described in the problem - particularly making sure the constraint(s) are considered." Both of these pertain to the role of the constraints of the problem. We will see below that this was common to all seven students in the study.

\section{Case Study 2 - Ashod}

Ashod began the problem-solving process by reading the problem and identifying it as an optimization problem. When he was asked why, he responded, "You know it's an optimization problem when it asks for the least amount of something or the most amount of something, dealing with cost or whatever." He then continued to set up the problem as follows. Table 15. Ashod Excerpt 1 


\begin{tabular}{|c|c|c|c|}
\hline \# & Speaker & Transcript & Codes \\
\hline 4. & Ashod & $\begin{array}{l}\text { So I start by drawing a rectangle that resembles a garden. } \\
\text { [Draws a rectangle] }\end{array}$ & $\mathrm{O}$ \\
\hline 5. & Ashod & $\begin{array}{l}\text { And I know the area is } 200 \text { and this would be my } y \text { value, } \\
\text { this would be my } x \text { values. [labels all two opposite sides } \\
\text { with } x \text { and the other two opposite sides with y, forgetting } \\
\text { that one side of the garden is alongside a barn and does } \\
\text { not need fencing] }\end{array}$ & $\mathrm{O}-\mathrm{C} 3-\mathrm{PC}$ \\
\hline 6. & Ashod & $\begin{array}{l}\text { And so... We know that area equals length times width, I } \\
\text { mean, you could say } x \text { times } y \text { in this case. }\end{array}$ & O-C3-PC \\
\hline 7. & Interviewer & Ok. & \\
\hline 8. & Ashod & $\begin{array}{l}\text { And um, the area is } 200 \text { equals } x \text { times } y \text {, but they want to } \\
\text { know the dimensions that require the least amount of } \\
\text { fencing if it protects one side of the garden, so we have to } \\
\text { use the perimeter formula as well. [Writes } P=2 l+2 w \text {, } \\
\text { neglects the fact that the garden is supposed to have a barn } \\
\text { on one side and does not need fencing] }\end{array}$ & O-C2-PC \\
\hline
\end{tabular}

In these few steps, Ashod did all of the tasks associated with the orienting phase identifying the problem, assigning variables, and assembling useful equations. He did not display any evidence of engaging in the desired conceptual and analytical thought processes for this phase, because although his work was mostly correct (aside from forgetting to exclude fencing along the barn), his explanations did not include mention of constraints or quantities to be 
maximized or minimized. The line, "they want to know the dimensions that require the least amount of fencing if it protects one side of the garden, so we have to use the perimeter formula as well," was not enough to qualify him as engaging in a conceptual or analytical thought process, because he was only rereading the problem aloud, not rephrasing it in his own language. Further questioning later in the interview explored this further.

Next, Ashod moved into the planning phase, beginning by describing his plan to solve the problem. He said, "Basically what we would do is, we solve for either variable to plug it in to find the perimeter of this. That's, to find the perimeter which would give us the dimensions of it." He spent some time deciding how to resolve the fact that the area equation was written in terms of $x$ and $y$, but the perimeter equation was written in terms of $l$ and $w$ and finally rewrote the perimeter equation as $P=2 y+2 x$. He chose to replace the $l$ with $y$ and the $w$ with $x$, because in his sketch, he had labeled the sides he traditionally thought of as the length and width using $y$ and $x$, respectively. Even though he could have used the commutative property of addition to write the equation in the more natural, alphabetical order that mathematicians tend to use, he left it as $P=2 y+2 x$.

After he was satisfied with his perimeter equation, Ashod used the area equation to find $y=\frac{200}{x}$ and plugged this into the perimeter equation, finding $P=\frac{400}{x}+2 x$.

Table 16. Ashod Excerpt 2

\begin{tabular}{|l|l|l|l|}
\hline$\#$ & Speaker & \multicolumn{1}{|c|}{ Transcript } & Codes \\
\hline 20. & Ashod & $\begin{array}{l}\text { And then from there, I have to find the derivative, because } \\
\text { they're asking for the least amount, and you know you get } \\
\text { that... And the derivative is... Uh, how do I explain this? I } \\
\text { find the derivative, because when it equals zero, that's }\end{array}$ & P-A3-PA \\
\hline
\end{tabular}




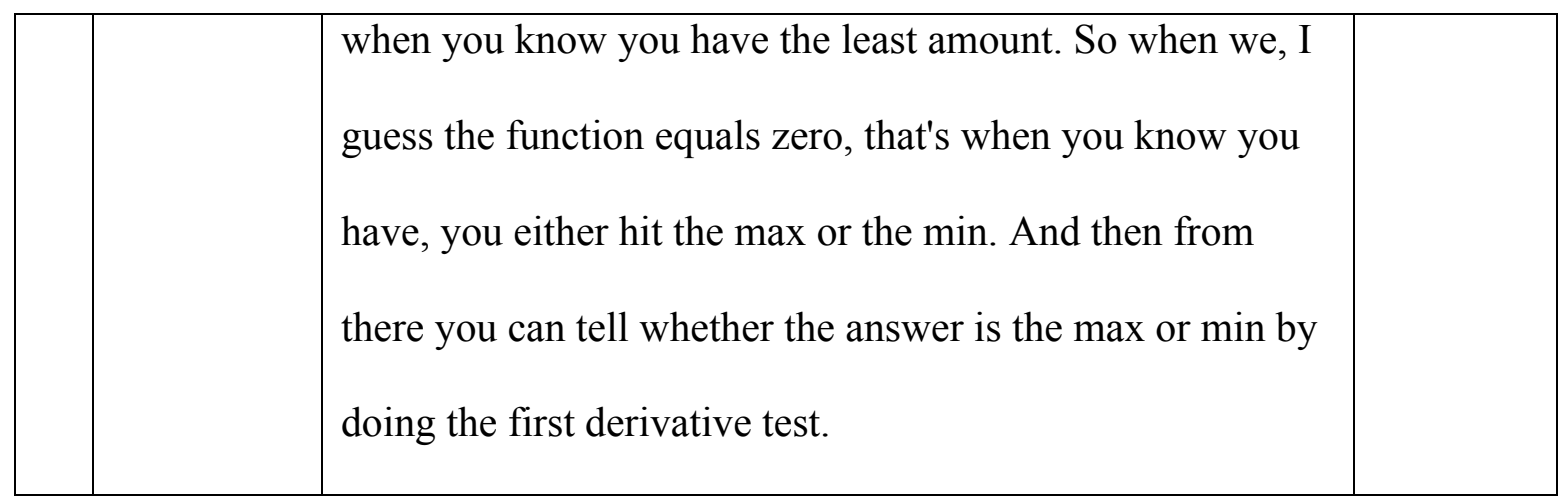

To solve the problem, Ashod correctly took the derivative, set it equal to zero, and solved to find $x=\sqrt{200}$. He drew a horizontal line, marked $x=\sqrt{200}$ on the line, and explained how he would use the first derivative test to verify that he had a minimum.

Table 17. Ashod Excerpt 3

\begin{tabular}{|l|l|l|l|}
\hline$\#$ & Speaker & \multicolumn{1}{|c|}{ Transcript } & Codes \\
\hline 29. & Ashod & $\begin{array}{l}\text { So I take the first derivative, negative } 400 \text { over squared } \\
{[\text { sic }] \text { plus two equals zero. And then, well, I'd say, on a }} \\
\text { graph line, square root of 200. I would use radical 199 and } \\
\text { radical } 201 \text { and if I were to plug that in for the } x \text { values, it } \\
\text { doesn't matter, as long as I get a negative value with 199 } \\
\text { and a positive value } 201, \text { I know that this is a min, because } \\
\text { this is going, because this is give me a negative [sic], so } \\
\text { you know the graph is going to look something like this, } \\
\text { and this will give me a positive, so you know the graph is } \\
\text { going to look something like this [sketches a line with a } \\
\text { negative slope above } \sqrt{199} \text { and a line with a positive slope } \\
\text { above } \sqrt{201}], \text { so I know I found my minimum. }\end{array}$ & C-A \\
\hline
\end{tabular}


Finally, Ashod plugged $x=\sqrt{200}$ into the area equation and solved to find $y=\sqrt{200}$, explaining, "Once I found my minimum, I just plug this right back in here to give me the $y$, and whatever answer this is, I have my dimensions."

At this point, Ashod had not demonstrated any evidence of engaging in a conceptual or analytical thought process while solving the problem. All of his comments were reflective of pseudo-conceptual or pseudo-analytical thought processes. Therefore, after Ashod finished solving the problem, he was asked questions to further illuminate his thought processes while solving the optimization problem. In the following exchange, Ashod was asked to explain his approach to solving the problem, and we see that he continued to rely on pseudo-conceptual and pseudo-analytical thought processes to explain how he determined how to solve the problem. Table 18. Ashod Excerpt 4

\begin{tabular}{|c|c|c|c|}
\hline \# & Speaker & Transcript & Codes \\
\hline 36. & Interviewer & $\begin{array}{l}\text { Can you tell me a little bit more about why setting the } \\
\text { derivative equal to zero works? Why is that the thing to } \\
\text { do? }\end{array}$ & \\
\hline 37. & Ashod & $\begin{array}{l}\text { I don't know. I just always just learned that, um, if you } \\
\text { want to find the least or the most amount, you would find } \\
\text { two equations that make sense and would equate to each } \\
\text { other in the problem, and whatever they give you, use the } \\
\text { other equation, so that's what I did. So I used perimeter, } \\
\text { and I just knew I had to set it equal to zero cause that's } \\
\text { when you know you have a max or a min, and that's the }\end{array}$ & $\begin{array}{l}\text { O-A1-PA } \\
\text { O-A2-PA } \\
\text { O-A3-PA } \\
\text { P-C1-PC } \\
\text { P-C2-PC } \\
\text { P-C3-PC } \\
\text { P-A1-PA }\end{array}$ \\
\hline
\end{tabular}




\begin{tabular}{|l|l|l|}
\hline & $\begin{array}{l}\text { same case as in the question, when I need... They could } \\
\text { have asked the most amount or the least amount. That's } \\
\text { how I know which ones which, and I know to get that you } \\
\text { have to set the equation equal to zero. }\end{array}$ & P-A2-PA \\
\hline
\end{tabular}

Notice Ashod's statement, "You would find two equations that make sense and would equate to each other in the problem, and whatever they give you, use the other equation," is a clear indication that he was thinking pseudo-conceptually and pseudo-analytically about the construction of the optimizing function. He gave no indication that he was thinking about the role of the constraints in the problem or the need for the function to represent the amount of fencing needed. Instead, he simply stated, "whatever they give you, use the other equation," a heuristic he had developed to allow him to think pseudo-conceptually and pseudo-analytically. Continuing this line of questioning, the interviewer reminded Ashod that he said where the derivative equals zero is where a max or min occurs and asked, "Is there a reason?" Ashod responded, "There is a reason, I just probably can't think about it now," another indication that he was not able to engage in the desired conceptual and analytical thought processes when asked.

In the following exchange, Ashod was asked to give more detail about how he thought about solving the problem. We see that he often used heuristics to determine what to do and he could not give better explanations when asked to do so.

Table 19. Ashod Excerpt 5

\begin{tabular}{|c|c|c|c|}
\hline$\#$ & Speaker & Transcript & Codes \\
\hline 71. & Interviewer & Ok, so, why did you start with a picture? & \\
\hline
\end{tabular}




\begin{tabular}{|c|c|c|c|}
\hline 72. & Ashod & $\begin{array}{l}\text { Um, that's always how I start usually with word problems. } \\
\text { I just draw a picture to make it easier. }\end{array}$ & $\mathrm{O}$ \\
\hline 73. & Interviewer & $\begin{array}{l}\text { Ok and then how did you know that you needed these two } \\
\text { equations? [points to area and perimeter equations] }\end{array}$ & \\
\hline 74. & Ashod & $\begin{array}{l}\text { Usually, um, well, it's kind of like a little, like a cheat sheet } \\
\text { for me. Usually when they ask for the area, you'd have to } \\
\text { use the perimeter. Or if they give you the perimeter, I'd } \\
\text { have to find it to use the area. So I know these are like } \\
\text { interchangeable within each other. But they usually ask for } \\
\text { the dimensions, so I'm guessing the sides... If they tell us } \\
\text { what the area was, so I just kind of created that set of } \\
\text { dimensions with being perimeter. So. }\end{array}$ & $\begin{array}{l}\text { O-A1-PA } \\
\text { O-A2-PA } \\
\text { O-A3-PA } \\
\text { P-C2-PC } \\
\text { P-C3-PC }\end{array}$ \\
\hline 75. & Interviewer & Is it, um, would it have been okay to put $2 x+2 y$ instead? & \\
\hline 76. & Ashod & I'm pretty sure. It would have been okay. & $\mathrm{O}$ \\
\hline 77. & Interviewer & $\begin{array}{l}\text { Ok. So why did you have to do this part? This right here? } \\
\text { Where you solve for one variable, like solve for } y \text { equals or } \\
\text { whatever. Why did you have to do that? }\end{array}$ & \\
\hline 78. & Ashod & $\begin{array}{l}\text { Well, I just have to get these equal on the same variable so } \\
\text { I could solve the problem. So I could've either done } x \text { or } y \text {. } \\
\text { It wouldn't matter. So basically once I got that, I just. So } \\
\text { basically, you knew what } 200,200 \text { was the area and you } \\
\text { know the area equals length times width and perimeter is } \\
\text { twice the length plus twice the width. So if I could just }\end{array}$ & $\begin{array}{l}\text { P-C2-PC } \\
\text { P-C3-PC } \\
\text { P-A2-PA } \\
\text { P-A3-PA }\end{array}$ \\
\hline
\end{tabular}




\begin{tabular}{|l|l|l|l|}
\hline & & kind of solve one variable to get all variables the same, it & \\
would be easy to figure this problem out. & & \\
\hline 79. & Interviewer & $\begin{array}{l}\text { Ok, and what tells you you're allowed to do that? Because } \\
\text { these are two separate equations, right? }\end{array}$ & \\
\hline 80. & Ashod & Mhm. & So what tells you, you're allowed to take this and take that \\
81. & Interviewer & and plug it in over here? & \\
\hline 82. & Ashod & $\begin{array}{l}\text { They have the same variable. So that's how I'm assuming } \\
\text { that allowed me to do that. }\end{array}$ & P-A2-PA \\
\hline
\end{tabular}

Of particular interest is Ashod's use of "cheat sheet" to describe how he decided how to set up the problem - a clear indication that he was engaging in a pseudo-conceptual thought process.

Finally, he was asked to describe what his answer meant in the context of the problem. Table 20. Ashod Excerpt 6

\begin{tabular}{|l|l|l|l|}
\hline$\#$ & Speaker & \multicolumn{1}{|c|}{ Transcript } & Codes \\
\hline 83. & Interviewer & $\begin{array}{l}\text { Ok. Ok. Ok. Ok, um, so, at the very end, we get x equals } \\
\text { square root of 200. What does that mean? That's your } \\
\text { answer, right? So that tells you what? }\end{array}$ & \\
\hline 84. & Ashod & $\begin{array}{l}\text { They said find the dimensions that will require the least } \\
\text { amount of fencing, so the least amount of fencing would be } \\
\text { when } x \text { is equal to radical } 200 \text { and } y \text { is equal to radical } \\
200 .\end{array}$ & P-C4-PC \\
\hline 85. & Interviewer & Ok, so is there the possibility of other amounts of fencing & \\
\hline
\end{tabular}




\begin{tabular}{|l|l|l|l|}
\hline 86. & Ashod & $\begin{array}{l}\text { also? } \\
\text { I believe that's the least cause that's when it was zero, so }\end{array}$ & P-A3-PA \\
that's the least amount it could possibly be. & & \\
\hline 87. & Interviewer & $\begin{array}{l}\text { I guess that's my question. What does it mean to have the } \\
\text { other amounts of fencing also? }\end{array}$ & \\
Ashod & $\begin{array}{l}\text { Mm. I mean, you could have other amounts of questions, } \\
\text { other amounts of fencing, but they just wanted the least } \\
\text { amount of fencing if a barn protects like, one side of the } \\
\text { garden, so this is how I found it, really. }\end{array}$ & C-C1-C \\
\hline
\end{tabular}

In this excerpt, we see that Ashod displayed evidence of engaging in a conceptual thought process about the meaning of his answer, because he was able to explain that other amounts of fencing are possible, but that his answer pertained to the least amount of fencing. His mention that other amounts of fencing are possible is what allowed us to label him as using a conceptual thought process, because this indicated that he was thinking about the the relationship of his answer to the context of the problem. By contrast, he only displayed evidence of a pseudoanalytical thought process about the process of finding the critical value, because his only explanation for why he set the derivative equal to zero was, "I believe that's the least cause that's when it was zero, so that's the least amount it could possibly be." This explanation does not have any valid mathematical basis, and is simply a restatement that setting the derivative equal to zero gives the least amount - somehow. 
Summary of Ashod's Interview Data. Overall, Ashod's responses were almost completely indicative of pseudo-conceptual and pseudo-analytical thought processes. For example, he chose how to construct his optimizing function using a "cheat sheet" and could only explain the reason for using the derivative to solve the problem by saying that when the derivative is zero, he will have the least or most amount - he could not explain why this was the case. Again, we remind the reader that Ashod solved the problem correctly. His written work would have received full credit on an exam, yet from his verbal explanations, we see a different story.

\section{Summary of the Results of Analyzing Transcripts from All Seven Students}

Here we present the results of analyzing all seven student responses to the Garden Problem using the Optimization Problem-Solving Framework. The goal here is two-fold. First, we give insight into students' thought processes while solving optimization problems in first semester calculus. Specifically, we describe how the students engage in conceptual and analytical thought processes while solving the problem, we identify the phases of the problem solving framework that are more likely to elicit pseudo-conceptual and pseudo-analytical thought processes, and we highlight barriers that prevent students from transitioning from pseudoconceptual and pseudo-analytical thought processes to the desired conceptual and analytical thought processes. Second, we demonstrate how the Optimization Problem-Solving Framework can be used to analyze students' optimization problem-solving activities. Below we have divided the results into four sections, corresponding with the four phases of the Optimization ProblemSolving Framework. For each phase, we will present a table summarizing the responses of all seven students and then highlight key findings from the table.

\section{A Note About Lars and Tracy}


Lars and Tracy were unable to solve the optimization problem without intervention, because they could not figure out how to construct the optimizing function for the problem. They both made statements indicating that they knew what steps they would take once the function was constructed, but they were unable to get to this point on their own. In lieu of ending the interview at this point, we chose to intervene and help the students determine how to construct the optimizing function. The intervention included asking questions about the goal of the problem, what equations were related to the goal of the problem, and how their comments about differentiating the function once constructed were related to these ideas. Eventually, both students determined how to construct the optimizing function and then proceeded to solve the problem. For the data analysis below, we analyzed their responses prior to the intervention for the orienting and planning phase, and then analyzed their responses after the intervention for the executing and checking phase.

\section{Orienting Phase}

The first step to solving an optimization problem is determining the goal of the problem and assembling equations that will be helpful for working towards that goal. Components $\mathrm{C} 1$ and $\mathrm{A} 1$ address the goal of the problem, while $\mathrm{C} 2, \mathrm{C} 3, \mathrm{~A} 2$, and $\mathrm{A} 3$ address the need for and the construction of specific equations related to the goal. In the Garden Problem, the goal of the problem is to determine how to design a garden using the least amount of fencing. The related equations are $P=2 x+y$ (representing the quantity to be maximized or minimized) and $200=$ $x y$ (representing the constraint).

Looking at Table 21, we see that our students used pseudo-analytical and pseudoconceptual thought processes frequently during the orienting phase of the problem-solving process. Only two students, Lars (S4) and Brandi (S6) used conceptual and analytical thought 
processes throughout the entire orienting phase. Franz (S1) and Ashod (S5) did not show

evidence of using conceptual or analytical thought processes at any point during the orienting phase, and the other students demonstrated a mixture of both kinds of thought processes. In this phase, each conceptual component can be paired with an analytical component, because they address the same ideas. The pairs are C1-A1, C2-A2, and C3-A3.

Table 21. Orienting Phase Summary

\begin{tabular}{|c|c|c|c|c|c|c|c|}
\hline Orienting Phase & S1 & S2 & S3 & S4 & S5 & S6 & S7 \\
\hline $\begin{array}{l}\text { C1. The goal of the problem is to determine how to maximize or } \\
\text { minimize some quantity }\end{array}$ & $\mathrm{PC}$ & $\mathrm{C}$ & $\mathrm{C}$ & $\mathrm{C}$ & $\mathrm{PC}$ & $\mathrm{C}$ & $\mathrm{PC}$ \\
\hline $\begin{array}{l}\mathrm{C} 2 . \text { We are interested in the quantity to be maximized or } \\
\text { minimized }\end{array}$ & $\mathrm{PC}$ & $\mathrm{C}$ & $\mathrm{PC}$ & $\mathrm{C}$ & $\mathrm{PC}$ & $\mathrm{C}$ & $\mathrm{PC}$ \\
\hline C3. The constraints given in the problem must be considered & $\mathrm{PC}$ & PC & PC & $\mathrm{C}$ & $\mathrm{PC}$ & $\mathrm{C}$ & C \\
\hline $\begin{array}{l}\text { A1. We need equations to relate the variables to the goal of the } \\
\text { problem }\end{array}$ & PA & A & A & $\mathrm{A}$ & PA & A & PA \\
\hline $\begin{array}{l}\text { A2. We need an expression for the quantity to be } \\
\text { maximized/minimized }\end{array}$ & PA & A & PA & A & PA & A & PA \\
\hline A3. We need an expression for the constraint(s) & $\mathrm{PA}$ & PA & PA & $\mathrm{A}$ & PA & $\mathrm{A}$ & PA \\
\hline
\end{tabular}

Primarily PC/PA. Franz (S1) and Ashod (S5) were identified as using pseudoconceptual and pseudo-analytical thought processes for the entire orienting phase. The work on their paper was correct, but they could not provide any meaningful explanations for their actions during the orienting phase. Franz continually explained his steps by saying things like "because we have to find $x$ now," and "I write it because when, like, you look at the stuff, when you want to make an equation, you use that. That's why." At one point he explained his work by saying that he had solved a similar problem previously and he was repeating the process he did the last time, a hallmark of pseudo-conceptual and pseudo-analytical thought processes. Ashod explained his choices of writing down perimeter and area by saying, "Well it's kind of like a little, like a cheat sheet for me. Usually when they ask for area, you'd have to use perimeter. Or if they give you the perimeter, I'd have to find it to use the area." Ashod relied on this area-perimeter 
heuristic to assemble the necessary equations for the problem, and could not give any other explanations for his choices.

Cy (S7) and Ashod (S5) focused on the key word "dimensions," suggesting that they believed the goal of the problem was to find the dimensions of a garden and leading us to label them as using a pseudo-conceptual thought process related to the goal of the problem. The problem asks for dimensions of the garden using the least amount of fencing, so they were not wrong to recognize the need to find dimensions, but other comments made by Ashod and $\mathrm{Cy}$ throughout the interview indicated that they were focusing entirely on finding dimensions and not focusing on the corresponding amount of fencing around the garden, which is the key idea. In choosing to write down the perimeter equation, Cy said he cared about perimeter, because "you're finding your dimensions which comes from perimeter." In other words, for Cy, the goal of the problem had very little to do with the amount of fencing. Rather, the equation for the amount of fencing was simply a tool for finding dimensions. Later, in the planning phase, we see that this confusion also influenced Cy's decision of how to construct his optimizing function.

Evidence of C/A. In contrast, Sam (S2), Tracy (S3), Lars (S4), and Brandi (S6) all clearly stated that the goal of the problem was to determine how to use the least amount of fencing. For example, Sam said, "I picked perimeter because I need to figure out how to use the least amount of fence," leading us to identify him as using a conceptual thought process to determine the goal of the problem and to recognize the importance of the quantity to be minimized. Additionally, he was labeled as using an analytical thought process to construct an equation to represent the amount of fencing. He was not labeled similarly for $\mathrm{C} 3$ and $\mathrm{A} 3$ which are related to recognizing the importance of and the need for an equation for the constraint in the problem, because the only reason he could give for writing down the area equation was that to 
solve an optimization problem, he needed two equations so he could create the "function of our problem." We also note that although Tracy (S3) was clear about the goal of the problem and attempted to assemble related equations, this did not translate to her being able to identify the quantities that would be useful for solving the problem or assembling their associated equations.

Further discussion about Cy. Cy's labels for C3 and A3 are interesting, because at a glance, they seem contradictory. He is labeled as using a conceptual thought process for C3, which states, "The constraints given in the problem must be considered," but is listed as using a pseudo-analytical thought process for A3, which states, "We need an expression for the constraint(s)." This is because he made it clear that he was thinking conceptually about the role of the constraints in the given situation by stating, "well, the area has to stay the same, so you can't compromise area to use even less fencing because that's just defeating the purpose. Then it would just be no fencing, because you'd have no area." However, when Cy chose to write down equations for area and perimeter, he said he was doing so because he "wouldn't know what other formulas to use really, in that situation, because area and perimeter seem to be old reliable when it comes to rectangular stuff." He also said that they were useful because they were "fairly easy to manipulate." Both of these comments clearly indicate that he was using pseudo-analytical and pseudo-conceptual thought processes for most of the orienting phase.

\section{Planning Phase}

The bulk of the hard work of solving an optimization problem occurs during the planning phase, and our data confirms that students are prone to pseudo-conceptual and pseudo-analytical thought processes during this phase (see Table 22). Components $\mathrm{C} 2, \mathrm{C} 3, \mathrm{C} 4, \mathrm{~A} 1$, and A2 are particularly interesting as only one student was identified as either conceptual or analytical for 
$\mathrm{C} 2, \mathrm{C} 3, \mathrm{C} 4$, and $\mathrm{A} 1$, and no students were labeled as analytical for A2. We also draw attention to the components $\mathrm{C} 1$ and $\mathrm{A} 3$, which had mixed results.

Table 22. Planning Phase Summary

\begin{tabular}{|l|c|c|c|c|c|c|c|}
\hline Planning Phase & S1 & S2 & S3 & S4 & S5 & S6 & S7 \\
\hline $\begin{array}{l}\text { C1. A function can be used to model the situation described in } \\
\text { the problem }\end{array}$ & PC & C & I & C & PC & C & C \\
\hline C2. The function must represent the desired quantity & PC & PC & NE & NE & PC & C & PC \\
\hline C3. The function must address the constraint(s) & PC & PC & NE & C & PC & PC & PC \\
\hline $\begin{array}{l}\text { C4. The maximum or minimum of this function will be the } \\
\text { maximum or minimum for the desired quantity }\end{array}$ & PC & PC & NE & NE & PC & C & PC \\
\hline $\begin{array}{l}\text { A1. The functional value of the optimizing function must be } \\
\text { the quantity we are trying to maximize or minimize }\end{array}$ & PA & PA & NE & NE & PA & A & PA \\
\hline $\begin{array}{l}\text { A2. Determine how to construct the optimizing function so it } \\
\text { accurately models the scenario described in the problem - } \\
\text { particularly making sure the constraint(s) are considered }\end{array}$ & PA & PA & NE & NE & PA & PA & PA \\
\hline $\begin{array}{l}\text { A3. Determine how to find the absolute max or absolute min } \\
\text { of a function (take the derivative, set equal to zero, solve for } \\
\text { critical value) }\end{array}$ & PA & A & I & I & PA & A & A \\
\hline
\end{tabular}

C - Conceptual, PC - Pseudo-Conceptual, A - Analytical, PA - Pseudo-Analytical

$\mathrm{NE}$ - No Evidence, I - Indeterminable

$\mathrm{S} 1=$ Franz, S2=Sam, S3=Tracy, S4=Lars, S5=Ashod, S6=Brandi, S7=Cy

Tracy and Lars. For Tracy (S3) and Lars (S4), we see labels of NE for several components of the thought processes associated with the planning phase. This is because both Tracy and Lars were unable to determine how to solve the optimization problem and therefore did not do much relevant planning. In order to be labeled as using pseudo-conceptual and pseudo-analytical thought processes, the students needed to demonstrate the correct actions without complete thought processes to back them up. Because Tracy and Lars were not able to complete the correct actions, they were categorized as showing no evidence of the indicated thought processes at all. 
Tracy (S3) wrote the equation minimize materials $=2 x+y$ for amount of fencing and the equation $A=y \cdot x$ for area, and then stated, "And this is where I get stuck every time, because I can never figure out how to find $y$ and $x$. Like, how to find where $y$ equals $x$. And my best guess here is to just do 200 equals $y$ times $x$ and then..." She trailed off, clarified that she meant " $y$ in terms of $x$ " when asked to repeat herself, and then stated, "So I would probably just have to make $y$ equals 200 over $x$." In these few lines, we see her indicate that she was "stuck" and could not "figure out how to find $y$ and $x$." Her uncertainty about how to proceed left her without a path forward, so she conjectured that using the area equation to solve for $y$ might work. This was a good start, but in the next excerpt, we see that as she makes a plan to use it and imagines how it would work, she discovers a problem. She attempted to plug the expression $y=$ $\frac{200}{x}$ back into the area equation (even though she had just derived it from that equation), saying “So area of $x$, area in terms of $x$ would just be 200 over $x$ times $x$. I don't, if, I don't think you can do that can you?" Asked what would happen if she did that, she said, "You can't plug in area again, it's going to go in a circle. So, I messed up." She subsequently discussed a few other approaches she could try, but each time concluded the approach would not work. Her approach here is in line with the conjecture-imagine-evaluate cycle that Carlson and Bloom (2005) include in the planning phase of their framework.

Tracy's (S3) thought processes were helpful in the sense that she tried a few different approaches, but for the purpose of the framework, she was not labeled as engaging in conceptual, analytical, pseudo-conceptual, or pseudo-analytical thought processes for most of the components of the planning phase, because for each of these classifications, the correct work must still be present. Tracy was never able to achieve correct work, with or without good 
explanations. Similarly, Lars (S4) also was unable to arrive at correct answers without intervention, but engaged in several cycles of conjecture-imagine-evaluate.

Recognizing the need for a function. To be labeled as using a conceptual thought process for $\mathrm{C} 1$, the students needed to demonstrate that they were intentionally trying to model the situation with a function. They did not need to be correct about how they were modeling the situation in the problem, because other components of the thought processes (i.e. P.C2 and P.C3) deal with that, but they did need to be striving to use a function to model the situation somehow. Franz (S1) and Ashod (S5) both constructed an optimizing function and referred to it as a function, but neither of them gave an indication of thinking of it as modeling the situation and were therefore labeled as thinking pseudo-conceptually. They indicated that they were constructing the function because it was how they had learned to solve optimization problems, and they did not have any other reasons. In contrast, Lars (S4) was unable to determine how to solve the optimization problem, but he began by stating, "I need to find, like, if this was a graph of the different values that $x$ could be, I need to find where the perimeter, the whole thing itself, the perimeter is the least it could possibly be and still have this area." So, although he experienced cognitive conflict as he proceeded, he began with a conceptual thought process about the need for a function to model the problem, taking the constraints into consideration.

Range of the function. Conceptual component $\mathrm{C} 2$ and analytical component $\mathrm{A} 1$ were designed to target the students' thought processes about the range of the optimizing function they were constructing. To solve an optimization problem one must construct a function modeling the situation, which means the range of the optimizing function must be the quantity to be maximized or minimized. We see that only one student, Brandi (S6) was identified as using a conceptual thought process for $\mathrm{C} 2$ and an analytical thought process for A1. She stated, "You 
want the dimensions of this that require the least amount of fencing. So you want the minimum amount for each side. So you want to find an equation for the perimeter and find the min of it."

Except for Tracy (S3) and Lars (S4), who were addressed above, all of the other students were identified as using pseudo-conceptual and pseudo-analytical thought processes pertaining to this idea. Ashod (S5) and Cy (S7) both developed a heuristic to help them know what the optimizing function should be. Cy said, "Whatever has the constant gets rearranged, whatever doesn't have the constant in it gets differentiated." Ashod said, "Whatever they give you, use the other equation, so that's what I did. So I used perimeter." Franz and Sam (S2) could not give any explanations for their choices of what to differentiate. Sam said, "I'm not sure why, you know?" Franz dodged the question every time by going back to his drawing and explaining why his equation for perimeter was $2 x+y$ instead of $2 x+2 y$. It was clear from his responses that he did not have an answer for the question and was therefore redirecting and focusing on something he was able to answer.

Role of the constraints. In addition to being unclear about the range of the optimizing function they were constructing, the students in this study demonstrated difficulty with the role of the constraints in constructing the optimizing function (see C3 and A2). Two students were identified as using a conceptual thought process related to $\mathrm{C} 3$ and none of the students were identified as using an analytical thought process related to A2. Because these are related, one might expect identical labels for both components, but as we will see in the case of Cy (S7), it is possible to think conceptually about an idea without thinking analytically about how to use it in the problem-solving process.

As stated during our discussion about the Orienting Phase, Cy (S7) thought conceptually about the role of the constraints, stating, "well, the area has to stay the same, so you can't 
compromise area to use even less fencing because that's just defeating the purpose. Then it would just be no fencing, because you'd have no area." He was clearly thinking about the role the fixed area played in the problem. However, when he was deciding how to construct his optimizing function, he did not think of considering this constraint. Instead, Cy said he used area because it had a constant in it, so it could be "rearranged" and plugged into the other equation to give him a function of one variable. He could not give further explanation for his decision to do this, which is why he was identified as using a pseudo-conceptual and pseudo-analytical thought process related to using the constraint for his optimizing function. Similarly, Lars (S4) gave a conceptual explanation of the role of the area in determining how to construct the garden, but he could not figure out how to use it to construct a function, leaving him labeled as showing no evidence of adequately engaging in the analytical thought process.

Cy's (S7's) explanation of rearranging the equation with a constant in it is an example of a heuristic used by students when engaging in pseudo-analytical thought processes related to the constraints of the optimizing function. Several of the other students made similar statements. To be classified as using an analytical thought process for A2, it needed to be clear from the student's responses that he or she was attempting to model the scenario described in the problem, especially incorporating the fact that the area of the garden must be $200 \mathrm{ft}^{2}$. While most of the students used the area equation to construct their function, they did not demonstrate evidence of doing so with the goal of accurately modeling the scenario described in the problem. Brandi's reasoning centered around constructing a function of only one variable. She explained, "The purpose of this is to find the minimum of the amount of fencing. And in order to do that, I would only need one variable." Constructing a function of only one variable is a by-product of constructing a function modeling this particular scenario, but is not the goal. Other, more 
complicated optimization problems may require a multivariable function to accurately model the situation.

Tracy (S3) was labeled with NE or I for every component of the planning phase because she was unable to correctly construct an optimizing function without intervention. When she began attempting to construct an optimizing function, she wrote down an equation for amount of fencing (writing minimize materials $=2 x+y)$ and an equation for area $\left(A=200 f t^{2}\right.$ and $A=y x)$. After writing these equations she said, "And this is where I get stuck every time, because I can never figure out how to find the $y$ and $x$. Like, how to find where $y=x$." Her continued explanations indicated that she knew she needed to isolate a variable and plug that expression into another equation (the result of considering the constraints), but she had trouble figuring out how to do this. Her mention of getting "stuck every time" confirms that her difficulty in this phase of solving the Garden Problem during the interview was representative of difficulties she typically had while solving other optimization problems.

Finding the absolute maximum(s) or minimum(s). Prior to learning how to solve optimization problems, the students had learned how to find maximums and minimums of functions. Analytical component A3 was designed to capture students' thought processes for planning how to find the maximum(s) or minimum(s) of the optimizing function. To be identified as engaging in an analytical thought process here, the students needed to give correct mathematical explanations for their plan. Franz (S1) and Ashod (S5) were labeled as engaging in pseudo-analytical thought processes. When asked to explain, Franz said, "It's a standard thing that we do," and continued on to say, "Like, I know that's how I did it, so it will be that way." Ashod said, “There is a reason, I just probably can't think about it now.” In contrast, see this excerpt from Sam's interview: 
Sam: The P prime will tell me the derivative of the function which I can, uh, plug into zero, or make equal to zero to find points that make it, uh, not exist or equal zero.

Int: Why equal zero? What's the zero have to do with it?

Sam: Well, equal zero, it'll be, uh, max or min values.

Interviewer: Ok. Why?

Sam: Cause that'll be where the slope equals zero on the original function.

Sam's response includes a clear, mathematical explanation of why he plans to take the derivative of the function and set it equal to zero, so he was identified as using an analytical thought process for A3.

In addition to their many labels of NE, Tracy (S3) and Lars (S4) received labels of I for A3. Tracy was labeled with an I for this component because she gave contradictory responses. At the beginning of the interview she said she was taking the derivative of area and wasn't sure why. She gave up on trying to solve the optimization problem, but before doing that she said, "the best I can figure out of that is finding the critical values in the derivative would help you find the minimums because you look at areas of increase and decrease." Later, after some intervention helped her determine how to construct the optimizing function, she continued on to the solve the problem. She was asked why she set the derivative equal to zero, and she said, “Doesn't it have a horizontal tangent line?" The phrasing of both of these responses indicate a degree of uncertainty in her responses, even though they are correct. Coupled with her initial approach of taking the derivative of area with no reason why, we could not classify her as using an analytical thought process. Likewise, classifying her as using a pseudo-analytical thought process would not be appropriate either. For this reason, she was labeled with the letter I - to indicate that it is not possible to categorize her either way. Lars was categorized the same way 
because he began using the correct procedure, which would have had him labeled as engaging in a pseudo-analytical thought process, but then he scratched it out, thinking it was incorrect.

Interpreting the answer. Conceptual component $\mathrm{C} 4$ states, "The maximum or minimum of this function will be the maximum or minimum for the desired quantity." Although we would like this component of the conceptual thought process to be used implicitly during the planning phase, it was typically not until later in the interview that we were able to assess whether the students were able to engage in this thought process or not.

After constructing his optimizing function, Sam (S2) stated that he was unsure how this function related to the context of the problem. He said he was having trouble figuring out "how taking the derivative and finding a minimal number for the function... I'm trying to think how that, how that means that it's going to be a minimal value of how much fence you need." The function he had constructed no longer looked like his equation for the amount of fencing, $P=2 x+2 y$ (he forgot to exclude fencing along the barn), and so he wasn't sure how the function or the critical value was related to the amount of fencing.

Brandi (S6) was the only student who showed evidence of thinking about this idea conceptually, continually mentioning that she was trying to find the minimum amount of fencing and saying that when she found her answer, she could use that dimension to find the other dimension of the garden and that would give her the minimum amount of fencing. The other students in the study either did not give any indication of appropriately thinking about the connection between the minimum of the function and the context of the problem or were unable to find the answer (in the case of Tracy (S3) and Lars (S4)).

\section{Executing Phase}


There are only two components to the Executing Phase of the Optimization ProblemSolving Framework, and both are related to the analytical thought process the students use to algebraically solve the optimization problem. All of the students demonstrated evidence of engaging in analytical thought processes while doing the algebraic work of solving the problem, and all but Franz (S1) demonstrated evidence of analytical thought processes while solving for the other unknown value.

Table 23. Executing Phase Summary

\begin{tabular}{|l|c|c|c|c|c|c|c|}
\hline Executing Phase & S1 & S2 & S3 & S4 & S5 & S6 & S7 \\
\hline A1. Use algebra to solve for the critical value & A & A & A & A & A & A & A \\
\hline A2. Solve for other unknown values as specified by the problem & PA & A & A & A & A & A & A \\
\hline
\end{tabular}

C - Conceptual, PC - Pseudo-Conceptual, A - Analytical, PA - Pseudo-Analytical

NE - No Evidence, I - Indeterminable

$\mathrm{S} 1=$ Franz, S2=Sam, S3=Tracy, S4=Lars, S5=Ashod, S6=Brandi, S7=Cy

To be identified as using a pseudo-analytical thought process for A1, the students would have needed to make algebraic errors, or make comments indicating that they were not clear about how to solve equations using algebra. None of the students provided any evidence of this. All of them were proficient at solving the equation once it had been set equal to zero, although a few made minor errors. These errors were not deemed to be indicative of anything except inattention to detail, which could be partially attributed to the presence of a video camera and an interviewer. The students quickly caught and corrected the mistakes when asked about them. We expect that the number of students who would be labeled as using analytical thought processes for the executing phase would decrease if the optimization problem involved more complicated algebraic techniques. The Garden Problem was chosen partly because it had simple algebra, which eliminated some of the difficulty of solving the problem. We hypothesize that future research about optimization problems involving more complicated algebra would yield different results. 
All but one of the students were identified as engaging in analytical thought processes while solving for the other unknown value in the problem. Lars (S3) was identified as engaging in an analytical thought process for A2, explaining, "If $x=10$, then these sides would equal ten so the $y$ would have to equal 20." It was clear from the context of this quote that he was using the fact that the area of the garden had to be $200 \mathrm{ft}^{2}$. All of the other students except Franz gave similar responses.

Franz (S1) knew he should use his critical value, $x=10$ to solve for the other side length, $y$, but did not know how to do this. Initially, he set the equation for perimeter equal to zero (writing $2 x+y=0$ ) and then plugged $x=10$ in for $x$. When that gave him a negative value for $y$, he tried again and correctly plugged $x=10$ into the equation for area, $x y=200$. When he was asked how he knew the second approach was correct, he said, "It works. I remember it." When pressed to explain further, he could only explain that he remembered this was the right way to do it, thus, he was identified as using a pseudo-analytical thought process for A2.

\section{Checking Phase}

All of the students except Franz showed evidence of using analytical and conceptual thought processes during the checking phase, as we can see in the following table. Conceptual component $\mathrm{C} 1$ states that the students should "Recognize that there are many scenarios that correspond to the problem, but the goal is to find the optimal solution." This component was designed to address the fact that students may be tempted to think of an optimization problem as static, rather than dynamic. By this, we mean that solving an optimization problem means constructing a function to model a situation, rather than constructing an equation to be solved. Eventually, an equation is solved (setting the derivative equal to zero), but the meaning of the 
answer should be thought about in terms of the function. The answer represents the best of many scenarios meeting the constraint(s) of the problem. While we deemed this an important part of the solution process, our protocol was not designed to examine this portion of the phase closely. Hence, our data for $\mathrm{C} 1$ in this phase is limited, and we suggest future studies focus on this phase of the problem-solving process. Below, we discuss the results of this somewhat limited data.

Table 24. Checking Phase Summary

\begin{tabular}{|c|c|c|c|c|c|c|c|}
\hline Checking Phase & S1 & $\mathrm{S} 2$ & $\mathrm{~S} 3$ & S4 & S5 & S6 & S7 \\
\hline $\begin{array}{l}\text { C1. Recognize that there are many scenarios that correspond to the } \\
\text { problem, but the goal is to find the optimal solution }\end{array}$ & I & I & I & I & $\mathrm{C}$ & $\mathrm{C}$ & I \\
\hline C2. Understand the connection to the graphical representation & NE & $\mathrm{C}$ & $\mathrm{C}$ & $\mathrm{C}$ & $\mathrm{C}$ & $\mathrm{C}$ & $\mathrm{C}$ \\
\hline A1. Verify that the answer makes sense & NE & A & A & A & A & A & A \\
\hline $\begin{array}{l}\text { A2. How to use the first or second derivative test (or some other } \\
\text { technique) to verify that the answer occurs at a max or min }\end{array}$ & NE & A & A & A & A & A & \\
\hline
\end{tabular}

In Paper 3 we have an in-depth discussion about the connections students are able to make between the graphical representation of the optimizing function and their algebraic work. In this paper, we are only discussing the graphical representation in connection to the checking phase when the students are verifying that they have a maximum or minimum. Component $\mathrm{C} 2$ states, "Understand the connection to the graphical representation," but in this case, we are only interested in whether the students can explain in mathematically correct terms how they are verifying that their answer corresponds to a maximum or minimum. We are looking for descriptions that involve the slopes of tangent lines, specifically a horizontal tangent line at the critical value, a decreasing function on one side and an increasing function on the other side. Thus, in Paper 3, we see the students having a lot more difficulty with the graphical representation of the optimizing function than we do in this paper, because in Paper 3, we expand 
the meaning of "graphical representation of the optimizing function" to include things like the labels of the axes and the meaning of an ordered pair on the function.

All of the students but Franz (S1) verified that their critical value made sense for the problem by using the first derivative test to check their answers, and each gave a mathematically correct explanation of why the first derivative test works. This led to all of them being identified as using conceptual and analytical thought processes for C2, A1, and A2. As an example, Lars (S4) said, "So because of the switch at the point, 10, you know that is at least a local minimum." When asked how the derivative corresponded to the function increasing or decreasing, he said, "The derivative of the function gives you the slope of the original function." While he didn't make the distinction that the derivative corresponds to the slope of the tangent line at each point on the original function, this explanation was satisfactory enough for our purposes to label him as engaging in an analytical thought process.

Franz did not do anything to check his answer at all and did not even remember it was something he should do when he was specifically asked how he knew his answer was correct. He said, "I have no idea. I just know it's the minimum." He continued on to explain that he was repeating a procedure he had done in class, and said, "I think most students probably feel that way. Like, the way we did it, it will be the right way."

\section{Discussion and Conclusion}

We see from the data above that the goal of an optimization problem is not always clear for students and that it is tempting for students to rely on heuristics when assembling necessary equations, rather than thinking carefully about the need for the equations to achieve the goal of the problem. For many students, the planning phase is the portion of the optimization problemsolving process when they were most prone to rely on pseudo-conceptual and pseudo-analytical 
thought processes. Comments from Cy (S7) and Ashod (S5) are representative of how many of the students approached the planning phase, including determining which equations to use and how to construct the function for solving the problem. Cy said, "whatever has the constant gets rearranged, whatever doesn't have the constant in it gets differentiated." Similarly, Ashod said, "I just always learned that, um, if you want to find the least or the most amount, you would find two equations that make sense and would equate to each other in the problem, and whatever they give you, use the other equation. So that's what I did."

In line with the results from White and Mitchelmore (1996), we found the students competent during the executing phase of the problem-solving framework. The students were mostly clear about the reasons for their analytic procedures. We expect that students might have more difficulty during this phase if the algebra were more complicated, but for this problem, the students encountered little resistance.

For the Garden Problem, the majority of students were comfortable verifying that their answer made sense in the context of the problem using mathematically sound reasoning. Some optimization problems, however, involve a closed interval domain, meaning the students must also consider endpoints when verifying their answers. Our study did not address these types of optimization problems, so future research is needed to expand our understanding of students' thought processes during the checking phase.

The goal of this paper was two-fold: first, to present and describe our theoretical Optimization Problem-Solving Framework so it can be used by others and second, to present the results of analyzing seven students' responses to solving a simple optimization problem using the framework. By analyzing the students' results using the framework we provided insight for those 
interested in understanding the ways students are prone to solving optimization problems and we provide further clarification on how the framework can be used to analyze data in the future.

Students can produce correct work for a simple optimization problem by relying almost entirely on pseudo-conceptual and pseudo-analytical thought processes, a disappointing reality for teachers. While this may serve the students well when solving a simple, straightforward optimization problem, it does not prepare them to solve more difficult optimization problems or to extend their knowledge, for example, to solving optimization problems involving multiple variables. Additionally, we see that it is possible for students to solve the optimization problem and write down a correct answer, without fully comprehending what the answer represents or how it is related to the context of the problem. This may allow the student to receive a good grade on a quiz or an exam, because he or she is able to write down the correct answer, but it does not suggest that the student will know how and when to use optimization problems when encountering them in real life or in other courses.

The biggest barriers preventing students from using conceptual and analytical thought processes while solving the Garden Problem were related to the idea that the optimizing function is constructed to model the situation described in the problem. Many of the students constructed a function representing the amount of fencing because it was the unspecified quantity in the problem, not because it pertained to the goal of the problem to minimize the amount of fencing needed. Additionally, most of the students used the area equation to construct their optimizing function because they had seen it done previously, could not think of any other relevant equations, or were trying to get the function to be a function of a single variable. By neglecting the role of the constraint in the problem, the students were missing the goal of the problem, which was to construct a garden with area $200 \boldsymbol{f} \boldsymbol{t}^{2}$ while using the least amount of fencing. 
Thus, their understanding of the answer to the problem was necessarily limited. In Paper 3, we discuss ways to use the graphical representation of the optimizing function to help students develop conceptual and analytical thought processes related to these ideas.

The Optimization Problem-Solving Framework illuminated the way students interpreted the problem, made a plan for solving, and eventually solved the problem. We see that, in line with the results of White and Mitchelmore (1996), the students were mostly able to carry out the steps of finding the absolute minimum of the optimizing function, once it was constructed. They encountered most of their difficulty while constructing the optimizing function, and even when they did not have difficulty constructing the function, their responses frequently indicated that they were not able to use conceptual and analytical thought processes to do so.

This study focused on a small number of students solving a simple optimization problem. We suggest future research focus on developing ways to analyze the responses of larger quantities of students, perhaps for a quantitative study, and on analyzing students' thought processes while solving more difficult optimization problems. This work is only the beginning phase of the work that needs to be done to better understand how students think and learn optimization problems in first semester calculus. 


\title{
PAPER 3: THE GRAPHICAL REPRESENTATION OF THE OPTIMIZING FUNCTION: THE MISSING LINK?
}

\begin{abstract}
Optimization problems help students bridge the gap between the techniques they are learning in their calculus class and real life situations. However, first semester calculus optimization problems tend to be very difficult for students. To solve optimization problems at this level, the students construct a function modeling the situation described in the problem (we call this the optimizing function) and then use previously learned calculus techniques to find the absolute maximum or absolute minimum of this function. In this paper we present students' responses when asked to consider the graphical representation of the optimizing function without labels or tick marks on the axes. In examining students' responses to this activity, we see that students often do not have as robust of a concept image of the optimizing function as we would hope. We use the results of this analysis to inform a series of teaching interventions described at the end of the paper that are designed to develop students' concept image of the optimizing function by considering its graphical representation.
\end{abstract}

Keywords: calculus, optimization, graphical representations

\section{Introduction}

Optimization problems in first semester calculus are notoriously difficult for students, but so far have received little attention from the research community. For our purposes, optimization problems are the word problems from first semester calculus that ask students to determine how to maximize or minimize a certain quantity under one or more constraints. To complete such a problem, students construct a function modeling the given situation (we call this function the optimizing function), find the optimizing function's absolute maximum or minimum, and use this 
information to answer the questions in the problem. Speer and Kung (2016) listed optimization as one of several calculus topics needing more research attention; our work aims to help fill that gap.

\section{Literature Review}

White and Mitchelmore (1996) report that students are more likely to be able to find the absolute maximum or minimum of a given algebraic function than they are to be able to interpret a word problem, construct an appropriate optimizing function, and then find its the absolute maximum or minimum. White and Mitchelmore (1996) attribute this to a weak concept image of variables, but their results also drew our attention to the importance of being able to construct the optimizing function, leading to our work in LaRue and Infante (2015) where we discuss mathematical concepts that play a role in students' concept images of the optimizing function.

There is a significant body of literature pertaining to students' understanding of functions (Breidenbach, Dubinsky, Hawks, \& Nichols, 1992; Dubinsky \& Harel, 1992; Sfard, 1992; Vinner \& Dreyfus, 1989). Of particular interest in this paper is the students' ability to move between the graphical and algebraic representation of a function. Even though the graphical representation of a function can be very useful, students are often reluctant to consider it, and when they do, they frequently have trouble interpreting the information correctly (Arcavi, 2008; Eisenberg, 1992; Even, 1998; Knuth, 2000; Sfard, 1992).

In Paper 2, we describe our Optimization Problem-Solving Framework and use it to discuss seven students' thought processes while solving optimization problems. In this paper, we focus on three interesting aspects of interviews from this larger study that have only been briefly discussed elsewhere, and use these to frame a discussion about teaching interventions for optimization. 


\section{Theoretical Perspective}

We frame our discussion using Tall and Vinner's (1981) language of concept image to discuss students' concept images of the optimizing function. Additionally, we use Vinner's (1997) language of conceptual and analytical thought processes to discuss students' overall approaches to solving optimization problems.

Tall and Vinner (1981) define concept image as "all the cognitive structure in the individual's mind that is associated with the given concept" (p. 1). This includes mental pictures, properties, processes, graphs, diagrams, symbols, pictures, or physical models the student associates with the concept (correctly or incorrectly). There are many components to a learner's concept image, and when the need for the concept image arises, the parts of the concept image that are directly related to the need are called upon. The part that has been activated is referred to as the evoked concept image. It is possible for the student to have conflicting information within his or her concept image, and if they are activated simultaneously, the learner experiences cognitive conflict.

Vinner (1997) uses the terms conceptual and analytical thought processes to describe the desirable thought processes used to solve math problems. In the case of optimization problems, we refer to conceptual thought processes as those related to the overall optimization problemsolving process, and analytical thought processes as those related to carrying out a specific step in the problem solving process. Students sometimes develop "simpler, easier, and shorter" processes, called pseudo-conceptual and pseudo-analytical thought processes to stand in place of true conceptual and true analytical thought processes (Vinner, 1997, p. 101). Sometimes these are used to alleviate the work the brain must do while attempting to quickly solve a problem, and other times these are used to avoid thinking deeply about underlying mathematical concepts that 
the student does not understand. Further detail about our use of Vinner's (1997) conceptual and analytical thought processes in the context of optimization problems can be found in Paper 2 .

\section{Methods}

The results presented here are part of a larger study about students' understanding of optimization problems in first semester calculus. Data was collected in the form of semistructured interviews with seven first semester calculus students (see Table 25). Four interviews took place during the summer semester of 2014 and the remaining three took place during the fall semester of 2014. All interviews took place at the end of the respective semester, just after the students had taken an exam covering optimization and just before their comprehensive final exam. During the interviews, the students solved two optimization problems, answered questions about functions, answered questions about the relationship between the area and the perimeter of a rectangle, and made connections between their algebraic work and a given graphical representation of the optimizing function while solving one of the two optimization problems. We call this the Blank Graph Activity because the shape of the graph was given, but nothing was labeled on the graph (i.e. axes, scale, maximum/minimum). The interviews were video recorded and transcribed for analysis.

Table 25. Summary of Participants

\begin{tabular}{|c|c|c|}
\hline Semester & Names & Majors Represented \\
\hline Summer 2014 & Franz, Sam, Tracy, Lars & Engineering (3), Psychology (1) \\
\hline Fall 2014 & Ashod, Brandi, Cy & Engineering (2), Biology (1) \\
\hline
\end{tabular}

Three optimization problems were used for the study (see Table 26). Q1 and Q2 were used during the summer semester and Q1 and Q3 were used during the fall semester. In the summer, students completed the Blank Graph Activity with their results from Q2, and in the fall, students completed the Blank Graph Activity with results from Q1. 
Table 26. Optimization Problems for the Study

\begin{tabular}{|l|l|}
\hline Q1 & $\begin{array}{l}\text { A rectangular garden of area } 200 \mathrm{ft}^{2} \text { is to be fenced off against rabbits. Find the } \\
\text { dimensions that will require the least amount of fencing if a barn already protects one } \\
\text { side of the garden. }\end{array}$ \\
\hline Q2 & $\begin{array}{l}\text { Suppose we want to maximize the volume of the rectangular box that can be constructed } \\
\text { from } 144 \mathrm{in}^{2} \text { of cardboard if the base is to be twice as long as it is wide. Assume that the } \\
\text { box has a top. Find the dimensions of the box and give its volume. }\end{array}$ \\
\hline Q3 & $\begin{array}{l}\text { Suppose we want to design a mold for bars of soap. The mold will be in the shape of a } \\
\text { semi-circle (like a halfmoon) and needs to hold } 10 \mathrm{oz} \text { of soap. Find the dimensions in } \\
\text { inches for the mold that will minimize the amount of packaging needed to cover the bar } \\
\text { of soap. Note: } 10 \mathrm{oz} \text { is equivalent to } 18.04 \text { cubic inches. }\end{array}$ \\
\hline
\end{tabular}

\section{Results}

Here we describe students' responses when comparing the graphical representation of the optimizing function to their algebraic work from the optimization problem. We focus on their responses pertaining to four things: the location of the critical value, labeling the axes, what ordered pairs of the function represent, and discovering usefulness of the graph. We will then use these results to frame our discussion about teaching interventions.

\section{The Graphical Representation of the Optimizing Function}

Students may not always consider the graphical representation of the optimizing function when solving an optimization problem; it is possible to solve an optimization problem and never consider the graphical representation. However, when presented with a graphical representation of the optimizing function they just constructed, students should be able to identify the important pieces of information about the graph. In particular, the students should be able to label the axes appropriately and identify the location on the graph that corresponds to the answer they just found. During the Blank Graph Activity, we picked one optimization problem and presented the students with a graphical representation of the optimizing function immediately after they solved the problem. We did not label the axes and adjusted the scale to make it easy to see the shape of 
the graph, particularly making it easy to identify the absolute maximum or minimum. The axes were blank, with no labels or tick marks to indicate the scale. The students were then asked to label any important information on the graph using their work from the optimization problem if needed. This task was challenging for most of the students, and we discuss the results below.

\section{Special Cases - Sam, Tracy, Lars}

Sam, Tracy, and Lars spent a lot of time discussing the graph of the optimizing function early in the interview - before they were presented with the Blank Graph Activity. Thus, by the time they were presented with the Blank Graph Activity, they had already spent time making sense of the graphical representation of the optimizing function and had figured out how to connect it to their algebraic work.

Two of these students, Lars and Tracy, were unable to solve the first optimization problem and required intervention, which was a decision made by the interviewer to continue eliciting information from the students, instead of terminating the interview. Part of that intervention involved the students thinking carefully about the graphical representation of the optimizing function and using it to help them determine how to solve the problem. Both of these students eventually determined that the function needed to represent the quantity to be maximized or minimized and that they could find the maximum or minimum by finding the location where the function had a horizontal tangent (where the derivative is zero).

The third student who spent a lot of time discussing the graph of the optimizing function early in the interview was Sam. He was able to solve the first optimization problem, Q1, but continually expressed discomfort with the realization that he did not understand how finding the minimum of the optimizing function corresponded to finding the minimum amount of fencing asked for in the problem. His responses as he tried to explain this discomfort eventually led to 
him considering the graphical representation of the optimizing function and attempting to connect his algebraic work to the graphical representation. At the end of the activity, Sam decided that each ordered pair of the optimizing function corresponded to a way to construct a rectangle with an area of $200 f t^{2}$ and that the goal of the optimization problem was to determine which way required the least fencing.

In the following sections, we examine Lars's, Tracy's, and Sam's responses when they initially considered the graphical representation of the optimizing function, instead of only considering their responses when they were officially presented with the Blank Graph Activity. This will give us insight into their views of the graphical representation of the optimizing function before the interventions.

\section{Critical Value}

The students were asked to label any important information on the graph. If they did not voluntarily mark and label the critical value on the graph, they were asked to do so. Three students completed this task with ease, while the other four had difficulty. See Table 27 for a summary of these results.

The students had just completed the optimization problem when they were presented with the graph. It is not necessary to think of the graphical representation of the optimizing function to solve an optimization problem, but if a student is able to think conceptually and analytically about the role of optimizing function in solving the problem, placing the critical value on the graph correctly should not be a challenge. Incorrect responses when placing the critical value on the graph suggest the students were using pseudo-conceptual and pseudo-analytical thought processes when solving the optimization problem. If the students were clear about the domain and range of the optimizing function, the goal of the problem, and what their answer meant, it 
would be obvious that the value they found corresponded to the lowest or highest point on the graph.

Table 27. Critical Value Summary

\begin{tabular}{|c|c|c|c|c|c|c|c|}
\hline Student & Franz & Sam & Tracy & Lars & Ashod & Brandi & Cy \\
\hline Response & Incorrect & Correct & Correct & Correct & Incorrect & Incorrect & $\begin{array}{c}\text { Correct (with } \\
\text { hesitation) }\end{array}$ \\
\hline
\end{tabular}

Sam, Tracy, and Lars all placed the critical value on the graph correctly. Although Tracy and Lars had trouble constructing an optimizing function for the first optimization problem, they both knew that once they did, their answer would correspond to the maximum or minimum of the function. Likewise, Sam was confused about the connection between the optimizing function and the goal of the optimization problem, but he was very clear about the connection between the graph of the optimizing function and the algebraic work he was doing.

Ashod, Brandi, and Franz all placed the critical value on the appropriate axis, but did not place it below the absolute maximum or minimum of the function (see Figure 2).
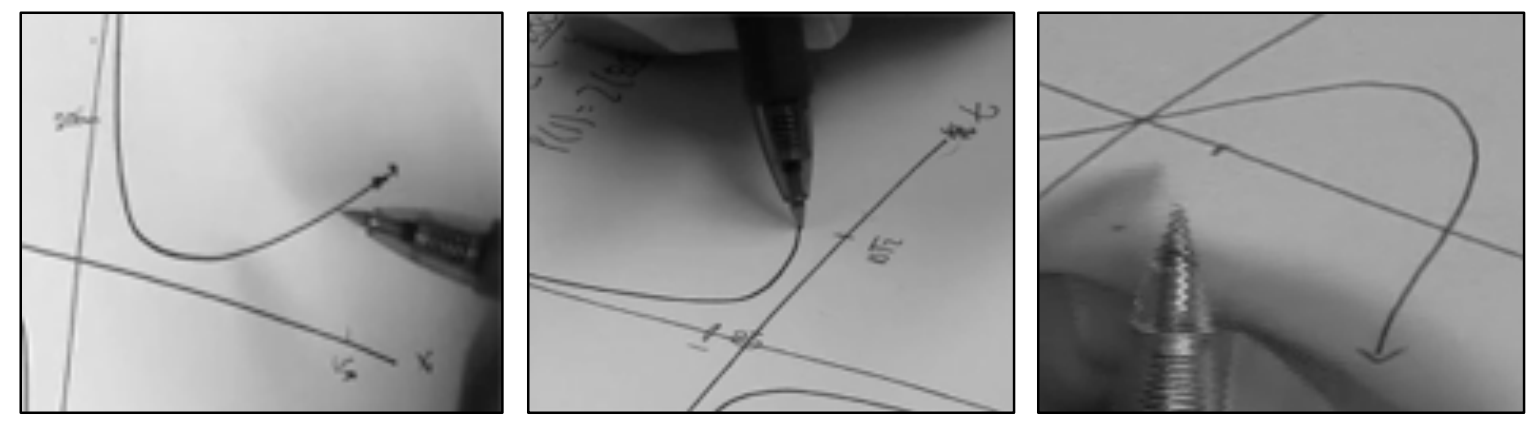

Figure 2. Ashod, Brandi, and Franz (in order) mark the location on the graph where they believe the critical value belongs. Note that all three students placed the mark somewhere other than below the obvious maximum or minimum.

All three of these students decided where to place their critical values on the graph by imagining a scale for the horizontal axis and approximating the location where the critical value would fall, based on their imaginary scale. They did not consider the shape of the graph or any of its other 
features, nor did they consider how or why they found the critical value in the first place. Franz and Brandi corrected their mistakes after they were pushed to discuss their decision further, but Ashod did not.

Ashod marked his critical value, $x=\sqrt{200}$, on the horizontal axis, traced this value up to the graph and over to the vertical axis, and then marked the functional value on that axis. His critical value was far to the right of the graph's minimum (see Figure 2). He explained there was no other way to determine where to put his answer on the graph, because he had found the answer $x=\sqrt{200}$ using the derivative, and the graph he had been given was of the original function. Through this response, we see that Ashod's concept image of the optimizing function lacked the conceptual knowledge that would help connect the critical value to the original optimizing function. His responses point to use of pseudo-conceptual and pseudo-analytical thought processes when algebraically solving the optimization problem.

Franz and Brandi also placed their critical value on the graph by guessing where it would fall on the horizontal axis. Unlike Ashod, when they were asked to explain what the critical value represented, they corrected their mistakes. Brandi said, "The ten square root of 2 is your critical number of the perimeter of this - well it's supposed to be one of them." She realized she had placed her critical value in the wrong location, and said, "The critical number is where your slope is equal to zero. So, ten square root of two would really be somewhere right there.” This quick realization indicates that Brandi was able to engage in conceptual and analytical thought processes when needed.

In contrast, Franz did not realize his mistake immediately. See this excerpt from the transcript:

Int: What was the original question asking? 
Franz: It was finding the maximum volume

Int: The maximum volume.

Franz: Yeah

Int: Ok. So how does that relate to the picture?

Franz: I don't know. I think it's because of the local maximum. It might be.

Int: So would it make sense for $2 \sqrt{3}$ to be right here?

Franz: No, I don't think so. I think it would have to be here because we find the maximum right?

Franz eventually realized his mistake, but he was still hesitant, and, unlike with Brandi, it was not immediate. He required direct questioning from the interviewer to reach the same conclusion.

Cy correctly placed his critical value on the horizontal axis below the minimum, but he was extremely hesitant about it. As he continued to think about it, he said he thought it might be wrong. Like Ashod, he said he was confused because he had solved for the critical value using the derivative, not the original function, and he was not sure his final answer was related to the graph of the original function at all. To check, he decided to use algebraic techniques to find the minimum of the function, which is exactly what he had done to solve the optimization problem. After completing a few steps, he noticed he was doing the same work as before. He concluded that his answer would be the same and that he had been correct to place it below the minimum. His need to do this to convince himself, indicates either his concept image of the optimizing function did not have a graphical component or it was not evoked.

We see from these responses that there is the potential for a gap between students' ability to find the critical value of the optimizing function using algebraic techniques and their ability to interpret the meaning of that answer in the context of the problem. Until the students who did 
this incorrectly experienced cognitive conflict due to the misplaced critical value, they were not being attentive to the meaning of their answer. The act of placing the critical value on the graph and then explaining what the critical value meant and how it related to the graph helped these students solidify their understanding of the critical value in an optimization problem and how it relates to the graphical representation of the optimizing function. Asking the students to place the answer on the graph of the optimizing function helps reinforce the notion that the critical value they are finding corresponds to the least or greatest amount of the desired quantity.

\section{Labeling Axes}

The graph of the optimizing function the students were given was sketched on a pair of unlabeled axes, and the students were asked to label the axes with appropriate variables. Three students used variables that corresponded to their optimizing function, one student did not label the axes at all, and the other three students used variables that did not correspond to their optimizing function. See Table 28 for a summary of these results. In some instances, using variables that did not correspond to the optimizing function created cognitive conflict for the students because they used $x$ and $y$ for their axes in the traditional way, but also used $x$ and $y$ for unknowns in the problem with different relationships than the relationships between the variables in the optimizing function. The students' responses to this task revealed whether they were paying attention to what the optimizing function represented and whether they were able to figure it out if they hadn't been paying attention to it previously.

Table 28. Labeling Axes Summary

\begin{tabular}{|c|c|c|c|c|c|c|c|}
\hline Student & Franz & Sam & Tracy & Lars & Ashod & Brandi & Cy \\
\hline Response & None & Correspond & $\begin{array}{c}\text { Correspond } \\
\text { (hesitation) }\end{array}$ & $\begin{array}{c}\text { Do Not } \\
\text { Correspond }\end{array}$ & $\begin{array}{c}\text { Do Not } \\
\text { Correspond }\end{array}$ & $\begin{array}{c}\text { Do Not } \\
\text { Correspond }\end{array}$ & Correspond \\
\hline
\end{tabular}


Sam correctly labeled his axes to correspond with his optimizing function for Q1, labeling the horizontal axis as $l$ and the vertical axis as $P$. His interview indicated that he did not understand what it meant for the domain to be $l$ values and the range to be $P$ values as we will see in the next section, but he knew where the variables belonged on the axes. Franz did not label his axes at all, but referred to values on the horizontal axis as $x$-values and values on the vertical axis as $y$-values, even though his function was expressed as $V(w)$. Because all of his variables were different, referring to the two axes as $x$ and $y$ did not create any cognitive conflict for him.

Ashod, Brandi, and Cy all began by labeling their axes using $x$ and $y$, relying on the heuristic of the standard $x$ and $y$ axes (we call this the $x, y$ heuristic). Cy used the $x, y$ heuristic, but also wrote a note to himself in the corner of the graph stating $y=P$ to remind himself that the vertical axis corresponded to $P$, not to the $y$ he used to label his rectangle. Ashod and Brandi did not make such a distinction, and because they had also labeled the sides of their rectangle using $x$ and $y$, this created a potential for confusion between the variables used in the problem and the variables used to label the axes. Brandi experienced cognitive conflict due to this labeling, but Ashod did not.

Brandi initially had trouble labeling her axes, partially due to the $x, y$ heuristic and partially due to a miscommunication leading her to believe the graph corresponded to the area equation. Even after figuring out what the graph was supposed to represent, she left her axes labeled with $x$ and $y$ and tried to discuss the graph of the perimeter using these labels. She eventually resolved her cognitive conflict by changing the independent variable in her optimizing function to $t$ and relabeling her horizontal axis as the $t$-axis. She still hesitated about labeling the vertical axis, because she was uncomfortable labeling it with $P(t)$ or $P$. Tracy had a similar problem with Q2. The optimizing function she looked at graphically was $V(w)=\frac{144}{3} w-\frac{4}{3} w^{3}$. 
She labeled her horizontal axis with a $w$, and said, "Like $V(w)$ ? I mean. This would have to be w. I don't really know what to call that."

Functions are often presented to students as $f(x)=$ some expression. When such a function is graphed, the axes are typically labeled $x$ and $y$, not $x$ and $f(x)$ or $x$ and $f$. Thus, when presented with a situation where the letter $y$ could not be used for the vertical axis, Brandi and Tracy were unsure how to proceed. This highlights one of the ways optimization problems can provide opportunities for students to expand their mathematical knowledge, in this case by becoming more comfortable using variables in nonstandard ways.

While solving Q1, Lars drew a graph he believed to be related to the optimization problem. When asked what the axes would be, he said the horizontal axis would be a side length and the vertical axis would be area. When he was asked why he put area on the vertical axis, he said, "That's the other rate or variable that we're working with. Because we have the dimensions and the area. That's the two things we're working with." Notice he is not considering perimeter at all, even though the goal of Q1 is to minimize the amount of fencing around a garden.

Thinking further, he decided the other side length needed to be involved as well, so he changed his axes to $x$ and $y$ (the two side lengths for the garden). Here we see why Lars was having trouble determining how to solve the optimization problem. He did not know what the input and output values of the optimizing function should be, so without pseudo-conceptual and pseudo-analytical thought processes to help him remember how to solve an optimization problem, he was unable to solve the problem without intervention.

From these responses we see that having the students label the axes of the graph of the optimizing function can provide valuable insight into their thoughts about the meaning of the optimizing function. It can also provide an opportunity to push the students to think more 
carefully about the meaning of the optimizing function if they have developed pseudo-conceptual and pseudo-analytical thought processes for solving the optimization problem without thinking deeply about the steps involved.

\section{What Ordered Pairs of the Graph Represent}

Another important aspect of the graphical representation of the optimizing function is what it means for an ordered pair $(a, b)$ to belong to the optimizing function. As with labeling the axes appropriately, interpreting the meaning of an ordered pair of the optimizing function requires the student to know what the input and output values of the function are. In the case of the axes, the student must only attend to the overall behavior of the function. For example, in the case of Q1, the optimizing function takes in a side length and outputs an amount of fencing. To label the axes, the student does not need to think of anything beyond this. To interpret the meaning of an ordered pair, however, the student must be able to say that for a side length of $a$, the corresponding amount of fencing needed to enclose an area of $200 f t^{2}$ is $b$. The small difference between labeling the axes and considering the ordered pair is that accurately interpreting the ordered pair requires the student to describe how the constraint(s) are involved in the construction of the optimizing function. Only two students in this study were able to correctly discuss the meaning of an ordered pair contextually (see Table 29). Two students attempted to discuss the ordered pair contextually, but did so incorrectly. The other three students could only discuss the meaning of an ordered pair of the optimizing function by stating that $a$ was the input and $b$ was the output.

Table 29. Ordered Pairs Summary

\begin{tabular}{|c|c|c|c|c|c|c|c|}
\hline Student & Franz & Sam & Tracy & Lars & Ashod & Brandi & Cy \\
\hline Response & $\begin{array}{c}\text { Input, } \\
\text { Output }\end{array}$ & $\begin{array}{c}\text { Contextual } \\
\text { (wrong) }\end{array}$ & $\begin{array}{c}\text { Input, } \\
\text { Output }\end{array}$ & $\begin{array}{c}\text { Contextual } \\
\text { (wrong) }\end{array}$ & $\begin{array}{c}\text { Input, } \\
\text { Output }\end{array}$ & Contextual & Contextual \\
\hline
\end{tabular}


Franz, Tracy, and Ashod all had concept images for the optimizing function that included the fact that if an ordered pair $(a, b)$ belonged to the optimizing function, it meant that for the input value $a$, the output value was $b$, but they could not discuss the ordered pair using terms related to the context of the problem. These students' concept images for the optimizing function included an algorithm (a partial algorithm in Tracy's case) for constructing the optimizing function, but lacked information about how the function related to the context of the problem. We account for the difference between Tracy's response when labeling axes and when discussing the ordered pair by stating that one can use the appropriate letters to label the axes by looking at the optimizing function by using a pseudo-analytical thought process without considering the context of the problem or what the variables represent.

Brandi and $\mathrm{Cy}$, however, were both able to report that in the case of Q1, if the input value of the optimizing function was 20 , the output value would indicate the corresponding amount of fencing required to fence in an area of $200 \mathrm{ft}^{2}$.

Lars initially thought the minimum of the optimizing function for Q1 was an ordered pair $(x, y)$ - corresponding to the side lengths $x$ and $y$ - that somehow "crossed" the perimeter at the lowest possible value. After answering several guided questions intended to help him figure out how to solve the problem, he was able to solve the first optimization problem and then solve the second optimization problem, Q2, without intervention. After solving Q2, he correctly stated that an ordered pair of the function would indicate that if the indicated side length was the input value, the output value would be the volume of the box having that side length. In this case we see that the interventions, while unplanned, led him to develop his concept image of the optimizing function to include correct contextual explanations of the meaning of an ordered pair 
of the function. This unplanned divergence helped inform some of the teaching interventions below.

Sam's concept image of the optimizing function did not give him sufficient information to determine the output of his optimizing function for Q1. His optimizing function was $P(l)=$

$2 l+\frac{400}{l}$, which represented the perimeter of a rectangle with area $200 f t^{2}$ in terms of one of its side lengths, $l$. Although he was able to label the axes of his graph with $P$ and $l$, Sam repeatedly said this function would tell him the length of $l$. Specifically, when he was told to consider $P(2)$, he found $P(2)=204$ and explained that it tells him "what the $l$ is at 2." He said this repeatedly, also stating that $P(2)$ was the "length of $l$ " and "I could tell you at $P(2)$ what the lengths of this rectangle would be." As is discussed in detail in the next section, Sam used a pseudo-conceptual thought process to construct his optimizing function, and clearly did not know what this function represented or how it related to the goal of the problem. This is especially apparent because of his inability to correctly describe what an ordered pair on the function represents, confirming that this task can reveal a lot about the students' thought processes.

\section{Discovering the Usefulness of Considering the Graph}

There were no questions in the interview protocol to assess this, but some of the students voluntarily made comments about connecting the graphical representation of the optimizing function to their algebraic work. From these comments, we see that they were reluctant to consider the graphical representation on their own, and some of the students had not thought about the graphical representation at all before the Blank Graph Activity.

Overall, Ashod was not able to make any meaningful connections between the algebraic work of the optimization problem and the graphical representation of the optimizing function. $\mathrm{He}$ labeled his axes using the $x, y$ heuristic, and when he was asked if he could use any of his work 
to determine any other information about the graph, he said no, because the paper he had been given was a graph of $P$ (his optimizing function), but all of his work pertained to the derivative. He stated that the graph of the derivative would look completely different, so he didn't think any of his work corresponded to the original function at all. He concluded the interview by saying, "We actually haven't done like in terms of like graphing with optimization. We haven't compared those two yet. We probably will in the future." Recall that the interviews took place at the end of the semester, just before the final exam, so this was clearly not the case.

Cy drew a graph to briefly explain the technique of finding the minimum of a function, but did not refer to it as the graph of his specific optimizing function, instead choosing to refer to it as some function $f(x)$. Later in the interview, when he was asked to connect his work to the graphical representation of the optimizing function, he said, "It's weird to like make the jump from numbers into a graph sometimes. In some situations, the numbers are really just a stand in for the work I'm doing in my head with graphs, but in this situation, it's more, the numbers are all I really ever thought about with this." So, although he mentioned a graph of a function when explaining how to find the minimum of a function, he was only using this as a tool to understand why to take the derivative and set it equal to zero, and was not thinking of it as the optimizing function he had just constructed.

For Sam, the algebraic work was sufficient for finding the minimum or maximum of the optimizing function function, and he said he did not think he needed to think about the graphical representation, even though during the interview he recognized the connections. Sam said, "Without the word problem, the way you would do it is you just get a function, which would be a graph, and you take the derivative, and it's kind of like there's two parts of it. There's the graph 
version and there's just the numbers. So I think they're always related, even though sometimes you don't really need the graph version for this. You just need the equations.”

When Sam solved the first optimization problem, Q1, he knew he was finding the maximum or minimum of a function which could be considered graphically, and was using conceptual and analytical thought processes to explain why he was taking the derivative of the function and setting it equal to zero to find its maximum or minimum. However, he could not connect the function and its graph to the context of the problem. He said he was having trouble relating, "how fences matter with the slope of a graph." He used the perimeter equation to construct his optimizing function, but he could not make sense of the optimizing function after he substituted $\frac{200}{x}$ for $y$ in the equation $P=2 x+2 y$. After this substitution, which created the optimizing function, he no longer thought of the expression as relating to amount of fencing. Because of this, he could not determine why finding the minimum of the optimizing function helped him answer the question posed in the problem. With Sam we see a need to discuss the meaning of the ordered pair $(a, b)$ on the optimizing function. He answered this question incorrectly during the interview, but we see evidence suggesting that if he learned what the ordered pair meant, it would give him insight into the connections between the optimizing function and the context of the problem.

At the beginning of the interview, Brandi attempted to discuss the graph of the optimizing function at first by saying, "Cause like the amount of feet that could be used, if you think about it on the graph. Like if this certain amount can be used, there's higher numbers that could be lower. You just. Ok." Giving up this line of thought she said, "I'll just say this, you take the derivative because you want a minimum amount for your perimeter and if you take the derivative of this, you can find, um, a certain value for $y$, well, you get your critical numbers." 
She knew there was a connection to the graph, but clearly had not spent much time thinking about it before the interview, as was evidenced by some of her difficulties later in the interview.

\section{Discussion}

Despite the students having correct work written on their paper for the optimization problem, their work with the graphical representation of the optimizing function revealed significant gaps in the students' concept images of the optimizing function. Observing these gaps in the students' concept images revealed that students may be using pseudo-conceptual and pseudo-analytical thought processes while solving optimization problems more frequently than teachers would hope. Changes in assessment and instruction may be necessary to encourage students to develop conceptual and analytical thought processes for optimization problems.

Our data suggests that students may be unaware of what the optimizing function they are constructing during the problem-solving process represents and how their answer corresponds to the optimizing function and the goal of the problem. This was particularly apparent when the students were asked to label the location on the graph corresponding to the critical value they found while solving the problem, to label the axes of the graph of the optimizing function with appropriate variables, and to describe the meaning of an ordered pair of the function.

When labeling the axes to correspond to the variables in the optimizing function, the students need to think about the input and output of the optimizing function. However, we observe that heuristics for drawing and labeling graphs may hinder students' thinking about the graph of the optimizing function, particularly in the case when students define two variables in the problem (such as the two sides of a rectangle) using $x$ and $y$. The heuristic of labeling the axes of a graph with the variables $x$ and $y$ was very dominant for some of our students, demonstrating that pushing students to consider the graphical representation of the optimizing 
function, including labeling the axes with appropriate variables, provides the students an opportunity to develop their concept images and uses of variables.

Being unable to label the axes appropriately signifies that the students are not clear about the input and output values of the function they have constructed. While all of the students seemed to be aware that they had constructed a function and that plugging a value into the function would result in another value being the output, some were unsure how the input and output values related to the context of the problem.

Most troubling for us was some students' inability to place the critical value below the maximum or minimum of the function immediately after solving the problem, indicating that while they may have correctly found the answer, they were not being attentive to what their answer meant in the context of the problem. This suggests that the students are engaging in pseudo-conceptual and pseudo-analytical thought processes while solving the optimization algebraically. All of the students except Lars knew to take the derivative of a function, set it equal to zero, and solve. However, many of these students did not know why they were performing this operation.

\section{Implications for Teaching}

Our results suggest two main implications for teaching. First, assessing students based on their ability to correctly solve an optimization problem may not accurately assess their conceptual and analytical thought processes while solving optimization problems. Similarly, teaching students to solve optimization problems using an algorithmic approach may help the students figure out how to find correct answers most of the time, but does little to encourage the students to think about the underlying mathematical concepts. 
Second, the graphical representation of the optimizing function provides an excellent medium through which to encourage students to think deeply about what the optimizing function represents and how it relates to the goal of the problem. Below we have listed three activities along with rationales explaining how we believe they may help students move from pseudoconceptual and pseudo-analytical thought processes while solving optimization problems to more desirable conceptual and analytical thought processes.

\section{Recommended Teaching Interventions}

Ideally students would have an opportunity to do all three of these activities

Blank graph activity. As described above, after the students have solved an optimization problem, provide the students with an unlabeled pair of axes with a sketch of the optimizing function drawn on it. The scale can be exaggerated to accentuate the shape of the graph and make it easy to see the maximum(s) or minimum(s). Ask the students to label the axes of the graph and use their algebraic work to mark and label any relevant points on the graph. Draw a point on the graph and label it with the appropriate ordered pairs or label as $(a, b)$. Ask the students to write a sentence or two describing what they know to be true if that point lies on the function. In the case of Q1 and an arbitrary point $(a, b)$, an ideal response would be that if the garden is to have an area of $200 \mathrm{ft}^{2}$ and one of the side lengths is $a$, then the amount of fencing needed will be $b$.

Rationale. This activity helps the students to make connections between the graphical representation of the optimizing function and their algebraic work. Additionally, it forces the students to think about the input and output of the optimizing function. Because the axes are unlabeled and there is no scale, the students must rely on the significance of the answer they found while doing the work algebraically (namely that it falls below the maximum or minimum). 
In this activity, it is best for the students to be without a graphing utility because they cannot "cheat" and use the numbers on the axes to approximate the location where their critical value would occur.

Examples. Before solving the optimization problem, ask the students to sketch and/or describe several scenarios that, while not necessarily optimal, will meet the requirements of the problem. For example, for Q1, the students would draw and label several gardens alongside a barn with an area of $200 \mathrm{ft}^{2}$. The gardens will use different amounts of fencing but will maintain the required area of $200 \mathrm{ft}^{2}$. For each example, the student should state the dimensions of the garden, the amount of fencing needed, and the area of the garden.

Rationale. This activity is designed to help the students develop an understanding of what we mean we we say we are trying to optimize a quantity. The students will see several scenarios that meet the constraints of the problem and observe that some scenarios are better than others. This activity pairs well with the part of the previous activity in which the students discuss the significance of an ordered pair of the function. The students can see that each scenario corresponds to an ordered pair of the function.

Constructing the Optimizing Function Only. Compile a list of optimization problems with a wide range of contexts. For each problem, ask the students to construct the optimizing function and state the function's domain and range. Also ask the students to identify whether they would be looking for a maximum or minimum if they were actually solving the problem and to identify whether the endpoints would need to be considered or not. Have the students graph the optimizing function using a graphing utility and then sketch and label the graph on their paper. Finally, have the students use the graphing utility to approximate the critical value. 
Rationale. One of the most difficult parts of the optimization problem solving process for students is constructing the optimizing function. This activity focuses solely on constructing and analyzing the optimizing function and allows the students to develop good conceptual and analytical thought processes about the optimizing function. Before looking at the graph, the students must think analytically about the domain and range of the function and think carefully about what sort of answer they should expect if the problem is solved correctly. The students will be considering the graphical representation of the optimizing function, just as in the Blank Graph activity, but this time they will be considering it before solving the problem and will be using a graphing utility. In this case, the students can predict the critical value either by looking at the numbers labeled on the axes or by using the calculator's tool for finding maximums and minimums (if the graphing utility has such a function). Using such a tool to find the value is not necessary, as the goal is to enforce the idea that the answer found in the optimization problem is a critical value of the optimizing function. It an be interesting for students, however, and can provide additional extrinsic motivation for them.

The Constructing the Optimizing Function Only activity can be extended to provide exercises for the students to solve when the instructor is ready for the students to completely solve optimization problems. After the students have constructed optimizing functions for all of the given optimization problems, a small subset can be selected for the students to completely solve. The instructor can select the problems or can group the problems based on the level of algebra required or based on problem contexts and then allow the students to chose one problem from each group. Another option is to divide the students into groups and have each group solve different optimization problems and then compile a class set of solutions for all of the optimization problems. 


\section{Conclusion}

In this paper we have presented data revealing ways students connect or fail to connect the graphical representation of the optimizing function to their algebraic work, and have suggested ways to use the graphical representation of the optimizing function to reinforce and strengthen students' thought processes while solving optimization problems in first semester calculus. We see evidence in line with the conclusions of Eisenberg (1992), Even (1998), and Sfard (1992) that students are often reluctant to consider graphical representations of their algebraic work, even in instances when doing so would be helpful. Additionally, we see that asking students questions about the graphical representation of the optimizing function can give us insight into their thought processes while setting up and solving the optimization problem and also suggests ways instructors can use the graphical representation to support understanding of the role of the optimizing function in the problem. If this is done well, we believe the graphical representation of the optimizing function can be the missing link in many students' concept images of the optimizing function, helping them connect their algebraic work to the goal and context of the problem. 


\section{DISSERTATION CONCLUSION}

The purpose of this dissertation was to examine how first semester calculus students understand optimization problems. The following three research questions guided the development of the study and the subsequent analysis of the data.

1. What mathematical concepts are involved in students' construction of the optimizing function? What aspects of students' concept images for these mathematical concepts and for the optimizing function play a role in their ability to construct an appropriate optimizing function?

2. How do students engage in conceptual and analytical thought processes while solving an optimization problem?

3. How can the above information inform teaching practices to support conceptual development of the optimization process?

These three research questions loosely correspond to three different lenses through which the research community can examine first semester calculus optimization problems. The first lens is focused on the mathematical concepts that play a role in students' ability to solve optimization problems. In this dissertation I specifically focused on the way these concepts play a role in students' concept image of the optimizing function, because the optimizing function emerged as a critical component of the optimization problem-solving process, in line with results from White and Mitchelmore (1996). The results of this analysis were presented in Paper 1 (LaRue \& Infante, 2015).

The second lens pertains to the students' thought processes while solving optimization problems. For this layer, we are interested in the thought processes that are connected to the overall optimization process, focusing on what it means to optimize a quantity, rather than 
focusing on the specific mathematical procedures involved. To do this, I created an Optimization Problem-Solving Framework and used it to analyze students' conceptual and analytical thought processes during each phase of the framework. These results were presented in Paper 2, which is titled “A Problem-Solving Framework for First Semester Calculus Optimization Problems.”

Finally, the third lens deals with the ways students learn how to solve optimization problems. Studying optimization problems through this lens might include conducting a teaching experiment, interviewing instructors, or doing classroom observations. Part of this lens also involves developing teaching interventions to improve the teaching and learning of optimization problems in first semester calculus. In this dissertation, I used data collected during the Blank Graph Activity to support suggested teaching interventions described in Paper 3, which is titled, "The Graphical Representation of the Optimizing Function: The Missing Link?"

The three papers in this dissertation are presented chronologically by their order of development. Initial analysis designed to answer the first research question led to the identification of six mathematical concepts that played a key role in the students' concept images of the optimizing function. These concepts are: variables, function notation, function composition, properties of rectangles and the relationships between them, the role of the optimizing function, and the graphical representation of the function. The way these concepts played a role in the students' concept image of the optimizing function were discussed in depth in Paper 1 (LaRue \& Infante, 2015).

In this paper, we pinpointed two key properties that we would like students to have in their concept image of the optimizing function. These two properties were: 1) The optimizing function is a single variable function representing the quantity we would like to maximize or minimize and 2) Our goal is to find the maximum or minimum value of this function. Each of the 
mathematical concepts listed above influenced whether these two properties were fully developed in their concept images of the optimizing function.

To answer the second research question, I developed an Optimization Problem-Solving Framework that was adapted from Carlson and Bloom's (2005) Multidimensional ProblemSolving Framework using Vinner's (1997) language of conceptual, analytical, pseudoconceptual, and pseudo-analytical thought processes. The framework divides the problemsolving process into four phases, taken from Carlson and Bloom's framework. These four phases are the orienting phase, the planning phase, the executing phase, and the checking phase. I identified the desired conceptual and analytical thought processes associated with each phase of the framework, and broke them into smaller components. In Paper 2, I provided a detailed description of the framework and then presented the results of analyzing the responses from the seven students in the study using this newly developed framework.

The students were found to engage in pseudo-conceptual and pseudo-analytical thought processes most frequently during the orienting and planning phase, with the planning phase being the phase most prone to this kind of thought. Even though most of the students wrote down correct equations and constructed appropriate optimizing functions, coding their explanations based on whether they were using the desired thought processes revealed that they were mostly relying on heuristics and memorization to set up and make a plan for solving the optimization problem. In particular, we found that students were generally unclear about the role the constraint played in the design of the problem and how the optimizing function related to the goal of the problem.

The third and final paper was designed to be a research to practice paper, in line with the third research question. In this paper I began by describing students' responses while doing the 
Blank Graph Activity, an activity in which the students were given a graph of the optimizing function on unlabeled axes with no scale. The students were asked to connect the result of their work while solving the optimization problem to this graphical representation of the optimizing function. These results were used to frame a discussion of several suggested teaching interventions designed to support a conceptual development of the optimization process.

Responses from students while doing the Blank Graph Activity confirmed results from the two previous papers that many of the students in the study were unclear about how the optimizing function corresponded to the goal of the problem and how the constraints influenced the construction of the optimizing function. Three of the seven students did not place the critical value directly below the maximum or minimum of the function when they were asked where it belonged on the graph. Appropriately labeling the axes and describing the information that can be gleaned from an ordered pair on the optimizing function was also difficult for some of the students. Analyzing the responses from students who were able to perform these tasks correctly alongside the responses from the students who were not able to perform these tasks correctly provided insight into ways teaching interventions can support the conceptual development of the optimization process for students, specifically focusing on their concept image of the optimizing function. An updated version of the Blank Graph Activity is one of the activities listed as a teaching intervention in Paper 3, and the other two activities focus on the graphical representation of the optimizing function as well. I posit here that the graphical representation of the optimizing function can help students move from using pseudo-analytical and pseudoconceptual thought processes while solving optimization problems to using the desired analytical and conceptual thought processes instead.

By focusing on different aspects of the optimization problem-solving process in each 
paper, this dissertation provides a well-rounded view of the entire process. We cannot neglect the role that students' concept images of certain mathematical concepts play on their ability to construct an appropriate optimizing function. Likewise, the students' thought processes about the entire optimization process and their motivation for constructing an optimizing function in the first place is pivotal to their ability to extend their knowledge of optimization problems to more complex situations. We have shown that students are able to produce correct algebraic work without having a fully developed concept image of the optimizing function and without engaging in conceptual and analytical thought processes. The teaching interventions described in Paper 3 are designed to help students make connections between the algebraic work of an optimization problem and a robust conceptual understanding of the optimization process. This dissertation has provided a strong foundation for future work related to optimization problems in first semester calculus and beyond. 


\section{FUTURE WORK}

This dissertation focused very specifically on a simple optimization problem from first semester calculus involving the amount of fencing enclosing a garden of fixed area. While some optimization problems involve geometric properties such as area and perimeter, many optimization problems involve other areas of mathematics. For example, optimization problems involving business, economics, distance, time, and population growth are all common applied optimization problems that do not involve geometry at all. Even within the small category of optimization problems that involve geometry, there are several possible scenarios. In this dissertation I focused almost entirely on a two-dimensional rectangular figure, although there are many optimization problems relating to three dimensional and circular/spherical objects.

Because I intended to probe deeply and conduct a focused analysis for the purposes of this dissertation, it was necessary to select one specific type of optimization problem. I chose to work with a very simple geometry optimization problem to eliminate complications due to poor algebra skills and limited background knowledge. Although each of my protocols also included a slightly more complicated scenario involving a three dimensional object, I found that there was a plethora of data to examine just within the Garden Problem. In the future, however, I would suggest conducting a similar study focusing instead on a simple optimization problem from another area of interest, such as economics or distance.

Similarly, the optimization problems I used in this study involved functions without open interval domains. Solving an optimization problem on a closed domain slightly complicates the situation, particularly during the executing and checking phase. More research on this is needed. I also suggest extending this work to optimization problems in multivariable calculus and 
perhaps the other direction - considering simpler optimization problems from the college algebra level.

I have identified the graphical representation of the optimizing function as an important tool for helping students develop the thought processes they use to solve optimization problems. Additionally, I have suggested teaching interventions to provide students with opportunities to work with and focus on the graphical representation of the optimizing function. A teaching experiment related to this or other teaching interventions based on the results of this dissertation would be an excellent place to continue researching optimization problems in calculus.

There are a few ways to proceed with research based on the Optimization ProblemSolving Framework. First, some research should be conducted to verify that the framework captures all of the desired thought processes related to the four phases of the framework. This could be done by comparing the framework to experts' explanations of their solution to optimization problems. Additionally, a study examining ways to use the framework on a larger scale for analyzing student work on assessments would be advantageous. In general, a large scale, quantitative study related to optimization could be very insightful. This study was limited to seven students, and while this kind of focused, qualitative study provided a lot of useful information, it would also be helpful to know how representative these students' responses are of other first semester calculus students.

Based on the results from the three papers in this dissertation, I have created a lesson to introduce students to optimization problems in first semester calculus. This lesson is a packet designed to be used by students in a classroom environment while working with a partner. It has not been used in a classroom setting yet, but I believe it could be very useful in helping students develop conceptual and analytical thought processes for solving optimization problems. This 
packet is attached in Appendix E, and I believe it could be used to form the basis of a future study related to first semester calculus optimization problems.

Optimization problems are an excellent opportunity for students to learn how to connect the calculus techniques they are learning in the classroom to real-world situations. Developing a robust understanding of how to solve such problems and learning to recognize when, why, and how optimization can be used in other contexts can make solving them a rewarding and motivating experience for students. This dissertation is an examination of students' interpretations of optimization problems and the ways they approach them. In turn, this examination provides us a lens for considering how we can improve the teaching of optimization in first semester calculus, a topic needing further work. 


\section{BIBLIOGRAPHY}

Arcavi, A. (2008). Modeling with Graphical Representations. For the Learning of Mathematics, $28(2), 2-10$.

Asiala, M., Cottrill, J., Dubinsky, E., \& Schwingendorf, K. E. (1997). The Development of Students' Graphical Understanding of the Derivative. Journal of Mathematical Behavior, 16(4), 399-431.

Beers, D. (1991). The Role of Applications in the New Calculus. PRIMUS, 1(4), 368-372.

Booth, R. D. L., \& Thomas, M. O. J. (2000). Visualization in Mathematics Learning: Arithmetic Problem-solving and Student Difficulties. Journal of Mathematical Behavior, 18(2), 169190.

Breidenbach, D., Dubinsky, E., Hawks, J., \& Nichols, D. (1992). Development of the Process Conception of Function. Educational Studies in Mathematics, 23(3), 247-285.

Bremigan, E. G. (2005). An Analysis of Diagram Modification and Construction in Students' Solutions to Applied Calculus Problems. Journal for Research in Mathematics Education, 36(3), 248-277.

Carlson, M. (1998). A Cross-Sectional Investigation of the Development of the Function Concept. CBMS Issues in Mathematics Education, 7, 114-162.

Carlson, M., \& Bloom, I. (2005). The Cyclic Nature of Problem Solving: An Emergent Multidimensional Problem-Solving Framework. Educational Studies in Mathematics, $58(1), 45-75$

Carlson, M., Jacobs, S., Coe, E., Larsen, S., \& Hsu, E. (2002). Applying Covariational Reasoning While Modeling Dynamic Events: A Framework and a Study. Journal for Research in Mathematics Education, 33(5), 352-378. 
Carlson, M., Oehrtman, M., \& Engelke, N. (2010). The Precalculus Concept Assessment: A Tool for Assessing Students' Reasoning Abilities and Understandings. Cognition and Instruction, 28(2), 113-145. doi: 10.1080/07370001003676587

Carlson, M., Oehrtman, M., \& Thompson, P. (2005). Key aspects of knowing and learning the concept of function. Retrieved October 16, 2014 http://www.maa.org/programs/faculty-anddepartments/curriculum-department-guidelines-recommendations/teaching-and-learning/9-key-aspects-ofknowing-and-learning-the-concept-of-function

Clement, J. (1985). Misconceptions in Graphing. Paper presented at the The Ninth Conference of the International Group for the Psychology of Mathematics Education, Noordwijkerhout, The Netherlands.

Clement, J. (2000). Analysis of Clinical Interviews: Foundations and Model Viability Handbook of Research Design in Mathematics and Science Education (pp. 547-589).

Clement, J., Lochhead, J., \& Monk, G. S. (1981). Translation Difficulties in Learning Mathematics. The American Mathematical Monthly, 88(4), 286-290.

Cohen, L., Manion, L., \& Morrison, K. (2011). Research methods in education. Milton Park. Abingdon, Oxon, [England]: Routledge.

Confrey, J., \& Smith, E. (1995). Splitting, Covariation, and Their Role in the Development of Exponential Functions. Journal for Research in Mathematics Education, 26(1), 66-86. doi: $10.2307 / 749228$

De Bock, D., Van Dooren, W., Janssens, D., \& Verschaffel, L. (2002). Improper use of linear reasoning: An in-depth study of the nature and the irresistibility of secondary school students' errors. Educational Studies in Mathematics, 50(3), 311-334. 
De Bock, D., Verschaffel, L., \& Janssens, D. (1998). The Predominance of the Linear Model in Secondary School Students' Solutions of Word Problems Involving Length and Area of Similar Plane Figures. Educational Studies in Mathematics, 35, 65-83.

Dubinsky, E., \& Harel, G. (1992). The Nature of the Process Conception of Function. The Concept of Function, Aspects of Epistemology and Pedagogy, MAA Notes, 25, 85-106.

Dubinsky, E., \& Wilson, R. T. (2013). High school students' understanding of the function concept. Journal of Mathematical Behavior, 32, 83-101.

Eisenberg, T. (1992). On the development of a sense for functions The concept of function: Aspects of epistemology and pedagogy (Vol. 25, pp. 153-174).

Engelke, N., Oehrtman, M., \& Carlson, M. (2005). Composition of functions: Precalculus students' understandings. Paper presented at the Proceedings of the Annual Meeting of the North American Chapter of the International Group for the Psychology of Mathematics Education.

Even, R. (1998). Factors involved in linking representations of functions. The Journal of Mathematical Behavior, 17(1), 105-121.

Goldin, G. A. (2000). A scientific perspective on structured, task-based interviews in mathematics education research. Handbook of research design in mathematics and science education, 517-545.

Gray, S. S., Loud, B. J., \& Sokolowski, C. P. (2007). Calculus Students' Difficulties in Using Variables as Changing Quantities. Paper presented at the Conference on Research in Undergraduate Mathematics Education San Diego, CA.

Hitchcock, G., \& Hughes, D. (1989). Research and the Teacher: A Qualitative Introduction to School-Based Research. London: Routledge. 
Hitt, F. (1998). Difficulties in the Articulation of Different Representations Linked to the Concept of Function. Journal of Mathematical Behavior, 17(1), 123-134.

Infante, N. M. E. (2007). Students' Understanding of Related Rates Problems in Calculus. (Doctoral Dissertation), Arizona State University, Ann Arbor. ProQuest Dissertations and Theses Full Text database.

Jacobson, E. (2014). Using Covariation Reasoning to Support Mathematical Modeling. The Mathematics Teacher, 107(7), 515-519.

Kaput, J. (1987). Towards a theory of symbol use in mathematics. Problems of representation in the teaching and learning of mathematics, 159-195.

Knuth, E. J. (2000). Student understanding of the Cartesian connection: An exploratory study. Journal for Research in Mathematics Education, 500-507.

Kospentaris, G., Spyrou, P., \& Lappas, D. (2011). Exploring students' strategies in area conservation geometrical tasks. Educational Studies in Mathematics, 77, 105-127.

LaRue, R., \& Infante, N. E. (2015). Optimization in first semester calculus: a look at a classic problem. International Journal of Mathematical Education in Science and Technology, 46(7), 1021-1031.

Leinhardt, G., Zaslavsky, O., \& Stein, M. K. (1990). Functions, Graphs, and Graphing: Tasks, Learning, and Teaching. Review of Educational Research, 60(1), 1-64. doi: $10.2307 / 1170224$

Malisani, E., \& Spagnolo, F. (2009). From Arithmetical Thought to Algebraic Thought: The Role of the "Variable". Educational Studies in Mathematics, 71(1), 19-41.

Monk, S. (1992). Students' Understanding of a Function Given by a Physical Model. The Concept of function: Aspects of Epistemology and Pedagogy, MAA Notes, 25, 175-194. 
Monk, S., \& Nemirovsky, R. (1994). The case of Dan: Student construction of a functional situation through visual attributes. CBMS Issues in Mathematics Education, 4, 139-168.

Moore, K. C., Paoletti, T., \& Musgrave, S. (2013). Covariational reasoning and invariance among coordinate systems. The Journal of Mathematical Behavior, 32(3), 461-473. doi: http://dx.doi.org/10.1016/i.jmathb.2013.05.002

Oehrtman, M., Carlson, M., \& Thompson, P. W. (2008). Foundational reasoning abilities that promote coherence in students' function understanding. Making the connection: Research and teaching in undergraduate mathematics education, 27-42.

Rogawski, J. (2012). Calculus: Early Transcendentals (Second ed.). New York, NY: W.H. Freeman and Company.

Sajka, M. (2003). A Secondary School Student's Understanding of the Concept of Function: A Case Study. Educational Studies in Mathematics, 53(3), 229-254.

Salas, S. L., Hille, E., \& Etgen, G. J. (2003). Calculus: One and Several Variables (Ninth ed.). Hoboken, NJ: John Wiley \& Sons, Inc.

Saldanha, L., \& Thompson, P. W. (1998). Re-thinking co-variation from a quantitative perspective: Simultaneous continuous variation. Paper presented at the Proceedings of the 20th annual meeting of the North American Chapter of the International Group for the Psychology of Mathematics Education.

Sfard, A. (1992). Operational Origins of Mathematics Objects and the Quandry of Reification The Case of Function. The Concept of Function, Aspects of Epistemology and Pedagogy, MAA Notes, 25, 59-84.

Speer, N., \& Kung, D. (2016). The complement of RUME: What's missing from our research? Paper presented at the Conference on Research in Undergraduate Mathematics Education, Pittsburgh, PA. 
Stewart, J. (2007). Essential Calculus: Early Transcendentals. Belmont, CA: Brooks/Cole.

Strauss, A., \& Corbin, J. (1998). Basics of qualitative research: Procedures and techniques for developing grounded theory: Thousand Oaks, CA: Sage.

Tall, D., \& Vinner, S. (1981). Concept image and concept definition in mathematics with particular reference to limits and continuity. Educational Studies in Mathematics, 12(2), 151-169.

Tirosh, D., \& Stavy, R. (1999). Intuitive Rules: A Way to Explain and Predict Students' Reasoning. Educational Studies in Mathematics, 38(1/3), 51-66.

Tsamir, P. (2003). Using the intuitive rule more A-more B for predicting and analysing students' solutions in geometry. International Journal of Mathematical Education in Science and Technology, 34(5), 639-650.

Vincent, B., LaRue, R., Sealey, V., \& Engelke, N. (2015). Calculus students' early concept images of tangent lines. International Journal of Mathematical Education in Science and Technology, 1-17. doi: 10.1080/0020739X.2015.1005700

Vinner, S. (1983). Concept definition, concept image and the notion of function. International Journal of Mathematical Education in Science and Technology, 14(3), 293-305.

Vinner, S. (1997). The Pseudo-Conceptual and the Pseudo-Analytical Thought Processes in Mathematics Learning. Educational Studies in Mathematics, 34, 97-129.

Vinner, S., \& Dreyfus, T. (1989). Images and Definitions for the Concept of Function. Journal for Research in Mathematics Education, 20(4), 356-366.

White, P., \& Mitchelmore, M. (1996). Conceptual Knowledge in Introductory Calculus. Journal for Research in Mathematics Education, 27(1), 79-95. 
Whiteley, W. J., \& Mamolo, A. (2012). The Popcorn Box Activity and Reasoning about Optimization. The Mathematics Teacher, 105(6), 420-426.

Woodward, E., \& Byrd, F. (1983). Area: Included Topic, Neglected Concept. School Science and Mathematics, 83(4), 343-347.

Zandieh, M. (2000). A Theoretical Framework for Analyzing Student Understanding of the Concept of Derivative. CBMS Issues in Mathematics Education, 8, 103-127.

Zeytun, A. S., Cetinkaya, B., \& Erbas, A. K. (2010). Mathematics Teachers' Covariational Reasoning Levels and Predictions about Students' Covariational Reasoning Abilities. Educational Sciences: Theory and Practice, 10(3), 1601-1612. 


\section{APPENDIX A: PILOT STUDY PROTOCOL}

Part I - Introduction/Ice Breaker

1. What is your name?

2. What math class are you currently taking?

3. When did you last take Calculus I?

4. Where did you take Calculus I? WVU or elsewhere? If at WVU, was it engineering or non-engineering?

5. How comfortable did you feel with the topics you learned in Calculus I?

6. Describe any mathematical strengths or weaknesses you think you have.

7. Please differentiate the following functions.

a. $f(x)=x^{3}-3 x^{2}+17$

b. $f(x)=\ln x-x+x^{8}+10$

$f(x)=\frac{3 x^{7}-4 x}{x^{5}}$

Part II - The Garden Problem

A rectangular garden of area $200 \mathrm{ft}^{2}$ is to be fenced off against rabbits. Find the dimensions that will require the least amount of fencing if a barn already protects one side of the garden.

Suggested questions (loose suggestions, will adjust according to students' work and responses)

1. Why did you start by drawing a picture?

2. How did you know you'd need these equations?

3. Why did you have to eliminate a variable?

4. Why did you differentiate? What does this have to do with finding the minimum amount of fencing?

5. If not already clear from previous answer, why did you set the derivative equal to zero and then solve?

Part II - Second Optimization Problem

What are the dimensions of the base of the rectangular box of greatest volume that can be constructed from 100in ${ }^{2}$ of cardboard if the base is to be twice as long as it is wide? Assume that the box has a top.

Same questions as in Part I, unless the answers were very definitive above and don't need to be revisited. The goal here is to observe their process and note any difficulties that might arise. If difficulties arise, ask appropriate questions to understand why the student is having difficulty.

Part III - Third Optimization Problem

A window in the shape of a rectangle capped by a semicircle is to have perimeter $p$ inches. Choose the radius of the semicircular part so that the window admits the greatest amount of light.

This problem may require more prompting. In this case, the focus is going to be on how the students go about coming up with the necessary equations, etc. If difficulties arise, ask appropriate questions to understand why the student is having difficulty. 


\section{APPENDIX B: PROTOCOL 1}

Part I - Introduction/Ice Breaker

1. What is your name?

2. Tell me a little about your math background.

a. What math class are you currently taking? How is it going?

b. Have you had Calculus I previously? If so, when and where?

c. What mathematical strengths and/or weaknesses do you think you have?

d. In general, how do you feel about what you've learned in Calculus I?

3. Please find the derivative of these two functions.

a. $f(x)=4 x^{3}-9 x^{2}-6 x+1$

b. $f(x)=\frac{4 x^{3}-6 x^{2}}{2 x}$

Part II - The Garden Problem

A rectangular garden of area $200 \mathrm{ft}^{2}$ is to be fenced off against rabbits. Find the dimensions that will require the least amount of fencing if a barn already protects one side of the garden.

Suggested questions (loose suggestions, will adjust according to students' work and responses)

1. Please explain your solution process to me, explaining why you did each step.

2. Why did you draw a picture? (OR: Many students often sketch a picture to represent the situation. Is there a reason you didn't do that?)

3. How did you know that you would need these equations?

4. How did you choose these variables?

5. Why did you have to go through this step of solving for one variable and plugging it in elsewhere?

6. How do you know that it is mathematically valid to do this?

7. Why did you take the derivative? How does this help us answer the question posed in the problem?

8. Why did you set the derivative equal to zero and solve? (if this is not already clear from answer to previous question)

9. How do you know for sure that this answer gives us a minimum?

Part III - Pre-requisite Material

\section{The Rectangle Problem}

1. Suppose we have a rectangle (present a picture of a rectangle)

a. If I change the area inside the rectangle, what will happen to the perimeter? How do you know?

b. If I change the perimeter of the rectangle, what will happen to the area? How do you know?

c. In general, how are area and perimeter related, if at all?

2. Suppose I ask you to draw a rectangle with perimeter 100 inches. How many different rectangles can you draw? Explain.

3. Suppose I ask you to draw a rectangle with area $60 \mathrm{in}^{2}$. How many different rectangles can you draw? Explain. 


\section{Functions}

1. When I say the word, "function," what comes to mind? What can you tell me about functions?

a. Discuss algebraic and graphical representations. Ask about input/output.

Part III: Second Optimization Problem

Suppose we want to maximize the volume of the rectangular box that can be constructed from $144 \mathrm{in}^{2}$ of cardboard if the base is to be twice as long as it is wide. Assume that the box has a top. Find the dimensions of the box and give its volume.

Note: I had written out the steps to a problem on a piece of paper and then cut it into small pieces, so each piece of paper had only one step of the problem on it. After the student described his or her next step, I handed him or her the piece of paper with that work already done. This eliminated the need for the student to do some of the algebra (which we already know is a problem) and allowed me to focus on their thought processes.

Suggested questions (loose suggestions, will adjust according to students' work and responses)

1. Explain how you would solve this problem. I may ask you to actually work out various parts of the problem as you go along.

2. What do we mean by "greatest volume?"

3. Here is the graph. How is this related to the problem?

4. Label the axes and any other important information on the graph

5. Where does $4 \sqrt{3}$ belong on the graph?

6. Where does $w=2 \sqrt{3}$ - or $l=4 \sqrt{3}$ belong on the graph?

7. Label this point (put dot on graph at max)

8. What does $V(3)=108$ mean?

9. What is $V(2 \sqrt{3})$-- or $V(4 \sqrt{3})$ ?

10. What about $V^{\prime}(2 \sqrt{3})$-- or $V^{\prime}(4 \sqrt{3})$ ?

11. What about the portions where the graph goes below the x-axis or to the left of the yaxis?

12. What if you had eliminated the w instead of the 1 (or vice versa)? How would that change things? 


\section{APPENDIX C: PROTOCOL 2}

Part I - Introduction/Ice Breaker

1. What is your name?

2. Tell me a little about your math background.

a. What math class are you currently taking? How is it going?

b. Have you had Calculus I previously? If so, when and where?

c. What mathematical strengths and/or weaknesses do you think you have?

d. In general, how do you feel about what you've learned in Calculus I?

3. Please calculate the area and perimeter of this rectangle. (Give a rectangle with dimensions $5 \times 6$ )

4. Suppose $f(x)=-3 x^{2}+1$. What is $f(2)$ ? Can you relate this information to the graph of the function?

5. Can you give me a formal definition of the term "function?" If not, what about an informal definition? If you were trying to explain to a friend what a function is, what would you say?

Part II - The Garden Problem

A rectangular garden of area $200 \mathrm{ft}^{2}$ is to be fenced off against rabbits. Find the dimensions that will require the least amount of fencing if a barn already protects one side of the garden.

Suggested questions (loose suggestions, will adjust according to students' work and responses)

10. Please explain your solution process to me, explaining why you did each step.

11. Why did you draw a picture? (OR: Many students often sketch a picture to represent the situation. Is there a reason you didn't do that?)

12. How did you know that you would need these equations?

13. How did you choose these variables?

14. Why did you have to go through this step of solving for one variable and plugging it in elsewhere?

15. How do you know that it is mathematically valid to do this?

16. Why did you take the derivative? How does this help us answer the question posed in the problem?

17. Why did you set the derivative equal to zero and solve? (if this is not already clear from answer to previous question)

18. What does your answer represent? What does $w=10$ mean?

19. How do you know for sure that this answer gives us a minimum?

20. What does it mean to have a least amount of fencing?

21. Assume this is the graph of the function you defined. Please label the axes and mark any important points.

22. What can you tell me about the portion of this graph where the function is to the left of the $y$-axis and below the $x$-axis?

Part III - Pre-requisite Material

The Rectangle Problem

1. Are area and perimeter related? If so, how? 
a. Follow up: Does changing one affect the other? If so, how?

b. Is it possible to keep the area of a rectangle constant while changing the perimeter?

c. What about keeping the perimeter constant while changing the area?

2. How many rectangles can you draw with area $100 \mathrm{in}^{2}$ ?

3. How many rectangles can you draw with perimeter $100 \mathrm{in}^{2}$ ?

4. What do you think this has to do with the optimization problem we just did?

$\underline{\text { Part IV - Second Optimization Problem }}$

Suppose we want to design a mold for bars of soap. The mold will be in the shape of a semicircle (like a halfmoon) and needs to hold $100 \mathrm{z}$ of soap. Find the dimensions in inches for the mold that will minimize the amount of packaging needed to cover the bar of soap. Note: $100 z$ is equivalent to 18.04 cubic inches.

Note: I had written out the steps to a problem on a piece of paper and then cut it into small pieces, so each piece of paper had only one step of the problem on it. After the student described his or her next step, I handed him or her the piece of paper with that work already done. This eliminated the need for the student to do some of the algebra (which we already know is a problem) and allowed me to focus on their thought processes.

Explain to me how we would solve the problem. You do not have to actually solve the problem; just give me an overview of how you would go about it.

Ask follow-up questions as necessary. 


\section{APPENDIX D: SUMMARY OF PARTICIPANTS' MATH BACKGROUND}

Table 30. Participants' Math Background

\begin{tabular}{|c|l|}
\hline Student & \multicolumn{1}{|c|}{ Discussion about math background - Student responses are in bold } \\
\hline & Can you tell me just like a little about your math background. So like what \\
classes you've had recently and... \\
In high school I was an ivy diploma. I didn't do well. \\
What does that mean? \\
It's an international baccalaureate. It's Cambridge. So. Because we had \\
options. If you could do that with the school diploma, we get credits \\
transferred to a uni to move on to get grades faster. And I took standard \\
math once. Which was pretty good. I did well. \\
What kind of math is it? \\
It's usually. It's not. I don't know how to say it. Like. It doesn't go deep \\
into the stuff, into the subjects. \\
Just kind of gets all the basics \\
Like calculus and all. Only a little bit of calculus, but not much. \\
So that's what you've done. So you're a sophomore. Were you here at WVU \\
(Engineering) \\
\begin{tabular}{l} 
last year? \\
Yeah. I was. \\
Did you take any math? \\
No. Yeah I did. 129 actually. \\
129 in the spring or the fall? \\
Fall. \\
And then you took the spring off? And then took Calc I this the summer? \\
Yeah \\
So in general. How do you feel about math? Like. Strengths of weaknesses? \\
Do you feel confident or? \\
If I practice, I can do well. Math is like, if you practice it's better. Yeah. \\
Ok. That's a good answer. I like that. \\
And math is my favorite subject. \\
\hline Tell me a little bit about your math background. Like your history, like what \\
kind of classes you've had. \\
Uh. I had the pretty standard math, like it was the mid level through high \\
school. I ended up in an honors calc class which went over most of what \\
Calc I is here. \\
Ok. \\
And then I got to college and I kind of goofed around my first time so I \\
may have taken this class once or twice, but this is as far as I've made it \\
so far. \\
Ok. So you're taking it again now? \\
Yeah \\
Did you take engineering or non-engineering? \\
I took engineering. \\
Both times? Or once or?
\end{tabular} \\
\hline
\end{tabular}




\begin{tabular}{|c|c|}
\hline & $\begin{array}{l}\text { Yeah. Both times. } \\
\text { Um. So, and in general, how do you feel about math? Do you like it? } \\
\text { I like math that's why.. I'm going for engineering and that's what I liked. } \\
\text { I like math and science and I just felt like I understood it so I wanted to } \\
\text { see how far I could go with it. } \\
\text { Yeah Ok. So, do you feel like you're pretty good about it? } \\
\text { Yeah. I understand things well. I feel like I can grasp concepts. And then } \\
\text { from that it's a lot of plug and chug and you just understand why and } \\
\text { how it works kinda. } \\
\text { Ok. So what. Um. Do you have any like weaknesses? Like things that you } \\
\text { think you have trouble with? } \\
\text { Trig! } \\
\text { Ok } \\
\text { Just trig. Especially trying to plug things into trig functions. It's just. } \\
\text { Like remembering like what like sine and cosine... Like those things? }\end{array}$ \\
\hline $\begin{array}{c}\text { Tracy } \\
\text { (Psychology) }\end{array}$ & $\begin{array}{l}\text { Can you just tell me a little bit about your math background? Like what } \\
\text { classes you're doing? } \\
\text { Um, I took a two semester pre-cal/cal in high school. It didn't count for } \\
\text { any college credit, our school hasn't gotten the AP program yet. } \\
\text { Gotcha } \\
\text { And then I took MATH } 129 \text { my first semester of college, I took Calc I my } \\
\text { second semester and got a D and then I'm retaking it now. } \\
\text { And you said it's going well? } \\
\text { Yeah, I have a 95, so. } \\
\text { Nice! Very nice. So do you have anything in particular that you think are like } \\
\text { weaknesses or strengths when it comes to math? } \\
\text { I'm really bad with anything that involves like, the problems where you } \\
\text { have to like look at the problem and know what you're supposed to do } \\
\text { and draw a picture and come up with a formula on your own. I'm really } \\
\text { bad with those. } \\
\text { Gotcha } \\
\text { Anything that involves word problems, honestly. }\end{array}$ \\
\hline $\begin{array}{c}\text { Lars } \\
\text { (Engineering) }\end{array}$ & $\begin{array}{l}\text { Can you just tell me a little bit about your math background? What classes } \\
\text { you've had? } \\
\text { I actually didn't have calculus until college. } \\
\text { Ok } \\
\text { So um yeah. My high school math background was a little weak, but as } \\
\text { far as like classes, but I've always really enjoyed math and have kind of, } \\
\text { you know. Math and physics have been like my favorite subjects, and so I } \\
\text { kind of have like looked into that stuff on my own and done stuff with it } \\
\text { on my own, so. It hasn't been too much of a problem. } \\
\text { So what did you do once you got to college? What classes? } \\
\text { I started out in Math } 129 \\
\text { Yeah } \\
\text { You know I figured it would be better to, you know, review that than } \\
\text { jump right into college calculus. And then, um, I'm an engineering }\end{array}$ \\
\hline
\end{tabular}




\begin{tabular}{|c|c|}
\hline & $\begin{array}{l}\text { major, so I went into engineering calculus, hit a break wall there, taking it } \\
\text { again. So. Yeah. } \\
\text { Ok. I've heard that before. Ok, so now you're taking it now. And how do you } \\
\text { feel about it now? How's it going? } \\
\text { It's presented a lot easier than it was in the last one, but um, it's also the } \\
\text { element of you know this is the second time taking it so it's been a lot } \\
\text { more solid this semester. } \\
\text { Do you have any like weaknesses or strengths or like anything in particular } \\
\text { that you think of? } \\
\text { Umm. Um. Related rates depending on the complexity of stuff has been } \\
\text { kind of a weak point for me. } \\
\text { What about them? Do you know what it is about it that makes it hard? } \\
\text { Kind of extrapolating from the information it gives you the equations that } \\
\text { you need to use to actually get related to each other. Cause that part's, } \\
\text { I'm okay at that, but figuring out the information that I have to work } \\
\text { with has been the difficult part. }\end{array}$ \\
\hline $\begin{array}{c}\text { Ashod } \\
\text { (Biology) }\end{array}$ & $\begin{array}{l}\text { Um and then can you tell me just a little bit about your math background? } \\
\text { Um, freshman year of high school I took algebra, sophomore I took } \\
\text { geometry, junior year I took trigonometry, senior year I took pre-calc. } \\
\text { And then uh I didn't have any AP credit to transfer over, so I had to take } \\
\text { algebra my freshman, my first semester freshman year, and then trig the } \\
\text { next semester and now I'm taking calc. } \\
\text { Now you're taking Calc I? } \\
\text { Yeah. } \\
\text { Um and how is that going? } \\
\text { It's good. I should get a B. } \\
\text { Yeah? Um. Do you like it? } \\
\text { Yeah. I like it. I thought it was going to be harder, like, but if you're good } \\
\text { at your trig and your algebra, you're going to be fine. } \\
\text { Ok, um do you have any like strengths or weaknesses, things you're } \\
\text { particularly good at in math or particularly bad at? Something that trips you } \\
\text { up? } \\
\text { I don't really like optimization that much. } \\
\text { Yeah? } \\
\text { Optimization and like related rates. I really don't like word problems. } \\
\text { Is there a reason? } \\
\text { I just never liked word problems in general. And um, what I'm good at it } \\
\text { is like differentiation, derivatives, stuff like that, concavity. Stuff like that. }\end{array}$ \\
\hline $\begin{array}{c}\text { Brandi } \\
\text { (Engineering) }\end{array}$ & $\begin{array}{l}\text { Ok, so the first thing that I want to ask you is just if you could just tell me a } \\
\text { little bit about your math background in general, like what classes you've had } \\
\text { and that kind of thing. } \\
\text { Uh, I have taken all the basic maths like Algebra I, II, I took trig and } \\
\text { geometry in high school and I took AP Calc in high school and I passed } \\
\text { the test, but by the time WVU got my scores, all the Calc II classes I could } \\
\text { take were full. } \\
\text { Oh! }\end{array}$ \\
\hline
\end{tabular}




\begin{tabular}{|c|c|}
\hline & $\begin{array}{l}\text { So I'm retaking Calc I. } \\
\text { Oh. Gotcha. That's fun. Is it. How's it going? } \\
\text { It's good. } \\
\text { Yeah? } \\
\text { It's fun. } \\
\text { Yeah? } \\
\text { I love math. } \\
\text { You like it? That's good. You should be good then. Do you have any } \\
\text { particular strengths or weaknesses in math? } \\
\text { More algebra is what I like to do. } \\
\text { Ok. } \\
\text { Like the basis of calculus kind of. I think it's fun. } \\
\text { Is there anything you struggle with, like when you see a problem like this or } \\
\text { with this in it or this kind of math... } \\
\text { Um approximations kind of give me a hard time, but it's nothing I can't } \\
\text { work my way through, it just takes me longer than others. }\end{array}$ \\
\hline $\begin{array}{c}\mathrm{Cy} \\
\text { (Engineering) }\end{array}$ & $\begin{array}{l}\text { So the first thing, I know you kind of already just told me this, but can you tell } \\
\text { me a little bit about your math background? } \\
\text { Ok. } \\
\text { Like what math classes you've had. } \\
\text { Uh yeah, I've had up to AP Calculus AB in high school and on coming } \\
\text { here I took Calculus I. I've had algebra based physics, so nothing too } \\
\text { much there. I don't know if there's a standard order to learn calculus in, } \\
\text { but I've learned up through like some integral stuff. } \\
\text { Ok. So in general, how do you feel about what you're, Calc I now? I think you } \\
\text { just told me this too. } \\
\text { Calc I? Yeah. It's pretty easy. It's like not even a problem really. } \\
\text { Not a problem. Um. Ok. This is probably redundant, but do you have any } \\
\text { strengths or weaknesses when it comes to math? } \\
\text { Oh, I would say, every now and, you know the standard, oh, sometimes I } \\
\text { make stupid mistakes sort of thing, but I wouldn't say anything stands } \\
\text { out, like, nothing comes to mind really. }\end{array}$ \\
\hline
\end{tabular}




\section{APPENDIX E: SAMPLE OPTIMIZATION LESSON}

\section{Review}

Find the absolute maximum(s) and/or absolute minimum(s) of the following function on the given interval.

$$
A(w)=w\left(\frac{160-4 w}{3}\right) \quad \text { Interval: }[0,40]
$$

Absolute maximum(s) of ___ at ___

Absolute minimum(s) of ___ at _

Go to http: $\backslash \backslash w w w . d e s m o s . c o m \backslash$ calculator. Type in the function (you will need to change the parameter to $x$ ). Looking at the graph of the function, find the absolute maximum(s) and minimum(s) of the function on the stated domain. If you click on the locations of these maximum(s)/minimum(s) Desmos should automatically display the ordered pair for the point. Use these ordered pairs to verify your answers. You may need to zoom in, zoom out, or change the scale of the graph to see the shape of the graph clearly. Sketch a graph of the function below. Label the axes using the variables given above (not $x$ and $y$ ). Mark and label the absolute maximum(s) and absolute minimum(s). 


\section{Optimization Problems - A First Example}

A farmer is going to enclose a rectangular area along the back edge of her property for a large plot of green beans. The edge of the property already has fencing, because the neighbors have fenced in their property to keep their free-range chickens and peacocks from escaping. Therefore, she will need to construct a fence for the other three sides of the garden. The edge of the property is a straight line $200 \mathrm{ft}$ long. The fenced area for the peppers can extend no more than $400 \mathrm{ft}$ from the back edge of her property towards the house.

If she wishes to enclose an area of $16,000 \mathrm{ft}^{2}$, what dimensions would allow her to purchase the least amount of fencing?

\section{Understanding the Solution}

1. The farmer wants to purchase as little fencing as possible, but she could still build the garden even if this goal isn't met. There are, however, some requirements that absolutely must be met. What are they?

2. Sketch and label several examples (at least three) of gardens that would meet these requirements. Calculate the amount of fencing needed for each example. Which one uses the least amount of fencing? 
3. If we model the situation given in the problem using a function, we can find the absolute minimum(s) of the function using what we already know about absolute maximums and minimums. If we are going to do this, the first step is to decide how to construct a function to model the problem.

(a) To be useful for accomplishing the goal of the problem, what must the range of the function be (in the context of the problem)? In other words, should the range represent the garden's area, amount of fencing, one of the side lengths, something else?

(b) You have identified the range of the function. To construct a function, we need to start with an equation for that quantity. Write that down.

(c) Does the equation you wrote down for part (b) take into account the requirements you listed in Question 1? If not, how can you change it to make sure all of the requirements are considered? Hint: There are two courses of action that might help. First, you may restrict the possible values for the variables in your equation. Second, you may notice that two (or more) variables must have a specific relationship in order for the requirements of the problem to be satisfied.

(d) If you did not already do so in part (c), construct a function modeling the problem. Make sure it is a function of one variable and meets all of the requirements of the problem. We'll call this our optimizing function. State the real-world domain of the function. 
4. Use the skills you already have and find the absolute minimum(s) of the optimizing function you constructed in Question 3.

5. Graph your optimizing function using Desmos and see if the minimum on the graph corresponds to the minimum you found.

6. Sketch the graph of your optimizing function below (you may have to adjust the scale so the features of the graph are clear). Only sketch the portion of the graph that pertains to your real-world domain. Label the axes according to the variables you used when constructing your function. Mark and label the minimum(s). 
7. How much fencing will the farmer need to buy if she designs her garden to use the least amount of fencing? What are the dimensions of the garden?

8. Click anywhere on the graph of the function and drag the cursor along the function. The ordered pairs for the points on the function should appear as you drag over them. Find the ordered pairs on the function that correspond to the three examples you sketched above for Question 2. Below, sketch each example again and write the corresponding ordered pair next to it. Label all sides of the garden and state the area and amount of fencing needed.

9. Now find the dimensions that would allow the farmer to use the least amount of fencing if she wanted to enclose an area of $24,000 \mathrm{ft}^{2}$. 
10. Construct an optimizing function that would allow the farmer to use the least amount of fencing if she wanted to enclose an area of $A f t^{2}$. In other words, what if a specific amount isn't given, and instead we just say the area is to be $A$ ? What would the optimizing function be?

11. Type in the optimizing function from the previous problem, including the letter $A$. A blue button should appear with a note that says add slider: A. Click the blue button. A slider should appear just below the function. Replace the default value for $A$ with a large value like 100, 000. You can now drag the bar on the slider back and forth and set different values for $A$. Click on the minimum of the function, making sure the ordered pair of the minimum appears and stays, and then drag the slider for $A$. The function should change and the ordered pairs showing should change. Describe what these different ordered pairs represent.

12. Choose two ordered pairs you saw while doing the previous problem. For each one, write down the ordered pair, then sketch a picture of the garden that corresponds to that ordered pair. Label all sides of the garden and state the area and amount of fencing needed. 


\section{Homework}

Repeat Questions 1-9 from the above activity (adjusting to match the new context) for the following problems.

1. A farmer wants to fence in a field and divide it into four side by side, equal areas. If he wants a total enclosed area of $8,000 \mathrm{ft}^{2}$, what dimensions should he use to minimize the amount of fencing?

2. You wish to construct a topless crate with a surface area of $230 \mathrm{in}^{2}$ and the base with one side three times as long as the other. Find the dimensions for the box that will maximize the volume.

3. You are tasked with designing a cylindrical can. The material for the top and bottom of the can costs $0.25 / \mathrm{cm}^{2}$. The material for the sides of the can costs $0.40 / \mathrm{cm}^{2}$. If you want the can to have a volume of $90 \mathrm{~cm}^{3}$, what dimensions should you use to minimize the cost of constructing the can? 